\section{OPEN ACCESS}

Edited by:

Frank Edgar Muller-Karger, University of South Florida,

United States

Reviewed by:

Toste Tanhua,

GEOMAR Helmholtz Center for Ocean

Research Kiel, Germany

Fabien Roquet,

University of Gothenburg, Sweden

*Correspondence:

Lisa A. Levin

llevin@ucsd.edu

Specialty section

This article was submitted to

Ocean Observation,

a section of the journal

Frontiers in Marine Science

Received: 10 October 2018

Accepted: 18 April 2019

Published: 29 May 2019

Citation:

Levin LA, Bett BJ, Gates AR, Heimbach $P$, Howe BM, Janssen $F$, McCurdy A, Ruhl HA, Snelgrove P, Stocks KI, Bailey D,

Baumann-Pickering S, Beaverson C, Benfield MC, Booth DJ, Carreiro-Silva M, Colaço A, Eblé $M C$, Fowler AM, Gjerde KM, Jones DOB, Katsumata K, Kelley D, Le Bris N,

Leonardi AP, Lejzerowicz $F$ Macreadie PI, McLean D, Meitz F, Morato T, Netburn A, Pawlowski J,

Smith CR, Sun S, Uchida $H$,

Vardaro MF, Venkatesan $R$ and Weller RA (2019) Global Observing

Needs in the Deep Ocean.

Front. Mar. Sci. 6:241.

doi: 10.3389/fmars.2019.00241

\title{
Global Observing Needs in the Deep Ocean
}

\begin{abstract}
Lisa A. Levin ${ }^{1 *}$, Brian J. Bett², Andrew R. Gates², Patrick Heimbach ${ }^{3}$, Bruce M. Howe 4 , Felix Janssen ${ }^{5}$, Andrea McCurdy ${ }^{6}$, Henry A. Ruhl ${ }^{2,7}$, Paul Snelgrove 8,9, Karen I. Stocks ${ }^{10}$, David Bailey ${ }^{11}$, Simone Baumann-Pickering ${ }^{1,12}$, Chris Beaverson ${ }^{13}$, Mark C. Benfield ${ }^{14}$, David J. Booth ${ }^{15}$, Marina Carreiro-Silva ${ }^{16}$, Ana Colaço ${ }^{16}$, Marie C. Eblé17, Ashley M. Fowler ${ }^{15,18, ~ K r i s t i n a ~ M . ~ G j e r d e ~}{ }^{19}$, Daniel O. B. Jones ${ }^{2}$, K. Katsumata ${ }^{20}$, Deborah Kelley ${ }^{21}$, Nadine Le Bris ${ }^{22}$, Alan P. Leonardi ${ }^{13}$, Franck Lejzerowicz ${ }^{23}$, Peter I. Macreadie ${ }^{24}$, Dianne McLean ${ }^{25}$, Fred Meitz ${ }^{26}$, Telmo Morato ${ }^{16}$, Amanda Netburn ${ }^{13}$, Jan Pawlowski27, Craig R. Smith ${ }^{28}$, Song Sun ${ }^{29}$, Hiroshi Uchida ${ }^{20,}$ Michael F. Vardaro ${ }^{21}$, R. Venkatesan ${ }^{30}$ and Robert A. Weller ${ }^{31}$
\end{abstract}

\begin{abstract}
1 Integrative Oceanography Division and Center for Marine Biodiversity and Conservation, Scripps Institution of Oceanography, University of California, San Diego, La Jolla, CA, United States, ${ }^{2}$ Ocean Biogeochemistry and Ecosystems Division, National Oceanography Centre, Southampton, United Kingdom, ${ }^{3}$ Oden Institute for Computational Engineering and Sciences, Institute for Geophysics, The University of Texas at Austin, Austin, TX, United States, ${ }^{4}$ Department of Ocean and Resources Engineering, University of Hawairi at Mānoa, Honolulu, HI, United States, ${ }^{5}$ Deep Sea Ecology and Technology Group, Alfred Wegener Institute, Helmholtz Centre for Polar and Marine Research, Bremerhaven, Germany, ${ }^{6}$ Cooperative Programs for the Advancement of Earth System Science, University Corporation for Atmospheric Research, Boulder, CO, United States, ${ }^{7}$ Monterey Bay Aquarium Research Institute, Moss Landing, CA, United States, ${ }^{8}$ Department of Ocean Sciences, Memorial University of Newfoundland, St. John's, NL, Canada, ${ }^{9}$ Department of Biology, Memorial University of Newfoundland, St. John's, NL, Canada, ${ }^{10}$ Geological Data Center, Scripps Institution of Oceanography, University of California, San Diego, La Jolla, CA, United States, ${ }^{11}$ Institute of Biodiversity, Animal Health and Comparative Medicine, University of Glasgow, Glasgow, United Kingdom, ${ }^{12}$ Marine Physical Laboratory, Scripps Institution of Oceanography, University of California, San Diego, La Jolla, CA, United States, ${ }^{13}$ Office of Ocean Exploration and Research, National Oceanic and Atmospheric Administration, Silver Spring, MD, United States, ${ }^{14}$ Department of Oceanography and Coastal Sciences, College of the Coast and Environment, Louisiana State University, Baton Rouge, LA, United States, ${ }^{15}$ School of Life Sciences, University of Technology Sydney, Sydney, NSW, Australia, ${ }^{16}$ Instituto do Mar, Marine and Environmental Sciences Centre, Centro OKEANOS, Universidade dos Açores, Horta, Portugal, ${ }^{17}$ Pacific Marine Environmental Laboratory, National Oceanic and Atmospheric Administration, Seattle, WA, United States, ${ }^{18}$ New South Wales Department of Primary Industries, Sydney Institute of Marine Science, Mosman, NSW, Australia, ${ }^{19}$ IUCN Global Marine and Polar Programme, Middlebury Institute of International Studies at Monterey, Monterey, CA, United States, ${ }^{20}$ Japan Agency for Marine-Earth Science and Technology, Yokosuka, Japan, ${ }^{21}$ School of Oceanography, University of Washington, Seattle, WA, United States, ${ }^{22}$ Observatoire Océanologique de Banyuls, Sorbonne Université, CNRS, Banyuls-sur-Mer, France, ${ }^{23}$ Department of Pediatrics, University of California, San Diego, San Diego, CA, United States, ${ }^{24}$ Centre for Integrative Ecology, School of Life and Environmental Sciences, Deakin University, Burwood, VIC, Australia, ${ }^{25}$ Australian Institute of Marine Science, Indian Ocean Marine Research Centre, Crawley, WA, Australia, ${ }^{26}$ Energy Consultant, Sausalito, CA, United States, ${ }^{27}$ Department of Genetics and Evolution, University of Geneva, Geneva, Switzerland, ${ }^{28}$ Department of Oceanography, School of Ocean and Earth Science and Technology, University of Hawai'i, Honolulu, HI, United States, ${ }^{29}$ Institute of Oceanology, Chinese Academy of Sciences, Qingdao, China, ${ }^{30}$ National Institute of Ocean Technology, Chennai, India, ${ }^{31}$ Woods Hole Oceanographic Institution, Woods Hole, MA, United States
\end{abstract}

The deep ocean below 200 m water depth is the least observed, but largest habitat on our planet by volume and area. Over 150 years of exploration has revealed that this dynamic system provides critical climate regulation, houses a wealth of energy, mineral, and biological resources, and represents a vast repository of biological diversity. A long history of deep-ocean exploration and observation led to the initial concept for the Deep-Ocean Observing Strategy (DOOS), under the auspices of the Global Ocean Observing System (GOOS). Here we discuss the scientific need for globally 
integrated deep-ocean observing, its status, and the key scientific questions and societal mandates driving observing requirements over the next decade. We consider the Essential Ocean Variables (EOVs) needed to address deep-ocean challenges within the physical, biogeochemical, and biological/ecosystem sciences according to the Framework for Ocean Observing (FOO), and map these onto scientific questions. Opportunities for new and expanded synergies among deep-ocean stakeholders are discussed, including academic-industry partnerships with the oil and gas, mining, cable and fishing industries, the ocean exploration and mapping community, and biodiversity conservation initiatives. Future deep-ocean observing will benefit from the greater integration across traditional disciplines and sectors, achieved through demonstration projects and facilitated reuse and repurposing of existing deep-sea data efforts. We highlight examples of existing and emerging deep-sea methods and technologies, noting key challenges associated with data volume, preservation, standardization, and accessibility. Emerging technologies relevant to deep-ocean sustainability and the blue economy include novel genomics approaches, imaging technologies, and ultradeep hydrographic measurements. Capacity building will be necessary to integrate capabilities into programs and projects at a global scale. Progress can be facilitated by Open Science and Findable, Accessible, Interoperable, Reusable (FAIR) data principles and converge on agreed to data standards, practices, vocabularies, and registries. We envision expansion of the deep-ocean observing community to embrace the participation of academia, industry, NGOs, national governments, international governmental organizations, and the public at large in order to unlock critical knowledge contained in the deep ocean over coming decades, and to realize the mutual benefits of thoughtful deep-ocean observing for all elements of a sustainable ocean.

Keywords: deep sea, ocean observation, blue economy, essential ocean variables, biodiversity, ocean sensors

\section{THE MANDATE AND BASIS FOR SUSTAINED DEEP-OCEAN OBSERVING}

\section{Scientific Need for Globally Integrated Deep-Ocean Observing}

Climate change, pollution, man-made structures and extraction of living and non-living resources will impact the deepest reaches of the global ocean (Mengerink et al., 2014). Despite these increasing threats, our understanding of the affected ecosystems and the nature of these impacts remains very limited. The vast majority of our oceans remain unseen and unquantified (Copley, 2014) in the face of current and emerging industrial activities and in spite of technologies that have expanded our capability to carry out globally integrated deep-sea observation.

Here we consider the deep sea to encompass waters below $200 \mathrm{~m}$. Physical oceanographers in the past defined the deep ocean as approximately $1,000 \mathrm{~m}$ based on an assumption of levels of no motion, but now we know these waters are dynamic. There was early recognition of $200 \mathrm{~m}$ as a useful approximate planetary-scale boundary between neritic and oceanic conditions and between the epipelagic and deep-ocean realms (Hedgpeth, 1957). Below $200 \mathrm{~m}$, changes in light, food supply, and the physical environment lead to altered animal taxonomic composition, morphologies, and lifestyles that are collectively understood to represent the deep sea both within the water column (Herring, 2002) and at the seafloor (Gage and Tyler, 1991; Tyler), 2003; Ramirez-Llodra et al., 2011; Levin and Sibuet, 2012; European Marine Board, 2013; Danovaro et al., 2014, 2017). Additionally, strong changes in biological and biogeochemical processes from 200 to $1000 \mathrm{~m}$ have a large influence on greater depths.

The deep sea is a highly connected environment, with links to the atmosphere and upper ocean as well as across depths and ocean basins. Contaminants, pollutants, and human exploitation readily cross oceans and political boundaries, as do the species, ecosystems, and biogeochemical processes that they impact. At the same time, many small-scale deep ocean phenomena, such as chemosynthesis-based hydrothermal vent, methane seep and organic (whale and wood) fall communities (e.g., Nishi and Rouse, 2014) contribute greatly to the Earth's biodiversity.

The great expanse of the deep ocean has to this point resulted in an extremely poor spatial and temporal resolution of observation. If future changes, threats, and impacts are to be appropriately monitored to enable mechanistic understanding and move toward sustainable management, that situation must change. A globally integrated deep-ocean observing system will require substantial international cooperation, collaboration and agreement, the support of many agencies and industries, and the adoption of 21st century remote and autonomous technologies. 


\section{Status of Deep-Ocean Observing}

Recognition of observation as key to the health of the oceans and sustainability of human activities on the planet has accelerated observing efforts since 2000, particularly in the upper ocean (Visbeck, 2018). However, the deep ocean remains under sampled and under observed at great depths and in many regions. For example, only $2 \%$ of observations in the Ocean Biogeographic Information System (OBIS) are from water depths greater than $500 \mathrm{~m}$ (Vanden Berghe, personal communication), despite recognition of high biodiversity in the deep ocean over the past half century (Rex and Etter, 2010). Multiple sustained observing programs and observatories in the coastal ocean (Corredor, 2018), global ocean (e.g., ARGO, OceanSITES, GOSHIP, OOI, ONC, EMSO), and on basin and regional scales (e.g., TPOS 2020, AtlantOS, SOOS, FRAM), carry out deep-ocean observations at near continuous to 10 -year intervals. But the ocean is vast, and, even with these observations, measurements are sparse. This is particularly true in the southern hemisphere, at depths below $2000 \mathrm{~m}$ (the maximum depth of most Argo floats), and for biological variables. For example, the Volunteer Observing Ship (VOS) program that deploys XBTs (expendable bathythermographs) along commercial ship tracks, providing valuable repeat sections, uses T7 XBTs which go only to $760 \mathrm{~m}$ and only measure temperature. In response, the Deep Ocean Observing Strategy (DOOS) represents a growing effort by the scientific community, under the auspices of the Global Ocean Observing System (GOOS), to coordinate and expand deep observing efforts, particularly with respect to essential ocean variables (EOVs) (Box 1).

As part of the DOOS effort, a 2016 census of sustained observations in the deep sea was conducted (Figure 1); it received 72 responses from 52 organizations, representing 75 countries, for programs funded by 55 agencies. Most programwide sampling occurred across large depth ranges $(200-6000 \mathrm{~m})$ and spatial scales. The most common mature EOVs sampled were temperature, salinity, dissolved oxygen, carbonate system components, and primary productivity. Research vessels, bottle samplers, and moorings were the most common platforms; the most common instruments were Conductivity, Temperature and Depths (CTDs), oxygen sensors, and acoustic Doppler profiler. These traditional observing tools are now being supplemented by a new generation of observing platforms and sensors, designed for longer duration, greater range, and the assessment of a broader suite of physical, chemical, and biological parameters. These new tools record sound and light, sequence genes, detect chemical constituents, collect high- resolution acoustic and optical imagery at any scale from marine snow particles to vast areas of seafloor habitats, provide animal-eye views, and bring exploration of the deep sea to the public.

\section{Quantitative Understanding of Natural Variability in the Deep Ocean and Causes of Long-Term Changes Climate change and related phenomena}

As the major anthropogenic carbon and heat sink, the ocean plays a critical role in mitigating climate change and determining how these changes impact society. With more than $90 \%$ of the anthropogenic heat imbalance absorbed by the ocean (Levitus et al., 2012), accurately monitoring its full depth provides a fundamental constraint on quantifying the warming of the planet (Johnson et al., 2016). Climate change has direct and indirect impacts on ocean biodiversity (Booth et al., 2018b) and processes, including surface ocean effects such as acidification impacts on plankton and oxygen production (Booth et al., 2018a). Deep-ocean biodiversity loss and climate-induced regime shifts are already occurring in some areas and are anticipated elsewhere (Levin and Le Bris, 2015). Polar regions are particularly vulnerable to warming which will affect stratification and ice cover, water chemistry, food supply, sedimentation, physical disturbance, metabolic processes and ultimately the biological composition of communities in the deep ocean (Sweetman et al., 2017). Large parts of the deeper portions of the Arctic have almost never been measured, and thus we lack even a baseline of deep Arctic Ocean properties (Nguyen et al., 2017). Expanded ocean measurements are also needed in the Southern Ocean to quantify heat budgets and understand interaction with shelf waters and their effects on regional climate, ice dynamics and ecology (Schofield et al., 2010). The need to anticipate extreme climate events and disruptive climate anomalies, such as El Niño, that affect ocean ecosystems and livelihoods requires

BOX 1 | Deep-ocean observing strategy (DOOS) history and status. The deep-sea community began discussions about coordinating deep-ocean observing and the development of essential ocean variables (EOVs) in 2011 that led to the formation of the Deep-Ocean Observing Strategy (DOOS), a project within the Global Ocean Observing System (GOOS). By advocating for observing EOVs, DOOS strives to improve understanding of the state of the deep ocean with respect to baseline conditions and response to climate variability and human disturbance.

- 2011: From Space to the Deep Seafloor Workshop Conducted

- 2014: DOOS adopted as a GOOS Project (GOOS SC-3)

- 2013-2016: DOOS Consultative Draft Distributed and Posted for Review

- Precursor to Implementation Guide: Levin, Boetius, Fischer, Johnson, Sloyan, Sibuet, Tanhua, Wanninkhof, (+ Ruhl, Heimbach, Song)

- www.deepoceanobserving.org/reports/consultative-report/

- 2016: Deep-Ocean Observing Inventory Launched (70+ Responses)

- www.deepoceanobserving.org/observations/deep-ocean-observations/

- 2016: DOOS Scoping Workshop Conducted (51 attendees from 9 countries)

- Summary Report: www.deepoceanobserving.org/reports/dec-2016-workshop-report/

- Terms of Reference: www.deepoceanobserving.org/about/doos-terms-of-reference/ - Key Science Questions: www.deepoceanobserving.org/observations/key-science-questions/

- 2017: First DOOS Steering Committee Meeting Convened

- Project Structure: www.deepoceanobserving.org/about/

- 2017: Project Plan and Engagement Plan Completed

- 2018: Community Communications Conducted

- OSM Town Hall: www.deepoceanobserving.org/2018/01/18/oceansciences-meeting-2018-doos-town-hall/

- Ocean Obs '19 Community White Paper submitted to Frontiers in Marine Sciences 


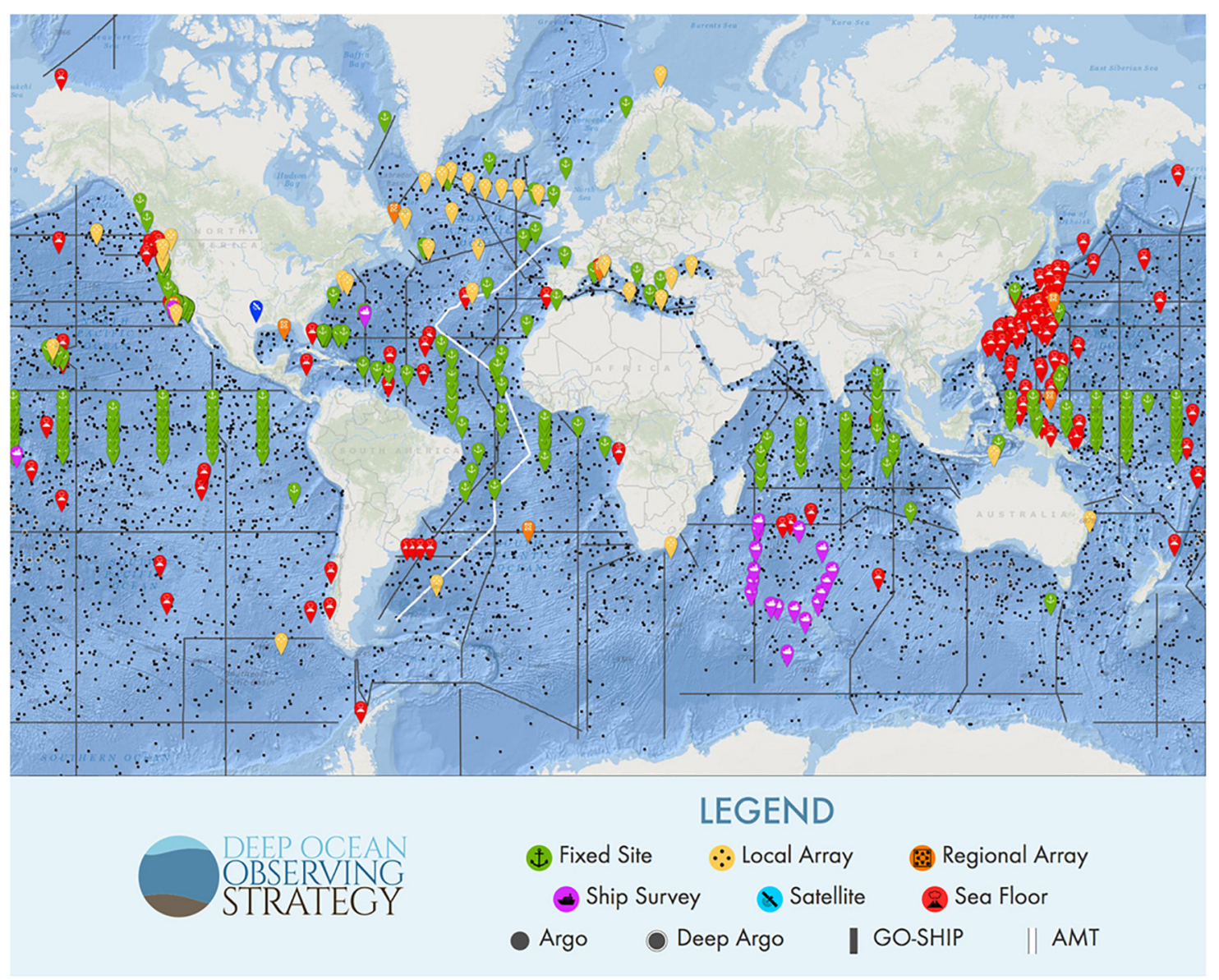

FIGURE 1 | Inventory of sustained deep-ocean observing (Interactive map available online, http://www.deepoceanobserving.org/observations/deep-oceanobservations/).

increased research into the deep ocean and its connection to the surface and atmosphere. Our ability to project future change and develop adaptive strategies to better enable society to cope with climate change would be greatly enhanced by new, well-coordinated physical, biogeochemical, and biological observations in deep waters.

\section{The deep sea as an analog for the origin of life and its extraterrestrial potential}

Extreme conditions found in deep-sea waters, at the seafloor, and in the deep biosphere offer insight into the processes enabling the origin of life and the potential for life on other planets and their moons. There are combinations of temperature, pressure, Eh, and $\mathrm{pH}$ found in the deep ocean that are conducive to abiotic processes that may generate primordial life (Cavanaugh et al., 2006; Schulte et al., 2006). Deep-sea settings with carbonate minerals, methane, and carbon dioxide may resemble those on Mars. Anoxic, hypersaline basins of the Mediterranean Sea support diverse microbial processes (sulfate reduction, methanogenesis, and heterotrophic activity) (van der Wielen et al., 2005) and even metazoan life forms (Danovaro et al., 2010), suggesting potential for such conditions to support extraterrestrial life, for example in water stored as brine lenses on Mars (Gilichinsky, 2002). Hydrothermal vents offer confirmation that life can thrive in the dark depths of the ocean, utilizing chemosynthesis as the base of the food chain; analogous geologically active seafloors may occur in the oceans of the moons of Jupiter (Europa) and Saturn (Enceladus), based on ejected plumes with mixtures of compounds characteristic of hydrothermal venting (Deamer and Damer, 2017). Increasingly, exploration and observation of the extreme deep sea offers unending novelty that reveals new possible modes of life on Earth and potentially other planets.

\section{Natural resource use}

The monetary value derived from the oceans, including energy, minerals, and fisheries, is estimated at USD 24 trillion (HoeghGuldberg, 2015). Significant assets lie in the deep ocean where the current state of knowledge is unlikely to be sufficient to guarantee safe and sustainable exploitation (Ramirez-Llodra et al., 2011). Threat prevention and mitigation require thorough understanding of the current state of the deep ocean and its natural variability (baseline data), as well as records of changing environmental quality to enable sustainable economic growth, 
food security and ecosystem-based management. Known natural temporal variability in deep-ocean biological assemblages (e.g., Smith et al., 2009) suggests that there is a "moving baseline" that cannot be captured by one-off observations, such that routine observations over time will be essential to appropriate environmental monitoring.

\section{Pollution, contamination and litter}

The deep ocean is the ultimate sink for materials on land; through the action of weathering and gravity, great mountain ranges are leveled and become a thin layer of sediment on the deepsea floor. Consequently, it is no surprise that human debris, environmental contaminants, and pollutants are widespread throughout the global deep ocean. Clinker, burnt coal from the age of steam, litters most of the deep-ocean floor; today, plastic debris appears equally pervasive (Ramirez-Llodra et al., 2013). As in coastal and shelf seas, the greatest concern is likely to be persistent compounds that bioaccumulate and biomagnify (e.g., organohalogens and organometals; Kress et al., 1998; Roberts, 2002; Ramirez-Llodra et al., 2011). Such contaminants can be found in animals inhabiting the deepest trenches (Jamieson et al., 2017). These pollutants and contaminants are rarely measured. That lack of attention may stem from an erroneous perception that such compounds are not present and technical difficulties in achieving such measurements. Somewhat perversely, the contamination of the global ocean by these compounds has proved useful in oceanographic science, for example in the use of organohalogens (chlorofluorocarbons and sulfur hexafluoride) as tracers of water masses and their movement (Fine, 2011). These forms of widespread contamination of the environment and fauna of the deep ocean are little reported, in marked contrast to major point-source contaminations of the ocean such as the 2010 Macondo oil spill in the Gulf of Mexico. The full acute and chronic impacts of the Macondo accident remain a largely unanswered question. Although there is evidence of toxicity from constituents of the oil to deep-water corals (White et al., 2012) and soft-bottom benthic communities (Montagna et al., 2013), a lack of pre-spill data has limited the full assessment of impact.

Accumulations of marine debris, particularly plastic material, occur commonly in the deep sea, along with microplastics in a wide range of ecosystem compartments (e.g., Bergmann et al., 2017). Large objects such as shipping containers and fishing gear (derelict nets and trawls) can alter habitats by providing hard substrate, toxicological impacts associated with coatings or contents (Taylor et al., 2014), or entangling organisms (Humborstad et al., 2003). Plastics resist degradation and can potentially last for centuries. Documentation of macroscopic plastic debris throughout the deep sea (RamirezLlodra et al., 2013; Schlining et al., 2013; Chiba et al., 2018), includes observations from the Mariana Trench (Chiba et al., 2018) and the Arctic Ocean (Bergmann et al., 2017). Ingestion of macroscopic plastics by fishes is documented (e.g., Anastasopoulou et al., 2013); however, the potential impacts of microplastics (particles less than $5 \mathrm{~mm}$ in diameter) raises issues that are still not well understood. Microplastics have been found to be abundant in sediment samples collected from a wide range of geographic locations at depths ranging from 300 to
BOX 2 | Key scientific questions.

1. What is the role of the deep ocean in the Earth's energy imbalance and land/sea water redistribution?

2. How are natural and anthropogenic variations in climate connected to the global overturning circulation and its variability?

3. How does deep pelagic ecology respond to natural variation and multiple climate change stressors?

4. How might natural and anthropogenic variations in climate influence the function of the solubility and biological carbon pumps, continental slope, nepheloid layer transport and the sequestering of carbon in the deep ocean, and the supply of organic carbon (food supplies) to deep-sea communities?

5. What drives observed variation in seafloor fluxes of heat, nutrients, tracers, oxygen and carbon?

6. How might natural and anthropogenic variations in climate and resource industry activities influence the functional importance of animals and microbes in the deep sea and the seafloor?

7. What are the sources, pathways, fates and consequences of deep-ocean contaminants (including plastics) introduced by humans from land and ocean activities?

3500 m (Van Cauwenberghe et al., 2013; Woodall et al., 2018). Additionally microplastics have been found to enter deep-sea food webs, with ingestion of microplastic fibers documented in cnidarians, echinoderms, and arthropods collected from 334 to $1783 \mathrm{~m}$ in the equatorial mid-Atlantic and SW Indian Oceans (Taylor et al., 2016). Benthic invertebrates ingested microplastics at depths deeper than $2200 \mathrm{~m}$ in the North Atlantic (Courtene-Jones et al., 2017). Physical, biogeochemical, and biological observations can improve understanding of the sources, pathways, fates and consequences of plastic and debris in the ocean and inform mitigation practices.

\section{Key Scientific Questions Driving Observing Requirements}

Even our limited knowledge raises fundamental questions requiring answers for prediction and management of deep-ocean connected systems and processes. Below we introduce a subset of these questions that underpin observational requirements for the deep ocean (Box 2), largely derived from the DOOS Science Implementation Guide.

\section{Societal Mandates Quantifying Change Through Science-Based Management and Planning}

Effective environmental management requires environmental monitoring (National Research Council, 1990). Environmental management targets different scales, from spatial planning and ecosystem-based management (Crowder and Norse, 2008) to management of individual offshore industrial projects (Ellis et al., 2017). Minimizing environmental degradation drives such management, and industry must strive to meet this goal to obtain its license to operate. Development in the marine environment in most jurisdictions requires an environmental impact assessment (EIA) process to anticipate, assess, and reduce environmental and social risks of a project prior to granting regulatory approval (Durden et al., 2018). The EIA process requires the proponent to describe the environment, estimate impacts of the project, 
and provide an environmental management plan (EMP), all of which demand environmental observations and establishment of a baseline of the physical, chemical and biological environment in and around the development (Ellis et al., 2017), and thus a wide range of ocean data. Most marine developments lack sufficient information for assessment at the project planning phase and thus require new data. The environmental baseline provides a reference point to assess impacts of the project relative to unimpacted "control" sites nearby (Underwood, 1992). Any project moving forward must monitor to evaluate potential impacts and their consequences to ensure appropriate management actions where significant impacts occur. Effective management typically requires good quality, quantitative environmental information. All aspects of the environmental management of deep-water industrial projects and policy bring significant uncertainty during development, punctuating the need for observational data to establish environmental conditions and responses to disturbance. Ocean observations can provide the necessary information for effective management of the marine environment, including measuring environmental baseline conditions, establishing change caused by both natural and anthropogenic activities, and in assessing recovery after disturbance. Deep-ocean observations provide the basis for prediction and modeling, where data enable model development, parameterization and testing. Deep-ocean observing also provides important information for engineering, particularly physical environmental conditions (e.g., current speeds, temperatures) and infrastructure risk (e.g., from submarine landslides, subsidence).

\section{Socio-Ecological and Environmental Policy Making}

The interactions and cumulative impacts of different human uses of the deep ocean require mechanistic understanding and comprehensive monitoring to inform integrative and adaptive management measures that ensure the long-term sustainability of critical ocean ecosystems and sustainable development. Numerous international policy-making bodies, initiatives and agreements either require or would benefit from deep-ocean observations and input from deep-sea scientists (see Table 1). Strong deep-ocean representation for defining critical issues, data generation, the detection of cumulative impacts, and technology transfer going forward will benefit all of these entities.

\section{Cultural Services}

The non-material human benefits obtained from the deep ocean are referred to as "cultural services." These include aesthetic inspiration, cultural identity, sense of home, and spiritual experience related to the natural environment. Education and science are sometimes included. The remote and, to humans, extremely hostile environment of the deep ocean render the prospects of tourism and recreation a rather distant prospect. Some small-scale, subsistence fishing does take place in deepwater and open-ocean environments and would be characterized as "fishers' way of life"/cultural identity. In the terminology of The Economics of Ecosystems and Biodiversity (TEEB) "Aesthetic appreciation and inspiration for culture, art and design" and "Spiritual experience and sense of place" are likely to be the primary cultural services provided by the deep ocean; in some cases these are largely provided by the media (e.g., BBC Blue Planet I and II). These concepts can be generally considered analogous with the "Common Heritage of Mankind," as incorporated in the United Nations (UN) Convention on the Law of the Sea, and considered by the International Seabed Authority in the context of proposed deep-ocean mining regulations (Bourrel et al., 2016).

\section{GENERATING DEEP-OCEAN DATA}

\section{Essential Deep-Ocean Variables}

The FOO (Lindstrom et al., 2012; Muller-Karger et al., 2014, 2018; Miloslavich et al., 2018) was developed following OceanObs'09 in Venice. It forms the basis for the identification and specification of EOVs within GOOS, and more recently DOOS. "Fit for purpose" essential variables are selected based on their ability to address pressing scientific questions and societal challenges, and on their feasibility. Proven, scientifically understood methods of sufficient readiness have to be available to allow for operational observations on a global scale. A multidisciplinary writing team of experts in the field of ocean climate, physics, carbon cycling, biogeochemistry, and biology, biodiversity and ecosystems initially selected EOVs required for the assessment of deep-ocean conditions for the DOOS. Following community review ${ }^{1}$, these were considered further at a scoping workshop in late 2016. Variables were assessed regarding how well they would serve the challenges posed by deep-ocean science and society (see Section "Scientific Need for Globally Integrated Deep-Ocean Observing" and Box 2) and the extent to which GOOS EOVs already covered them. The group also considered specific deep-sea phenomena that required unusual spatiotemporal coverage and resolution, as well as suitable platforms and sensors, and confirmed the need for a deep-ocean component as part of the EOV process that supports GOOS.

The EOV processes of the FOO are based on lessons learned from the global climate observing community, which had great success organizing its efforts around essential climate variables (ECVs). ECVs are physical, chemical or biological variables or a group of linked variables that critically contribute to the characterization of Earth's climate. The Global Climate Observing System (GCOS) currently specifies 54 ECVs (Bellward et al., 2016) required to support the work of the UN Framework Convention on Climate Change (UNFCCC) and the Intergovernmental Panel on Climate Change (IPCC). Applying the concept of EOVs to ocean observations has considerable conceptual overlap among ECVs introduced by GCOS, the Essential Variables defined for meteorological services by the World Meteorological Organization (WMO) Resolution 40 (Cg-XII), and the Essential Biodiversity Variables (EVBs) as defined by the global biodiversity observing system The Group On Earth Observations Biodiversity Observation Network (GEO BON).

\footnotetext{
${ }^{1}$ http://www.deepoceanobserving.org/reports/consultative-report/
} 
TABLE 1 | International policy-making bodies, initiatives and agreements that either require or would benefit from deep-ocean observations.

\begin{tabular}{|c|c|c|c|}
\hline Theme & Body or Convention & Goals & Links to the Deep Ocean \\
\hline \multirow[t]{4}{*}{ Climate } & $\begin{array}{l}\text { United Nations Framework } \\
\text { Convention on Climate Change } \\
\text { (UNFCCC) }\end{array}$ & $\begin{array}{l}\text { An intergovernmental treaty developed to address the } \\
\text { problem of climate change }\end{array}$ & $\begin{array}{l}\text { Climate change cannot be understood without an } \\
\text { improved understanding of ocean processes and } \\
\text { sinks }\end{array}$ \\
\hline & Paris Agreement & $\begin{array}{l}\text { An agreement to reduce carbon emissions and limit } \\
\text { warming }\end{array}$ & $\begin{array}{l}\text { Requires a broader understanding of deep-ocean } \\
\text { processes }\end{array}$ \\
\hline & $\begin{array}{l}\text { Intergovernmental Panel on Climate } \\
\text { Change (IPCC) }\end{array}$ & $\begin{array}{l}\text { Scientific body to provide information to policy makers; } \\
\text { summarizes ocean changes and consequences; } \\
\text { Prepares assessment reports and special reports }\end{array}$ & $\begin{array}{l}\text { The deep ocean vulnerabilities and roles in climate } \\
\text { mitigation are increasingly recognized, including in } \\
\text { the Special Report on Ocean and Cryosphere }\end{array}$ \\
\hline & Sustainable Development Goal 13 & $\begin{array}{l}\text { Take urgent action to combat climate change and its } \\
\text { impacts }\end{array}$ & The deep ocean requires a higher profile in SDG 13 \\
\hline \multirow[t]{4}{*}{ Biodiversity } & SDG 14 (Life Below Water) & $\begin{array}{l}\text { Calls for, among other things, an increase in scientific } \\
\text { knowledge, covers pollution, sustainable fisheries, } \\
\text { ocean acidification }\end{array}$ & $\begin{array}{l}\text { DOOS has teamed up with DOSI and INDEEP } \\
\text { (scientific networks) to build global scientific } \\
\text { capacity to address SDG } 14 \text { targets as they relate } \\
\text { to the deep ocean }\end{array}$ \\
\hline & $\begin{array}{l}\text { The UN Decade of Ocean Science } \\
\text { for Sustainable Development } \\
2021-2030\end{array}$ & $\begin{array}{l}\text { Addresses the ocean science needed to implement } \\
\text { SDG } 14\end{array}$ & $\begin{array}{l}\text { The deep ocean has a major role to play in each of } \\
\text { the Decade } R \text { and } D \text { priority areas }\end{array}$ \\
\hline & $\begin{array}{l}\text { UN Intergovernmental Conference } \\
\text { to negotiate the new Biodiversity } \\
\text { Beyond National Jurisdiction } \\
\text { (BBNJ) instrument }\end{array}$ & $\begin{array}{l}\text { Negotiations to develop a new treaty for biodiversity } \\
\text { beyond national boundaries. Elements include } \\
\text { Area-based management tools including MPAs, } \\
\text { Environmental Impact Assessment, Marine Genetic } \\
\text { Resources, and Capacity building and technology } \\
\text { transfer }\end{array}$ & $\begin{array}{l}\text { Deep-ocean observing can contribute to each of } \\
\text { the key elements, informing on connectivity, habitat } \\
\text { suitability and more }\end{array}$ \\
\hline & Convention on Biological Diversity & $\begin{array}{l}\text { Calls for in situ conservation of marine and coastal } \\
\text { biodiversity as well as more general sustainable use. } \\
\text { Has spearheaded the description of Ecologically and } \\
\text { Biologically Significant Areas (EBSAs) in marine and } \\
\text { coastal waters }\end{array}$ & $\begin{array}{l}\text { A specific program of work focused on impacts of } \\
\text { ocean acidification and other stressors in cold } \\
\text { water ecosystems. Deep-ocean observing can } \\
\text { contribute to EBSA designation and development }\end{array}$ \\
\hline $\begin{array}{l}\text { Deep } \\
\text { Seabed } \\
\text { Mining }\end{array}$ & International Seabed Authority (ISA) & $\begin{array}{l}\text { Oversees seabed mining activities and protection of the } \\
\text { marine environment from mining impacts }\end{array}$ & $\begin{array}{l}\text { Will need to assess, predict and control mining } \\
\text { impacts entailing an understanding of the impacts } \\
\text { of climate change on the deep ocean }\end{array}$ \\
\hline \multirow[t]{5}{*}{ Fishing } & $\begin{array}{l}\text { Food and Agriculture Organization, } \\
\text { Regional Fisheries Management } \\
\text { Organizations (RFMOs) }\end{array}$ & $\begin{array}{l}\text { RFMOs designate Vulnerable Marine Ecosystems } \\
\text { (VMEs) and fishing grounds for demersal fisheries }\end{array}$ & $\begin{array}{l}\text { New fisheries require environmental impact } \\
\text { assessments, and will need to consider broader } \\
\text { impacts of climate change }\end{array}$ \\
\hline & $\begin{array}{l}\text { UN Agreement on Highly Migratory } \\
\text { and Straddling Fish Stocks }\end{array}$ & $\begin{array}{l}\text { Aim to sustain shared fisheries, while protecting } \\
\text { biodiversity in the marine environment }\end{array}$ & $\begin{array}{l}\text { Will need to understand how deep-ocean changes } \\
\text { affect health and resilience of fish stocks, } \\
\text { biodiversity and associated marine ecosystems }\end{array}$ \\
\hline & Convention on Migratory Species & $\begin{array}{l}\text { Coordinating initiatives to safeguard highly migratory } \\
\text { species }\end{array}$ & $\begin{array}{l}\text { Will need to understand how deep-ocean changes } \\
\text { and human activities in the deep ocean affect } \\
\text { migratory species }\end{array}$ \\
\hline & $\begin{array}{l}\text { Regional Seas Organizations } \\
\text { (RSOs) }\end{array}$ & $\begin{array}{l}\text { Regional platforms to coordinate policies and activities } \\
\text { related to conservation and sustainable development }\end{array}$ & $\begin{array}{l}\text { Considerable deep ocean lies within regional seas } \\
\text { jurisdiction }\end{array}$ \\
\hline & UN Environment Program & $\begin{array}{l}\text { Coordinates many ocean and coastal programs, } \\
\text { initiatives and agreements, including on land-based } \\
\text { sources of marine pollution, regional cooperation and } \\
\text { marine debris }\end{array}$ & $\begin{array}{l}\text { The deep ocean is recipient of much land-based } \\
\text { pollution and marine debris }\end{array}$ \\
\hline $\begin{array}{l}\text { Shipping } \\
\text { and } \\
\text { Dumping }\end{array}$ & $\begin{array}{l}\text { International Maritime Organization } \\
(\mathrm{IMO})\end{array}$ & $\begin{array}{l}\text { Adopts global regulations to manage merchant } \\
\text { shipping, dumping from sea and geoengineering in the } \\
\text { ocean }\end{array}$ & $\begin{array}{l}\text { Activities and environment are both increasingly } \\
\text { vulnerable to climate change }\end{array}$ \\
\hline $\begin{array}{l}\text { Ocean } \\
\text { Assessment }\end{array}$ & $\begin{array}{l}\text { UN Regular Process for Global } \\
\text { Reporting and Assessment of the } \\
\text { State of the Marine Environment }\end{array}$ & $\begin{array}{l}\text { Created the Global Integrated Marine Assessment } \\
\text { (World Ocean Assessment-1) that demonstrated the } \\
\text { need for sustained ocean observations to monitor and } \\
\text { understand ocean change. A second integrated ocean } \\
\text { assessment process is now underway (WOA-2) with } \\
\text { emphasis on recent change in knowledge and human } \\
\text { activities relative to ocean sustainability }\end{array}$ & $\begin{array}{l}\text { Ocean sustainability and health will be } \\
\text { fundamentally affected by deep-ocean changes } \\
\text { from rising } \mathrm{CO}_{2} \text { emissions and direct human } \\
\text { impacts }\end{array}$ \\
\hline
\end{tabular}

Noting that EOV selection is an ongoing, iterative process, we discuss key variables below. The FOO requires that EOVs can be observed or derived on a global scale, and are technically feasible using accessible, well-accepted methods. Levels of readiness in developing EOVs differ across the three disciplines, pointing to a need to bring relevant deep-ocean requirements, variables, 
technologies, and data products with a low readiness level from "concept" to "maturity." In particular, many biodiversity and ecosystem EOVs developed for shallow-water environments are not relevant for deep water and the status, maturity level, and ubiquity of EOVs for all disciplines often differ between shallow and deep water.

\section{Physics}

Deep-ocean physical science gaps include: deep-ocean circulation, ventilation rates and their variability, meridional overturning circulation, deep-ocean warming and freshening, impact on patterns of sea level rise, abyssal mixing, ocean bottom boundary layers and their representation in ocean climate models, and geothermal heating. To close these knowledge gaps, we must quantify flow velocity, density ( $T, S, r)$, and pressure variations in space and time as well as turbulent stresses, bottom boundary conditions, and seafloor geometry. Four existing EOVs capture the subsurface state. Sea surface height, an integrating (whole water column) measurement, connects intimately with ocean bottom pressure (OBP) as well as deep temperature and salinity (density) measurements. EOVs already include subsurface temperature, salinity, and currents. Proposed new EOVs include OBP, ocean turbulence, and ocean bottom boundary fluxes (Table 2).

\section{Ocean bottom pressure}

Ocean bottom pressure observations are necessary to understand causes of sea level rise specifically related to changes in mass due to circulation changes (locally) and land ice drainage (integrated globally). Distributed OBP sensors can define how water column mass varies geographically, helping to validate climate change model predictions and support satellite remotesensing missions, e.g., the Gravity Recovery and Climate Experiment (GRACE) and its follow-on (GRACE-FO) mission. Unlike remote sensing approaches, distributed OBP sensors can provide high temporal resolution, as well as a better horizontal resolution.

Bottom pressure measurements, particularly on the global continental slope, can monitor ocean circulation important for global-scale ocean variability and climate. GOOS should prioritize such measurements (Hughes et al., 2018). At high frequencies, OBP is sensitive to barotropic tides, internal waves and tides, infragravity waves, storm surges and tsunamis. De-aliasing many other measurements, especially those from satellites, requires accurate determination of tidal constants (and secular changes). OBP observations contribute directly to tsunami early warning, a critical task for GOOS.

Self-calibration of modern OBP sensors increases the value of observations by eliminating long-term drift that severely hampered their use for studying interannual and longer time scale variability (Sasagawa and Zumberge, 2013; Kajikawa and Kobata, 2014). The Ocean Observations Panel for Climate (OOPC) has approved OBP as an emerging EOV.

\section{Ocean turbulence}

Oceanic tracers exist in an advective-diffusive balance. Diffusion is ultimately achieved through micro-scale mixing, which plays a central role in the formation and modification of water masses, the distribution and flow of heat, and relates to biological populations and processes, e.g., by providing nutrients and oxygen. Mixing processes play a central role at many stages of the Earth's carbon cycle. de Lavergne et al. (2016a) argue "that the largely unchartered bottom boundary waters are as central to ocean functioning as their surface counterparts." The lack of understanding of deep-ocean processes, especially mixing and dissipation, may be the main challenge to further progress, becoming a bottleneck to a truly adequate understanding of ocean circulation and climate on the time scales commensurate with human society (Naveira Garabato, 2012).

TABLE 2 | Global Ocean Observing System (GOOS) Essential Ocean Variables (EOVs) and new EOVs proposed by the Deep Ocean Observing Strategy (DOOS).

\begin{tabular}{|c|c|c|c|}
\hline & Physics & Biogeochemistry & Biology and Ecosystems \\
\hline \multirow[t]{11}{*}{ GOOS EOVs } & Sea state & Oxygen & Phytoplankton biomass and diversity \\
\hline & Ocean surface stress & Nutrients & Zooplankton biomass and diversity \\
\hline & Sea ice & Inorganic carbon & Fish abundance and distribution \\
\hline & Sea surface height & Transient tracers & $\begin{array}{l}\text { Marine turtle, bird, mammal abundance and } \\
\text { distribution }\end{array}$ \\
\hline & Sea surface temperature & Particulate matter & Hard coral cover and composition \\
\hline & Subsurface temperature & Nitrous oxide & Seagrass cover \\
\hline & Surface currents & Stable carbon isotopes & Macroalgal canopy cover \\
\hline & Subsurface currents & Dissolved organic carbon & Mangrove cover \\
\hline & Sea surface salinity & Ocean color & Ocean sound \\
\hline & Subsurface salinity & & Microbe biomass and diversity (emerging) \\
\hline & Ocean surface heat flux & & $\begin{array}{l}\text { Benthic invertebrate abundance and distribution } \\
\text { (emerging) }\end{array}$ \\
\hline EOVs under consideration & Ocean Bottom Pressure & Seafloor labile organic matter & Body size \\
\hline \multirow[t]{3}{*}{ by Doos } & Seafloor Fluxes & Seafloor respiration & Seafloor sponge habitat cover \\
\hline & Ocean Turbulence & Seafloor fluid and gas effluxes (focus on methane) & Connectivity of species \\
\hline & & Litter including microplastics & \\
\hline
\end{tabular}


Several studies demonstrate the relevance of mixing for large-scale oceanic processes (Wunsch and Ferrari, 2004). Incorporation of a very simple bottom-enhanced mixing eddy diffusivity into existing climate models results in a major change in predicted deep ocean structure (MacKinnon et al., 2017). Existing parameterizations that relate fine-scale variability (5-100 m) to mixing are known to be in error at intense topographic mixing sites (Klymak et al., 2008). The challenge is to develop parameterizations that remain accurate through major departures from our present climate. It is clear that deep mixing will vary as stratification and bottom currents change (Melet et al., 2016). Observations required to quantify these effects are needed. While numerous techniques exist to map the flow of the ocean, the ability to directly measure ocean mixing has been gained only recently. The ability to routinely collect the microscale observations necessary to infer ocean mixing is emerging rapidly. Future global ocean observing programs must recognize rapidly developing methods and the cost effectiveness of incorporating microscale sensing systems into existing observational assets (Figure 2). Understanding the co-variability of chemical, biological, and physical parameters across a wide range of space and time scales will provide great scientific and societal benefit.

\section{Bottom fluxes}

Despite small hydrothermal flux of water (0.005 Sv estimated) relative to all other boundary fluxes, geothermal heat flux (GHF) from the Earth's interior to the oceans globally averages $\sim 100 \mathrm{~mW} / \mathrm{m}^{2}$, although with large variation (Davies, 2013). The average level is significant compared to the global net radiative imbalance of $\sim 500 \mathrm{~mW} / \mathrm{m}^{2}$ (Stephens et al., 2012), corresponding to a mean temperature change of $0.01^{\circ} \mathrm{C}$ in a decade (Wunsch, 2016). As we accumulate data records

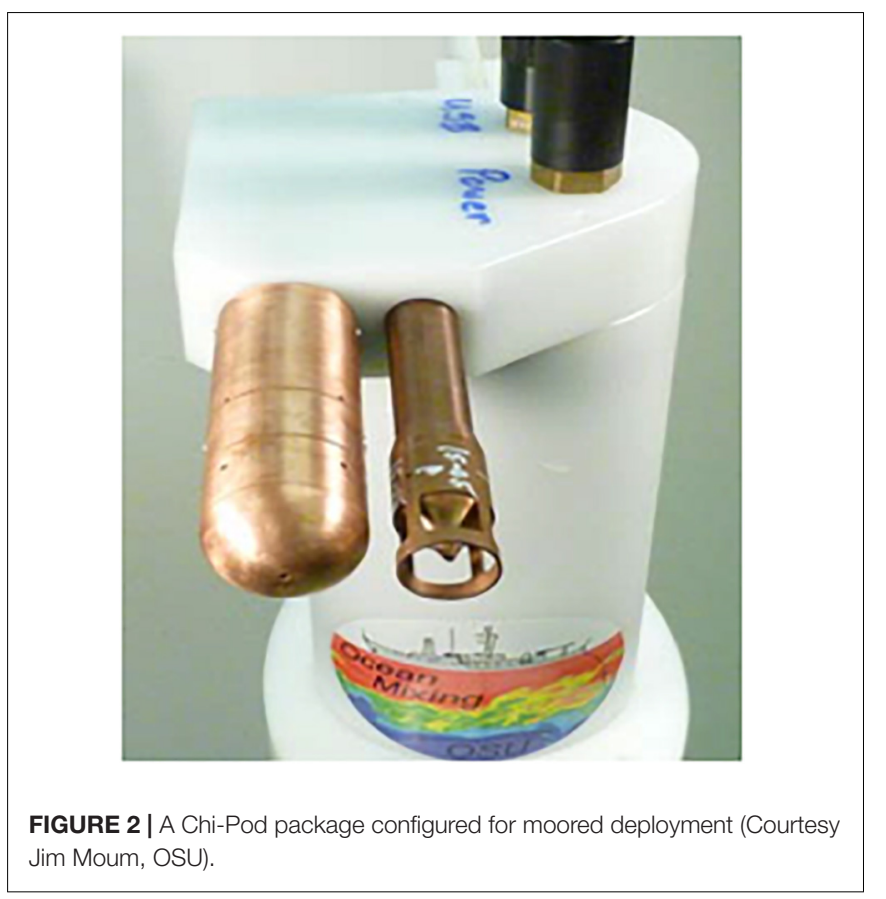

longer than decades, accounting for bottom geothermal flux, including spatial and temporal variability, will be necessary. Heat fluxes can destabilize the density profile at depth, facilitating mixing, and are comparable to internal wave and lee wave dissipation in terms of energy dissipation and the mixing of deep waters. Ocean bottom GHF is about $28 \mathrm{TW}$; assuming even a few percent efficiency in conversion to mechanical energy, puts GHF on the same level as tides ( $\sim 1-2 \mathrm{TW}$; de Lavergne et al., 2016b). Few of today's ocean circulation or climate models account for these geothermal fluxes (e.g., less than half in the intercomparison study by Griffies et al., 2014), but modeling groups are beginning to assess more rigorously the impact of geothermal fluxes on large-scale ocean circulation (e.g., Mashayek et al., 2013; Piecuch et al., 2015). The DOOS EOV Task Team is considering a long-term plan for observing heat and mass flux.

Comprehensive and sustained observation of deep- and bottom-water formation processes in key regions of water mass transformation (e.g., in polar regions) is an ongoing challenge in both hemispheres, with remaining surprises that challenge conventional depictions of the global overturning circulation, both in terms of their source regions (e.g., Lozier et al., 2019) as well as their abyssal component (de Lavergne et al., 2017). Equally challenging remains their adequate representation in ocean climate models (e.g., Lohmann et al., 2014; Snow et al., 2015, 2016).

\section{Biogeochemistry}

The deep ocean plays a critical role in global biogeochemical cycles and hosts key marine ecosystem functions and services, e.g., in terms of carbon sequestration or nutrient regeneration for sustained oceanic productivity (e.g., Thurber et al., 2014). It contains over $90 \%$ of the labile carbon and inorganic nutrients residing in the Earth system and increasing atmospheric carbon dioxide levels and other global climate change-related and anthropogenic impacts affect deep-water ecosystems (e.g., Ramirez-Llodra et al., 2011; Levin and Le Bris, 2015). Changes in surface water productivity, deep-water respiration and remineralization, and circulation and mixing of the deep ocean all affect carbon cycling, as well as oxygen and nutrient levels (e.g., Talley et al., 2016). Most key biogeochemistry-centered questions (Box 2) relate to the deep ocean's ability to store carbon dioxide drawn from the atmosphere to mitigate anthropogenic carbon emissions, either by direct uptake via the ocean surface and physical transport to the ocean interior (i.e., solubility pump) or by uptake through biomass export to depth for longterm residence in the deep ocean or ultimate sequestration in deep-ocean sediments (i.e., biological pump). The uptake of inorganic carbon or its release upon remineralization of organic matter leads to changes in ocean chemistry, i.e., $\mathrm{pH}$ and carbonate ion concentration, which in turn may affect biogeochemical processes in deep waters (e.g., Sarmiento et al., 1998; Feely et al., 2009). Hence, there is a strong need to extend routine observations to the deep-water column and to the deep seafloor to assess the biological pump as a key process with a particularly strong deep-ocean component (e.g., MullerKarger et al., 2005; Honjo et al., 2014). Important biogeochemical 


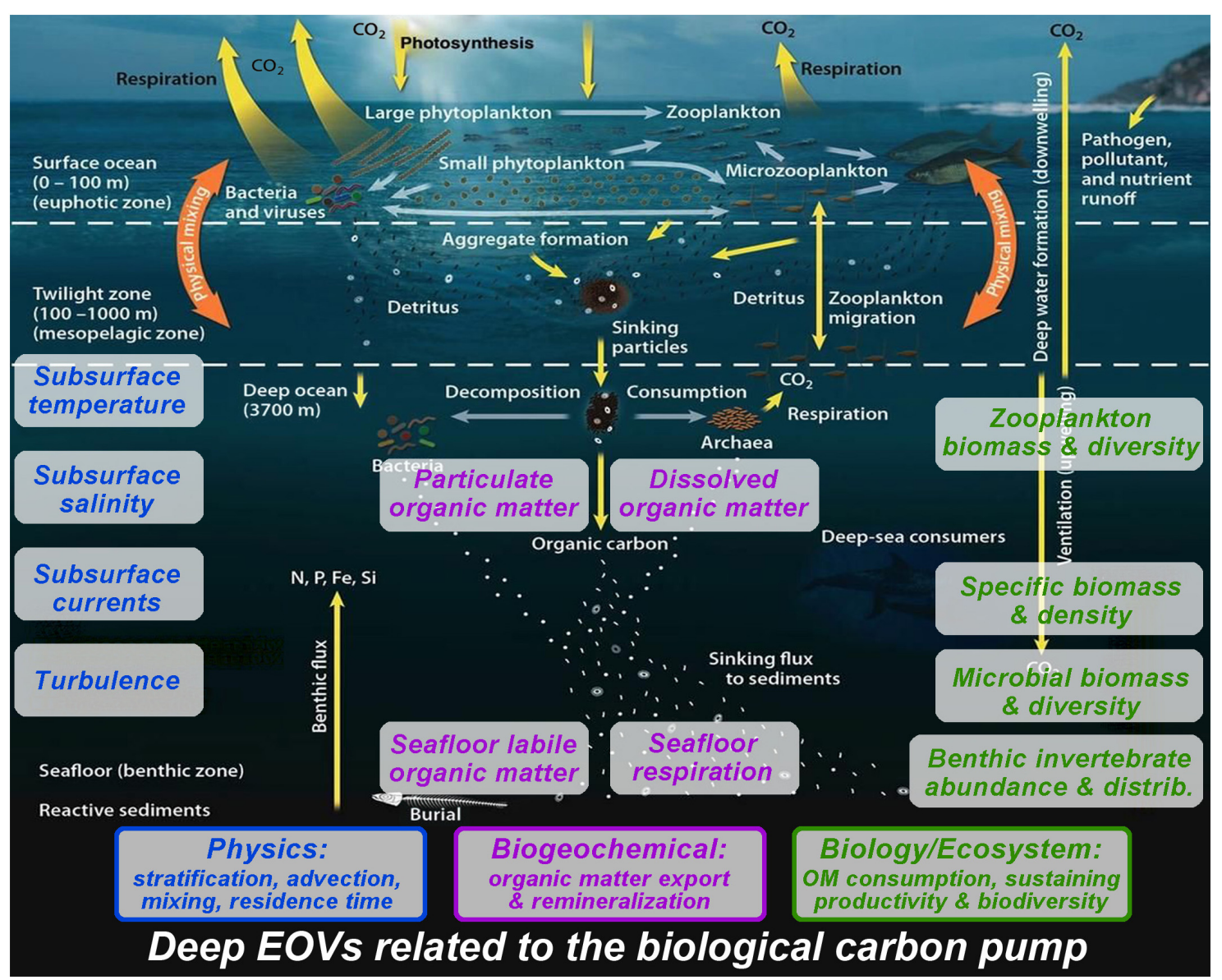

FIGURE 3 | Multidisciplinary observations throughout the water column are necessary to fully address the biological pump. Information that can be derived from EOVs: Physics: stratification affects particle sinking; understanding the origin of the particles and the residence time of the DIC from particle remineralization in the deep ocean requires measurement of advection and mixing. Biogeochemistry: export/mixing down of particulate and dissolved organic matter from the surface layer determines labile organic matter arriving at the seafloor, which is either respired by seafloor biota or stored for longer times in the sediment. Biology and ecosystems: zooplankton and microorganisms break down and remineralize sinking particles in the water column. Exported organic matter feeds all water column and benthic biota (zooplankton, benthic invertebrates, microbes) sustaining their biomass, density, and biodiversity. Background Image: U.S. DOE. 2008. Carbon Cycling and Biosequestration: Report from the March 2008 Workshop, DOE/SC-108, U.S. Department of Energy Office of Science, https://genomicscience.energy.gov/ carboncycle/report/.

variables to quantify the efficiency of biological pump transfer of carbon dioxide from the atmosphere to the deep ocean include remineralization rates and solute fluxes at the sedimentwater interface, as well as redox conditions in sediments and deep waters. A review of deep-ocean biogeochemical EOVs emphasizes development and review of sensors for deep-ocean particle fluxes, seafloor labile organic matter, and seafloor respiration rates, in the context of assessing the biological pump (Figure 3).

Sensors to observe multiple variables have matured, but not always at the precision required to assess potentially small and slow natural variability and trends in the deep ocean. The recent list of EOVs specified by the GOOS biogeochemical expert panel encompass most of the biogeochemical EOVs suggested in the DOOS consultative report: inorganic carbon and its isotopic composition, nutrients, oxygen, particulate and dissolved organic matter (Table 2).
Characterizing spatial, seasonal, and inter-annual variability in bathypelagic flux characteristics requires sustained observations both with traditional moored particle traps as well as novel instrumentation for high resolution observations (e.g., particle cameras, optical sensors) deployed with novel platforms (e.g., neutrally buoyant, drifting particle traps). Constraining the supply and ultimate fate of organic matter at the bottom of the ocean requires time series of detritus deposition and respiration rates at the seafloor using moored or mobile platforms (e.g., Smith et al., 2017). The turnover time of DOM at varying depths and temperatures will affect carbon sequestration and calls for in situ measurements of DOM concentrations and turnover along with concurrent observations of DOC and ocean microbiome characteristics (e.g., Moran et al., 2016). Key factors determining ocean health and productivity link to the transport of organic matter to the ocean interior, deep-water oxygenation and nutrient pools. Most life in the ocean requires oxygen, 
hence predicting biological response to climate change requires understanding the nature and causes of oxygen variation (e.g., Keeling et al., 2010; Friedrich et al., 2014). Ocean warminginduced changes in solubility, stratification, ventilation, other wind-driven local hydrodynamic forces, and respiration drive global declines in oxygenation, even in the open and deep ocean (e.g., Stramma et al., 2008; Helm et al., 2011). Assessing oxygen variability over seasonal to decadal time scales and the longer-term secular oxygen trends in the deep ocean (Levin, 2018) requires long-term observations e.g., with moored oxygen sensors and deep Argo floats equipped with oxygen sensors. New technologies (e.g., optical and Lab-on-a-chip sensors and biogeochemical Argo floats) offer high resolution nutrient measurements to resolve deep-ocean nutrient pools and their dynamics in order to address open ocean productivity and its changes - including feedback to the biological carbon pump. In addition, measurement of bioturbation, seafloor fluid and gas/methane efflux at key locations, as well as microplastics could clarify deep-sea biogeochemical processes, human pressures on deep sea ecosystems, and the role of the deep sea as a potential source for greenhouse gases.

\section{Biology and Ecosystems}

The GOOS has identified biological and ecosystem EOVs for implementation in a sustained, global observing system (Table 2). The many dimensions of biology and ecology and the associated challenges with the multitude of approaches for quantitative measurement, sampling, and data management added significant complexity to this task. Given the complexity of marine ecosystems and the challenge of selecting key variables, GOOS used a Driver-Pressure-State-Impact-Response (DPSIR) model with input from surveys and literature searches to prioritize variables (Miloslavich et al., 2018). This process also considered key societal drivers including sustainable use of natural resources, biodiversity conservation, and knowledge; environmental quality and threat prevention and mitigation; capacity building, sustainable economic growth, and ecosystembased management; and food security. It also considered the need to identify which scientific and societal needs require sustained biological and ecological oceanographic observations, as well as examining impact and feasibility (Lindstrom et al., 2012).

The GOOS also identified EOVs to assess impacts of major pressures related to the deep ocean including habitat loss, climate change, pollution (including debris and litter), solid waste disposal, ocean acidification, and direct anthropogenic disturbances, e.g., connected to fishing, hydrocarbon and seafloor mining industries (Ramirez-Llodra et al., 2011; Ruhl et al., 2011). Reviewing EOVs indicated GOOS specifications that could be easily evolved to include a deep-sea context, including hard coral cover and composition, zooplankton biomass and diversity, fish abundance and distribution, ocean sound, microbial biomass and diversity (emerging), and benthic invertebrate abundance and distribution (emerging). Indeed, the GOOS EOVs now include most of the DOOS recommendations, either as direct EOVs, variables derived from existing EOVs (e.g., biodiversity metrics), or as supporting variables identified in existing EOV specifications.
The designation of marine protected areas and vulnerable marine ecosystems that influence fishery operations often invoke special regulations for deep (cold-water) corals (e.g., Huvenne et al., 2016), although other forms of living habitat merit consideration, including sponge grounds (e.g., Konnecker, 2002; Beazley et al., 2013). Beyond existing EOVs, body size defines a key feature for ecological understanding and represents a fundamental macroecological structuring feature, sensu the Metabolic Theory of Ecology (e.g., Brown et al., 2004). The utility of body size information in forming budgets of the stocks and flows of carbon, as well as understanding several basic physiological dimensions, makes body size a valuable EOV consideration. EOVs that measure aspects of connectivity of species between locations also merit consideration. Connectivity has been identified as a key variable in designing marine protected area networks and in understanding how areas impacted by human disturbances might recover (e.g., from seabed mining, Vanreusel et al., 2016; Durden et al., 2018). The presence of a particular taxon at specific locations, effectively an existing EOV, can indicate connectivity. However, information on movement of individuals (e.g., Block et al., 2011) and genetic variation adds considerable information on the degree to which different populations might be connected by various forms of dispersion.

The GOOS and DOOS efforts on EOVs for biology and ecosystems are informed, in part, by the efforts of GEO BON. This international network has several regional and national component projects including the Marine Biodiversity Observation Network (MBON) projects contributing to the US Integrated Ocean Observing System (IOOS) or the European Biodiversity Observation Network. GEO BON efforts have included the specification of EBVs (Muller-Karger et al., 2018).

Critical to the success of the GOOS EOV concept is the ability to discover, access, share and analyze these data. For some disciplines, this is already operational at a mature level, such as with temperature data being reported through the Global Telecommunication System and assimilated into weather forecast models. Biology and ecosystem data sit in a relatively developmental stage. However, the vision of machine readable "big data" for biology is being realized for the ocean at a global level with the maturation of the Darwin Core body of metadata standards (De Pooter et al., 2017) and their application in data being made available through globally important data portals such as the OBIS (Grassle and Stocks, 1999) using ontologies of the World Register of Marine Species (WoRMS; Horton et al., 2017).

\section{New and Expanded Synergies Among Stakeholders}

To address the breadth of scientific questions and societal needs that require sustained deep-ocean observing, it will be necessary to engage a broader suite of practitioners and approaches. In addition to traditional scientific community operations, a growing number of organizations, industries, and individual businesses are now engaged in the collection of relevant deepocean data. A successful global deep-ocean observing system will need to capture those data, coordinate that nascent network of 
observatories, and help guide its further development. Below we highlight several opportunities for new and expanded synergies among the various members of the extended deepocean observing community.

\section{Industry}

\section{Oil and gas}

The offshore energy industry invests considerable resources into data collection from the deep oceans throughout the life of an oil field, from exploration to decommissioning. In exploration this includes high-resolution acoustic (Posamentier and Kolla, 2003) and electromagnetic (Constable and Srnka, 2007) mapping of oil reservoirs, fields and the surrounding sedimentary environment to inform subsequent development, the siting of infrastructure including pipelines, and the identification of potential geohazards. The industry is also required to collect environmental baseline data and to carry out environmental monitoring in order to secure the license to operate. Those data are used to support the EIA and to ensure continuing appropriate environmental management. If appropriately archived and discoverable, these data are of considerable value to deep-ocean observing and broader scientific interest in the deep-sea floor.

While academic recognition of oil and gas industry environmental impacts is widespread (Cordes et al., 2016), the industry collaboration with the academic community is long-established and, in some areas, very highly developed. Multi-partner collaborations on both the industry and academic side have been successful in tackling regional issues (Bett, 2001), but there is clear scope for expansion to basin- and global-scale efforts. There is genuine mutual benefit in these collaborations, including improved survey, monitoring, and observing approaches, increased data value and decreased costs to individual operators, and ultimately increased spatial and temporal resolution in our deep-ocean observations (Jones et al., 2014). A simple but effective ongoing collaboration with global reach is the Scientific and Environmental ROV Partnership using Existing iNdustrial Technology (SERPENT) project. This project operates by accessing unused Remotely Operated Vehicle (ROV) capacity to acquire deep-ocean data with added value. To date SERPENT has run over 125 missions to deep-water locations in Europe, North and South America, Africa and Australia and generated over 50 peer-reviewed scientific papers (e.g., Hoving et al., 2013; Higgs et al., 2014; McLean et al., 2017; Macreadie et al., 2018).

There are numerous examples of other successful shortterm collaborations investigating a range of key questions, including: extent of anthropogenic impacts (Netto et al., 2010); recovery from anthropogenic impacts (Jones et al., 2012), role of infrastructure (Bond et al., 2018); potential impacts on reef-forming corals (Purser, 2015), and characterization of local biodiversity (Jamieson et al., 2017). In the deep-ocean observing context, long-term collaborations are a key focus for further expansion of these synergies. Early examples include the pair of Deep-ocean Environmental Long-term Observatory System (DELOS) seafloor observatories installed in a deep-water $(1400 \mathrm{~m}$ ) oil field on the Angola Margin in 2009 (Vardaro et al., 2013), which provides publicly accessible data through a series of scientific collaborations. DELOS adopts a "controlimpact" long-term monitoring approach, with one observatory immediately adjacent to oil and gas seabed infrastructure, the second some 16-km distant. The Lofoten-Vesterålen (LoVe) cabled seafloor observatory is located on the deep $(258 \mathrm{~m})$ Norwegian Shelf, with plans for subsequent extension to deeper water (Godø et al., 2014). The LoVe observatory was situated in an area of strongly "competing" interests: oil and gas development, fisheries, and biodiversity, a key focus of which has been reef-forming corals (Osterloff et al., 2016). The data from the LoVe observatory is made available publicly in real time. Environmental data associated with oil and gas activities is typically not regarded as being commercially important and hence can usually be shared. These two examples of industry observatories, while focused on specific regions, demonstrate the potential for such infrastructure to enhance environmental management and generate data of direct operational use to industry. Furthermore, such infrastructure may be installed at modest additional cost to industry if it is done during the right point in the field development, providing continual highresolution data that would otherwise be expensive to obtain.

Installation of deep-water observing nodes at all regional centers of oil and gas activity could improve survey, monitoring, and observing approaches, increasing the value and decreasing the cost of such efforts to industry and increasing spatial and temporal comparability. Data and samples collected as part of science-industry collaboration could then be of greater value to industry, regulators, and academic researchers to address questions beyond the industrial requirements (e.g., Jones et al., 2014), for example insights provided into the ecology of deep-sea organisms (Hoving et al., 2013; Higgs et al., 2014) and enhancing the social license to operate (Box 3$)$.

\section{Fisheries}

Deep-sea habitats provide key feeding grounds, spawning grounds and nursery grounds (seamounts, cold water coral reefs, canyons, seeps) for fish increasingly targeted by commercial fisheries (Watson and Morato, 2013). Fisheries vessels could offer potential research platforms ${ }^{2}$, given that fishers offer the necessary skills and experience to deploy and recover diverse scientific equipment spanning from specialized cameras on longlines (Welsford et al., 2014) to sophisticated acoustic systems that support seabed mapping (Wynn et al., 2014).

Vessel monitoring system (VMS) data can show how fisheries utilize the deep sea and the status of deep-sea target species (Bueno-Pardo et al., 2017), however, VMS data are often confidential. Fishers often resist providing data or Remote Electronic Monitoring, fearing increased restriction on operations by regulators (e.g., creation of Marine Protected Areas). Nonetheless, the many fishery vessels globally could greatly enhance deep-sea data collection and monitoring, perhaps through involvement in global VME mapping, documenting fish distributions, tools to $\log$ unusual species (potentially aiding discovery of new ecosystems), or attaching loggers to fishing gear to characterize environments (as in Keller et al., 2015). High

\footnotetext{
${ }^{2}$ https://www.scotsman.com/news/opinion/it-s-just-a-net-waste-to-ignore-
} fishermen-1-3715118 
BOX 3 | Case study - Ocean observing and the social license to operate. In the late 1990's NGOs raised concerns about whether offshore energy companies were being responsible custodians of the deep-ocean environment, arguing that they could not observe activities in the deep ocean as they could on land. The oil and gas sector was also concerned that if they were unable to prove their operations were environmentally sound then they may lose their license to operate. This led to some oil and gas operators (e.g BP DELOS) installing deep-ocean observatories near their operations and making data publicly available. Twenty-five years later, the oil and gas sector is again being asked to be more transparent in their operations to be better corporate citizens with regards to climate change. Observation of both physical and biological changes by this sector in the deep oceans and their linkage to increases in greenhouse gases are increasingly seen as necessary to increase long-term corporate performance by reducing company risks (asset, environmental, etc.) and financial unknowns (production, operability, etc.).

Partnerships between scientists and the offshore energy industry are particularly beneficial for ocean observing owing to the complementary skills and resources of both groups. Ocean scientists offer knowledge on a broad range of physical and biological aspects of deep-ocean ecosystems that are relevant to industry operations but may not typically be available within industry, while industry offers operational expertise that is essential for observation in the offshore environment, as well as in-kind resources including observational platforms (i.e. fixed infrastructure) and transportation (i.e. vessels) that are typically not feasible for independent scientific investigation (Gates et al., 2017). Further efficiencies can be generated during ongoing partnerships through training of offshore personnel in scientific observational protocols. Such ongoing partnerships and the accelerated knowledge of marine ecosystems they facilitate are key to sustainable growth in the offshore energy sector

value fisheries with resources and observer programs offer a particularly good opportunity for engagement.

\section{Mining}

The deep ocean contains massive reserves of commercially important minerals, particularly metals (Miller et al., 2018). Currently most of these resources remain untapped. However, exploration activities and commercial interest is increasing. Areas of mining interest occur around the world for a range of resources, including in remote areas and abyssal depths. These resources include polymetallic nodules, typically found on abyssal plains; seafloor massive sulfides, created by hydrothermal activity at mid-ocean ridges and back-arc basins; and cobalt-rich crusts, which occur in highest densities on seamounts (Levin et al., 2016; Cuyvers et al., 2018).

The mining industry is expanding, and deep-sea contractors are currently in the exploration phase. Deep-ocean data on a wide variety of parameters are necessary for establishing the commercial and social viability of projects. Baseline data on the biological, physical and chemical environment are required for management and to secure the permits for mining activities (Durden et al., 2018).

As the impacts of mining activities in the deep ocean are expected to be extensive in space and time (Jones et al., 2017), evaluations of impact and recovery from experiments and early mining activities are also critical to inform management and set the policy framework for future exploitation activities. This is particularly critical in the case of mining activities beyond national jurisdiction, where the International Seabed Authority has a remit under the UN
Convention on the Law of the Sea to prevent serious harm to the marine environment (UNCLOS, 1982). As a potentially global industry in its infancy, with internationally coherent regulations, environmental measurements associated with environmental management of deep-sea mining offers great potential to increase the frequency and extent of deep-ocean observations to the benefit of both the mining industry and deep-ocean science. The ISA is already taking action to harmonize the data provided by its contractors as part of exploration activities to enhance the amount of regional deep-ocean data available. As mining companies move to exploitation, have greater presence in the deep ocean, and begin monitoring activities, the data collected will increase in volume. At present, most data are obtained from individual shipboard expeditions or regular cruise programs. Some physical oceanographic data have been obtained by moorings, put in place for up to 3 years (Aleynik et al., 2017). As yet, the only truly multidisciplinary, deep-water seafloor observatories in areas of potential mining interest are on the midAtlantic ridge (e.g., the MoMAR observatory at Lucky Strike; Ballu et al., 2008). Furthermore, long-term seafloor or water column observatories and integrated multi-stakeholder cruise programs would result in improvements in the temporal and spatial extent of ocean observations.

In the context of exploration activities, strong bilateral partnerships exist between specific contractors and scientific institutions. Actions that might promote cooperation on a broader level, e.g., as part of international academic-industry partnerships, as described above for the energy industry, could involve the creation of multi-stakeholder regional working groups focused on areas that have been targeted for mining like the Clarion Clipperton Fracture Zone, mid-Atlantic or Southwest Indian Ridges or West Pacific seamounts. These could work through existing networks (e.g., DOOS or DOSI, ISA or World Ocean Council) to coordinate among the different stakeholders or integrate sustained academic observing network efforts (e.g., Argo floats, including Deep and BCG Argo, Go SHIP, OceanSITES, GeoTRACES, and/or TPOS 2020) with industrial observing programs and environmental monitoring needs, possibly as demonstration projects or observatories. A better integration with large-scale marine scientific networks would add credibility to industry and its activities. It may also facilitate integration among different contractors to allow for ecosystem observations beyond claim areas, as they are urgently needed for environmental assessment and management at the relevant scales (e.g., in the context of Regional Strategic Environment Assessment and Regional EMPs).

\section{Ships at sea}

Many types of commercial vessels can be used as "ships of opportunity" to provide additional platforms for oceanographic observation. This approach has a very long history that can be traced to Robert FitzRoy, captain of HMS Beagle during Charles Darwin's voyages, who would later found the forerunner of the UK Meteorological Office by organizing the collection of weather data at sea, and the provision of standard instruments to those vessels (Mellersh, 1968). In the upper ocean, the longestrunning effort is the Continuous Plankton Recorder (CPR) 
Survey $^{3}$. Since its first deployment in 1931 by its inventor Sir Alister Hardy, it has covered over 6.5 million nautical miles $\left(12 \times 10^{6} \mathrm{~km}\right)$. Standardized vessel-mounted instrumentation has proved successful for surface-ocean biogeochemistry data collection, for example the "Ferrybox" program (Hartman et al., 2014; Petersen, 2014). The ferry ( = ship of opportunity) box ( = instrument package) concept may be particularly valuable in monitoring substances, including pollutants and contaminants, that are currently difficult or impossible to detect with self-contained autonomous instruments (see e.g., Brumovsk $\imath$ et al., 2016). Surface vessels, however, offer relatively limited opportunities for deep-ocean observations beyond bathymetric data, which may nonetheless be significant to the extent that the International Hydrographic Office has established a Crowdsourced Bathymetry Working Group ${ }^{4}$. An obvious exception is the deep-water fishing fleet (discussed above), for whom recovery of deep-ocean "samples" is normal operating procedure.

\section{Submarine cables}

The increase in demand for both global connectivity and deepocean data is creating strong synergy between the submarine telecommunications cables industry and the ocean observing community. Emerging out of this shared demand is the concept of "Science Monitoring and Reliable Telecommunication" (SMART) cables, dual-purpose cables in which scientific sensors "piggyback" on the undersea cables, allowing them to generate real-time oceanographic and seismic data in addition to performing their primary telecommunications mission (You, 2010). The International Telecommunication Union, the WMO, and the UNESCO Intergovernmental Oceanographic Commission (IOC) have formed the Joint Task Force (JTF) to move this concept forward (ITU/WMO/IOC JTF ${ }^{5}$ ). The prospect is seen to be mutually beneficial to both the industry and the science partners, and ultimately of significant value to societal needs not least in relation to climate change, and tsunami and seismic early warning (Howe and Workshop Participants, 2015).

\section{Exploration and Mapping Communities}

Knowing the depth, shape and character of the seafloor is fundamental for ocean science and has been identified by the Decade of Ocean Science for Sustainable Development as a major research and development priority for 2021-2030 (IOC, 2018). Seafloor bathymetry is a foundational dataset for understanding ocean circulation, tides, tsunami forecasting, fishing resources, environmental change, underwater geo-hazards, cable and pipeline routing, mineral extraction, oil and gas exploration and development, and infrastructure construction and maintenance. The ocean exploration community collects bathymetry and other initial characterization datasets using a routine, systematic or "mapping" methodology with the objective of making results publicly available and accessible soon after collection. The current ocean exploration survey methodology includes multi-beam bathymetric data collection and making initial observations and

\footnotetext{
${ }^{3}$ https://www.cprsurvey.org/

${ }^{4}$ https://www.iho.int/

${ }^{5}$ https://www.itu.int/en/ITU-T/climatechange/task-force-sc
}

assessments of living and non-living marine resources using conventional midwater acoustics and near-bottom imagery and sensing. The ocean exploration mapping survey approach plays a unique role in the discovery and initial characterization of lesser-known areas of the ocean and particularly the deeper regions, which are difficult to access. Even after many years of bathymetric mapping effort, only a small fraction, less than 20 percent, of the world ocean's seafloor has been mapped with modern methods, with even less characterized in any standardized way. Less than $18 \%$ of the seafloor has been directly measured with echo sounders and approximately $8 \%$ with modern multi-beam methods (Mayer et al., 2018; Figure 4). A coordinated international effort is needed to bring together existing ocean data sets and identify areas for future exploration and mapping surveys.

The larger ocean science community, including governments, industry, and academia recognize the need for ocean mapping information and are working together on initiatives to collect new mapping data and to make archived data publicly available in standardized formats. The General Bathymetric Chart of the Oceans (GEBCO) Seabed 2030 Project is an example international effort with the objective of facilitating the complete mapping of the world ocean by 2030 (Mayer et al., 2018). GEBCO is an international group of mapping experts developing a range of bathymetric data sets and data products. It operates under the joint auspices of the International Hydrographic Organization (IHO) and UNESCO's IOC. The project was launched at the UN Ocean Conference in June 2017 and is aligned with the UN's Sustainable Development Goal \#14 to conserve and sustainably use the oceans, seas and marine resources.

The Seabed 2030 Project will apply GOOS concepts and establish distributed regional data assembly and coordination centers that will identify existing data from their assigned regions that are not currently in publicly available databases and seek to make these data available. They will also develop protocols for data collection and common tools to assemble and attribute metadata by regional grids using standardized techniques. A Global Data Assembly and Coordination Center (GDACC) will integrate the regional grids into a global grid and distribute to users world-wide. The GEBCO Seabed 2030 Project will encourage and help coordinate and track new survey efforts and facilitate the development of new and innovative technologies to increase the efficiency of seafloor mapping and help to achieve the ambitious goals of the project.

While the GEBCO effort is significant, it is limited to seafloor bathymetry. A similar effort is needed that can be expanded to include a limited set of variables that could be systematically collected and complement bathymetry to provide an initial characterization of the deep-sea environment. The revision of EOVs carried out by DOOS (see above) and community input during OceanObs'19 will help define those variables for the ocean exploration community to adopt and provide increased value to the science community.

\section{Biodiversity and Ecosystem Services}

Deep-ocean biodiversity and the services it supports is an increasing focus of both the conservation community aligned 


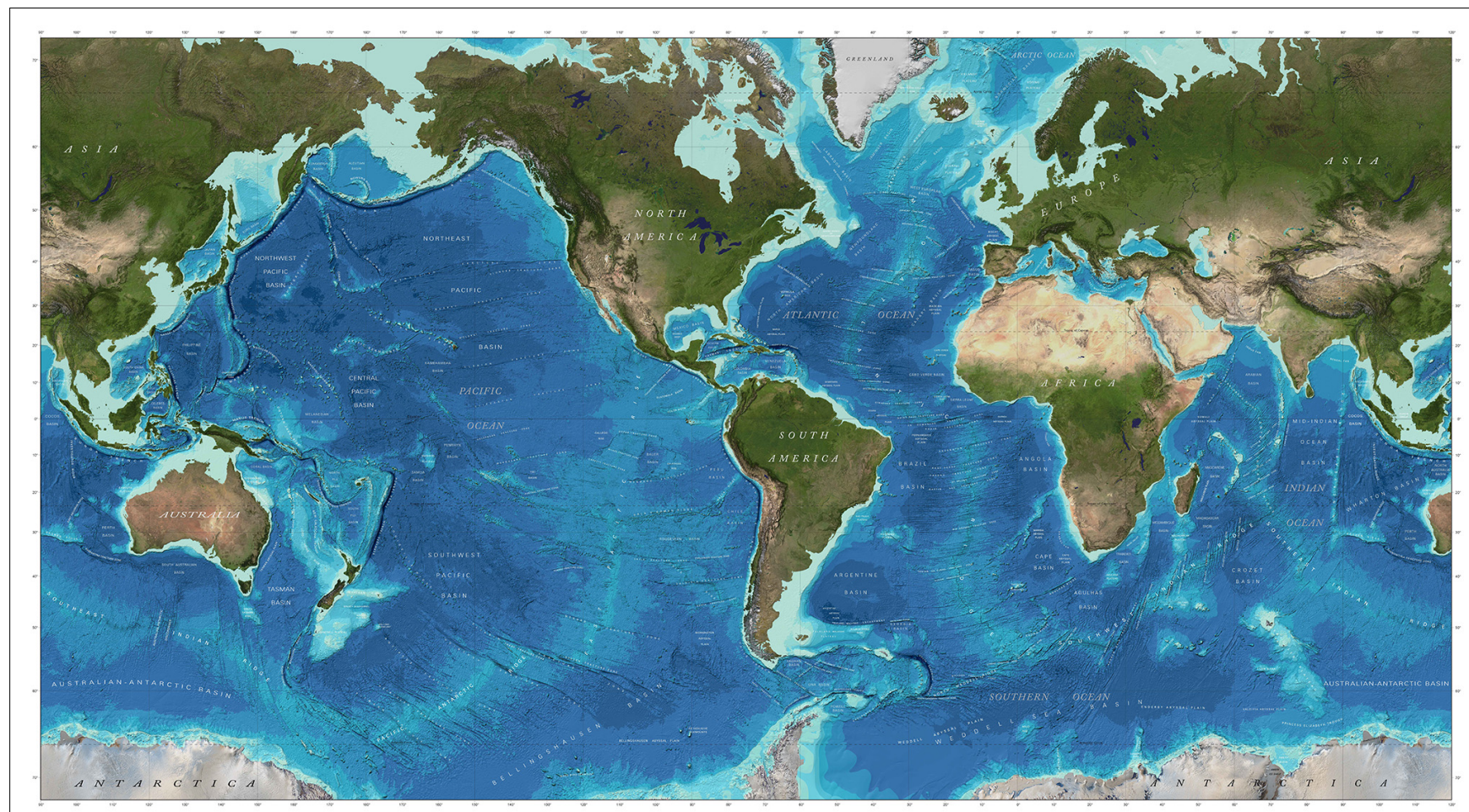

FIGURE 4 | World map of currently available hi-resolution bathymetric data. Image reproduced from the GEBCO world map 2014, www.gebco.net.

with sustainable development and an emerging bioprospecting industry. Deep-ocean biodiversity underpins key support functions and ecosystem services provided by the deep ocean (Duffy and Stachowicz, 2006; Snelgrove et al., 2014). Included among these are the sequestration and burial of carbon, the remineralization and cycling of nutrients, and the provision of habitat, nursery grounds, food, and refugia for living resources (Thurber et al., 2014). Microbial activity contributes to the generation of oil and gas (Rice and Claypool, 1981), polymetallic nodules and crusts (Wang and Müller, 2009), and other potential mineral and energy resources of extractive interest, although these occur on geologic time scales - much longer than what is considered sustainable. Many of these "services" and other natural products can provide a template for novel biopharmaceuticals, industrial agents, and biomimetic materials, with a multitude of realized or potential human benefits (e.g., Blasiak et al., 2018); these are often referred to as genetic resources (Harden-Davies, 2017). Biodiversity, as an irreplaceable entity, also has intrinsic or inherent value, independent of its service to people (Harrington et al., 2010).

A growing mandate for biodiversity observation in the deep ocean emerges not only from human curiosity, but also from a desire for sustainability in the face of intensifying or new human activities that generate disturbance such as bottom fishing, energy extraction, cable laying, and potentially seabed mining (Ramirez-Llodra et al., 2011; Mengerink et al., 2014). These practices, and the negotiation of a new international biodiversity treaty (Wright et al., 2018), are generating a growing need for biodiversity baseline and monitoring data to inform ecosystem-based management, spatial planning and protected area designation, and impact assessment, both at the national and international levels (Danovaro et al., 2016). New stakeholders in deep-ocean biodiversity observation include those entities mandated to protect the marine environment by UNCLOS (Table 1, e.g., the ISA, the FAO and RFMOs, the International Maritime Organization, and the Convention on Biological Diversity) as well as industry and civil society. As biodiversity observations expand in the deep ocean, linkages to the MBON of the GEO BON and GEO Blue Planet can help develop the necessary protocols and standards and provide connections between the EBVs of MBON and biology and ecology EOVs (e.g., Muller-Karger et al., 2018).

\section{Reusing and Repurposing Data}

Investigators around the world routinely collect, analyze, and publish data for specific studies or to further scientific knowledge in areas of interest. Collectively, these data represent a vast amount of measurements that, more often than not, could be repurposed. Here we describe two examples of the integration between different communities (scientific disciplines, and observation networks, hazard monitoring, offshore industry) that allow for the innovative use of existing datasets for applications other than what was originally intended.

Deep-ocean Assessment and Recording of Tsunami (DART) measurements are routinely made to detect tsunamis in the deep ocean and serve as the basis for warning coastal populations at the time of tsunami propagation. These data represent years, sometimes decades, of consecutive time series 
of highly resolved pressure and temperature in areas of the deep ocean for which measurements are scarce. Bottom pressure measurements have been repurposed to validate satellite altimetry measurements and improve global tide models (Ray, 2013). Measurements made as part of the GRACE in particular, were instrumental in investigating the main processes that affect variability of pressure in the deep ocean (Chambers and Willis, 2010). Initial comparisons of GRACE-derived bottom pressure (from altimetry) with bottom pressure from the Ocean Model for Circulation and Tides highlighted sampling interval shortcomings that in turn led to both improved data analysis and greater interest in the use of DART bottom pressure sampled every 15 s. Williams et al. (2015) showed the value of long duration and stable bottom pressure records for studies of ocean circulation and ocean mass considerations due to sea level change. In addition to the use of bottom pressure for investigations into ocean processes, recent investigations into the sonification of bottom pressure time series have shown promise in identifying an earthquake signature in advance of rupture (McKinney personal communication). This work follows that of Ballora and Evans (2017) who sonified hurricane data, noting that "our ears are better at sensing properties that change and fluctuate" (Ballora and Evans, 2017). Temperature data recorded by DART systems are being used by investigators for validation of global models and to identify climate variability signatures in the deep ocean. The spatial and temporal scales of use of these data, however, are limited due to a calibration process that prohibits inter-record comparisons. Another example involves assimilation and analysis of the Global Navigation Satellite System (GLONASS) data which are being explored to quantify seafloor displacement as a new approach to rapid characterization of a tsunami source.

Underwater video and still images are routinely collected by ROVs during offshore energy industry operations as part of site surveys and inspections of infrastructure and are usually retained indefinitely by operating companies. Although not intended for scientific research, industry video and images can be repurposed to provide data on a range of biological, ecological and oceanographic variables in areas that are challenging for independent research (Gates et al., 2017). Industry video and images have already provided information on the distribution of threatened species (Gass and Roberts, 2006), productivity of offshore ecosystems for commercial fishes (McLean et al., 2017), and anthropogenic impacts on deep-water fauna (Jones et al., 2012).

Existing media archives could be used to investigate longerterm processes occurring in ocean ecosystems. The offshore energy industry already holds millions of hours of underwater video, covering decades of offshore operation and spanning a broad range of ocean environments, from shallow coastal margins to the deep sea (Macreadie et al., 2018). This collection could be used to investigate the effects of environmental change and anthropogenic disturbance on biological communities, track the spread of invasive species across ocean basins, and ground-truth oceanographic models, among other applications. ROV imaging methods could be refined at minimal cost to provide standardized data on a continual basis, to assist identification of future changes in vulnerable offshore ecosystems (Roberts et al., 2006).

Improved partnerships between researchers and the offshore industries are critical for effective repurposing of data. Industry collects extensive data on the geology, oceanography, and ecology of potential operating sites. Access to these data is often limited by concerns of confidentiality. However, trust developed through ongoing partnerships can increase data-sharing for mutual benefit. By partnering with researchers, industry can add value to data they are required to collect for environmental reporting, and researchers can gain access to datasets that would otherwise be challenging to obtain.

\section{INTEGRATING DISCIPLINES THROUGH DEMONSTRATION PROJECTS}

To demonstrate the feasibility of sustained deep-ocean observing, relevant technologies, and the impact and utilization of deep-ocean observations, the DOOS proposes a series of potential region-specific, interdisciplinary projects. These would demonstrate the end-to-end process of deep-ocean observing, data processing, and quality control, as well as ensure availability of data to users with appropriate documentation. Such efforts would advance well-vetted EOVs, state-of-the-art technological capacities, and modular dimensions of associated platforms, projects, and data products. These would provide a template that could ideally scale from local to quasi-global coverage. We summarize key features, science questions, societal relevance and infrastructure for each of these candidate projects (Table 3 ) and provide brief, relevant background.

\section{Clarion-Clipperton Zone}

The Clarion-Clipperton Zone (CCZ), an abyssal area between the Clarion and Clipperton fractures, with polymetallic nodule mining potential in the central eastern Pacific (Lodge et al., 2014), covers six million $\mathrm{km}^{2}$ at water depths between 3800 and $6000 \mathrm{~m}$. All seventeen deep-sea mining contractors with exploration claims in the CCZ must collect and provide physical, chemical and biological data to the ISA. Although oceanographic moorings have been deployed there for up to 3 years (Aleynik et al., 2017), the CCZ lacks any long-term observatory infrastructure. Many discoveries followed the recently expanded presence in the CCZ area, from regional faunal patterns (e.g., Amon et al., 2016; Vanreusel et al., 2016), discovery of new species (Gooday et al., 2017; Lim et al., 2017), and remarkable microbial biodiversity (Lindh et al., 2017), to a better understanding of temporal variation in seabed currents (e.g., Aleynik et al., 2017). A demonstration project, if well-integrated to ongoing studies by contractors, e.g., JPI Oceans and others, could feed data into the current EMP for the CCZ (ISA, 2012), inform all stakeholders of the environmental setting and contribute to assessing the consequences of nodule mining.

\section{Azores Archipelago}

The Azores volcanic northeast Atlantic archipelago sits above a tectonically active triple plate junction, surrounded by abyssal 
TABLE 3 | Summary of possible demonstration projects, questions, advantages and assets.

\begin{tabular}{|c|c|c|c|}
\hline Location & Key Questions & Strategic Advantages & Existing Assets \\
\hline Clarion-Clipperton & Effects of seabed mining on deep-sea fauna and functions & $\begin{array}{l}\text { Significant baseline data } \\
\text { collected by industry and } \\
\text { academics; some observations } \\
\text { over long time periods }\end{array}$ & $\begin{array}{l}\text { Industry moorings; regular } \\
\text { baseline assessment cruises as } \\
\text { part of industry activity }\end{array}$ \\
\hline Azores Archipelago & $\begin{array}{l}\text { Evaluate ocean change in relation to climate and AMOC patterns; } \\
\text { integrated characterization of deep-sea communities and ecosystems } \\
\text { subject to fishing and potential mining }\end{array}$ & $\begin{array}{l}\text { Easy access and well } \\
\text { positioned to link to other } \\
\text { Atlantic observing activities }\end{array}$ & $\begin{array}{l}\text { Fixed observatories at Lucky } \\
\text { Strike and planned soon for } \\
\text { Condor Seamount with } \\
\text { biogeochemical sensors }\end{array}$ \\
\hline Northeast Pacific & $\begin{array}{l}\text { Operational data to inform hypoxia, event response, tsunamis, fisheries, } \\
\text { and whales; The linkage of vents and seeps to each other and oceanic } \\
\text { processes; shelf-slope exchanges; bentho-pelagic coupling }\end{array}$ & $\begin{array}{l}\text { Shelf, slope, abyss, vents and } \\
\text { seeps are instrumented; } \\
\text { naturally occurring hypoxia } \\
\text { altered by climate change }\end{array}$ & $\begin{array}{l}\text { Many moorings and } \\
\text { instruments are in place over } \\
\text { regional scales at } \mathrm{OOI} \text { and } \mathrm{ONC}\end{array}$ \\
\hline Western Pacific & $\begin{array}{l}\text { Air-sea interaction in the western Pacific; comparative research } \\
\text { between Eastern and Western Pacific circulation and heat exchange; } \\
\text { marine weather and climate forecasts, and ensuring safety }\end{array}$ & $\begin{array}{l}\text { Significant previous effort } \\
\text { associated with a Scientific } \\
\text { Observation Network ( } 20 \\
\text { moorings) }\end{array}$ & \\
\hline $\begin{array}{l}\text { Ocean Trenches: } \\
\text { Izu-Ogasawara } \\
\text { Trench and Mariana } \\
\text { Trench }\end{array}$ & $\begin{array}{l}\text { Monitoring long-term changes in the deep-sea environment, such as } \\
\text { warming and freshening of abyssal waters, requires data of the highest } \\
\text { possible quality from the ocean trenches }\end{array}$ & $\begin{array}{l}\text { Significant previous scientific } \\
\text { interest; good access, existing } \\
\text { protections }\end{array}$ & \\
\hline
\end{tabular}

plains with numerous seamounts, deep fracture zones, trenches, and a considerable extension of the Mid-Atlantic Ridge. It is located at the northeastern edge of the North Atlantic subtropical gyre, the Atlantic Meridional Overturning Circulation (AMOC) influences regional oceanography and Earth's climate system (Amorim et al., 2017). Prominent vulnerable marine ecosystems include deep-sea hydrothermal vents, sponge aggregations, cold water coral gardens and reefs, and extensive fields of xenophyophores (Morato et al., 2016). The Azores will host two fixed-point, well-equipped observatories, with an existing node at the Lucky Strike hydrothermal vent (Colaço et al., 2011) and another planned soon for coral gardens on the Condor seamount. These nodes will monitor the biogeochemical coupling of the benthos, water column, and atmosphere, and can provide information on ocean change in relation to climate and AMOC patterns.

\section{Northeast Pacific: Cascadia Margin to the Juan de Fuca Ridge}

The Cascadia Margin and Juan de Fuca Plate offer existing infrastructure to support significant opportunities for technologically advanced interdisciplinary ocean observation based largely on existing infrastructure. Here, the coupling of the US NSF Ocean Observatories Initiative (OOI) Cabled Array and the Ocean Networks Canada (ONC) Neptune observatory (Barnes et al., 2013; Kelley et al., 2016) provides unprecedented opportunities for regional in-depth study and decadal time-series observations of complex oceanographic processes, with a possible extension to the open-ocean Station Papa site. Collectively, the submarine cabled observatories span ocean depths from 80 to $2900 \mathrm{~m}$, including approximately $1700 \mathrm{~km}$ of high power and high bandwidth fiber optic cables, 14 subsea terminals, and more than 30 secondary junction boxes at key experimental sites. This infrastructure provides power and communication to hundreds of seafloor instruments and state-of-the-art moorings with instrumented profilers streaming data to shore at the speed of light. The continuous, real-time, two-way communication can capture interannual and interdecadal variability, as well as document, quantify, and respond to NE Pacific transient events. The observatories also span biogeochemical and physical environments that include a continental margin strongly influenced by upwelling and expanding hypoxia (e.g., De Leo et al., 2017) and acidification (Feely et al., 2008), with widely contrasting pelagic and benthic physical and biological regimes (Barth et al., 2007; Belley et al., 2016) and host hundreds of active methane seep sites (e.g., Xu et al., 2017). A preliminary workshop in 2018 gathered NE Pacific cabled observatory operators and the wider deep-sea community to explore linking OOI and ONC demonstration project opportunities. These projects would build from existing assets by integrating observations already carried out by the cabled arrays, adding sensors and instruments to the installations and carrying out ship-based investigations during maintenance cruises.

\section{Western Pacific}

Over the last 5 years, the Institute of Oceanology, Chinese Academy of Sciences (IOCAS) has developed a Scientific Observation Network in the Western Pacific Ocean focused on a warm region of complex seafloor where variation in the deepsea current system affects regional heat fluxes. China's Western Pacific Scientific Observation Network, established based on 20 sets of deep-sea subsurface moorings, has successfully acquired temperature, salinity, and ocean current data from the Western Pacific for three consecutive years. During the 2016 expedition, IOCAS achieved "live transmission" of deep-sea data, extending observations in 2017 to $3000 \mathrm{~m}$ water depth. In parallel, the ROV on the $R / V$ Kexue, with a depth capability of $4500 \mathrm{~m}$, mapped the seafloor including seamounts, hydrothermal vents, and cold 
seeps. This research has significantly advanced understanding of the structure, variability, and dynamic mechanism of threedimensional circulation in the western Pacific, and for mass and energy exchanges between the Western Pacific Ocean and surrounding areas.

\section{Ocean Trenches: Izu-Ogasawara Trench and Mariana Trench}

Monitoring long-term changes in the deep-sea environment, such as warming and freshening of abyssal waters, requires data of the highest possible quality from the ocean trenches. Past hadal observations focused on physical parameters (Taira et al., 2005; van Haren et al., 2017), and geochemical (Gamo and Shitashima, 2018) and microbial (Nunoura et al., 2015) observations. The R/V Kaimei, launched in 2015, has obtained integrated observations to full ocean depths (nearly 11,000 m) using a 12,000-m-long synthetic fiber cable with conductivitytemperature-depth/dissolved oxygen sensors $\left(\mathrm{CTD} / \mathrm{O}_{2}\right)$, water bottles, and piston or multiple corers for sampling bottom sediments. The Kaimei Trench Expedition (KATE), conducted along the Izu-Ogasawara and northern Mariana trenches in 2016/2017, sampled to $9760 \mathrm{~m}$ for practical salinity, absolute salinity, dissolved oxygen, carbonate system parameters, carbon and oxygen isotopes, and tracers of sedimentary organic and microbial nitrogen metabolism (Kawagucci et al., 2018). KATE data will be merged with historical hydrographic data and shared on the JAMSTEC website. Hadal KATE samples analyzed for microbial diversity and environmental metagenomics provide a basis for future integrated biological studies.

\section{DEEP-SEA INSTRUMENTATION AND OBSERVATION TECHNOLOGY}

\section{Platform and Sensor Infrastructure}

In very general terms, the essential infrastructure elements needed to support sensors and their observation include power, communications, timing, and positioning. Sometimes all of these elements may co-occur in the form of a ship or a cable node, providing large bandwidth and power. Smaller platforms (isolated mooring and surface floats) offer only a few milliwatts along a time/space trajectory, with intermittent communications and position. "Platforms" implies point infrastructure (float, mooring), whereas "observatories" implies multi-purpose, distributed and cross-platform connections, e.g., a cabled acoustic network that uses GPS to position floats and Autonomous Underwater Vehicles (AUVs), and simultaneously supports sensors such as passive acoustic monitoring, thermometry, and tomography (Duda et al., 2006; Howe et al., 2010; Mikhalevsky et al., 2015).

Historically, deep-sea data collection relied on research ships and survey vessels. Technological advances have increased their capabilities for methods such as bathymetric mapping of the deep seabed using modern multibeam echo-sounders. Devices lowered from ships can sample the water column (e.g., Rosette water samplers with CTD sensors and other sensors) and biota (various nets and trawls depending on organism size, e.g., Roe and Shale, 1979). The GO-SHIP program conducts fixed hydrographic transects every 10 years globally (Talley et al., 2016; Figure 1). A variety of types of corers and grabs can sample seabed sediments for geology and biology, whereas larger deepsea organisms require epi-benthic sledges and trawls, or imaging with towed camera systems, ROVs or AUVs; the latter tools are particularly important for imaging and sampling biological communities and geological features on hard surfaces such as bedrock. A long-running effort to sample ocean temperature used XBTs deployed from research and military vessels as well as from commercial ships under the Volunteer Observing System. With the advent of Argo floats, the global, broad scale sampling by XBTs ended. The deployment of XBTs to sample temperature along repeating tracks by commercial ships has continued, mostly using T7 XBTs falling to $760 \mathrm{~m}$. Some 16,000 to 20,000 XBTs are deployed annually ${ }^{6}$.

Long-term data collection has relied on platforms such as the OceanSITES moorings that form a global network (Figure 1) of sensors to measure water column physical and biogeochemical parameters (e.g., sediment traps to quantify particle flux to the seabed). Bottom landers deliver sampling equipment, experiments and sensor packages to the seabed including long-term time-lapse imaging (Bett et al., 2001) and baited camera systems to observe scavenging organisms (Janssen et al., 2000), even in the deepest trenches (Jamieson et al., 2011).

Recently, permanent underwater cabled observatories have advanced fixed-point ocean observation (Figure 1) by enhancing their dedicated power and communication capabilities, allowing for long-term ocean and climatically important environmental observations, as well as early warning for earthquake and tsunami mitigation. Substantial innovations are expected through the use of cabled observatories for oceanography.

Over the last two decades, installation and operation of undersea cable systems for ocean observing include: the single node 4728-m deep ALOHA Cabled Observatory (ACO at Station ALOHA, the site of the Hawaii Ocean Time series); regional scale systems with multiple nodes over $100 \mathrm{~s}$ of kilometers represented by ONC and the United States OOI Regional Cabled Array (RCA) and DONET that also functions as a seismic/tsunami early warning system; and the S-Net system off Japan that is strictly an operational warning system $(5000 \mathrm{~km}, 200$ sensors). Beyond the many sensors and instruments that a broadband cabled observatory can support, some can host data-intensive technologies such as robotics, video, and in situ molecular measurement techniques. Observatories focused on the seafloor will offer earth and ocean scientists new opportunities to study multiple, interrelated processes over time scales from seconds to decades. These include episodic processes such as sporadic deepocean convection at high latitudes and submarine slides, along with their resulting biological, chemical and physical changes, as well as global and long-term changes including warming trends and ocean acidification (Favali et al., 2015).

A new effort proposes adding environmental sensors to transoceanic commercial telecommunications cable systems (JTF

\footnotetext{
${ }^{6}$ https://www.aoml.noaa.gov/phod/goos/xbtscience/faqs.php
} 
SMART Cables ${ }^{7}$ ). Repeaters in these systems every 50-100 km (e.g., mesoscale resolving along the cable path), can provide modest power and communications ${ }^{8}$. Current plans call for OBP and temperature (both EOVs), with 3-component acceleration, to monitor ocean circulation and climate as well as tsunamis and earthquakes. A complete ocean, and earth, observing package generally must include seismic sensors for tsunami warnings, the study of the Earth beneath the oceans, and rapid analyses of great subduction zone earthquakes.

Manned submersibles offer directed observation and sampling (Moorhouse, 2015), targeting features of particular interest (e.g., Normark et al., 1987), to the greatest depths (e.g., Challenger Deep; Gallo et al., 2015). ROVs, and hybrid ROVs, of differing size and capability enhance such exploration. Recently, livestreaming of ROV video feeds has enabled "telepresence" of experts to enhance the value of the work undertaken at sea and share deep-sea observations widely (Bell et al., 2016). Manned submersibles and ROVs have been of great importance in expanding biological observations and sampling. Interesting developments on the ROV concept include benthic crawlers, including those hosted at deep-ocean observatories and operated via the internet (Doya et al., 2017). As opposed to benthic lander systems, these moving platforms can address spatial heterogeneity and gradients at the seafloor. As they are able to move between observations, they also allow for semi or non-destructive measurements (e.g., of seafloor respiration with benthic chambers; Smith et al., 2014) or, once the technique is available, time series sampling of material from the seafloor (Brandt et al., 2016). Ideally, crawlers are connected to underwater nodes of submarine cables (e.g., Purser et al., 2013) but there are also crawlers that allow for autonomous operation in other regions of the open ocean.

Recent rapid technological advances have increased the diversity of ocean observation, driven by a need for greater spatial and temporal data collection and improved efficiency. Most notably, autonomous technology has expanded the increased capability of oceanographic research ships, and vessel-launched sensors. For example, the autonomous network of around 3500 Lagrangian Argo floats, now deployed throughout the global ocean, report temperature and salinity profiles from the upper 2000 m (Gould, 2005; Figure 1). Recently developed "Deep Argo" floats expand the parameters measured and depth range to $6000 \mathrm{~m}$, while the BCG Argo initiative seeks to extend observation capacities of autonomous profiling floats to include biogeochemical and biological variables.

Marine Autonomous Systems (MAS) for ocean observing include static, fixed-point observatories (Cristini et al., 2016), and a variety of mobile platforms. Collectively, these systems extend oceanographic observations to broader spatial and temporal scales (Rudnick et al., 2004; Hartman et al., 2012) in oceanography (Rudnick et al., 2004), marine geoscience (Wynn et al., 2014), habitat mapping (Robert et al., 2016), and benthic ecology (Morris et al., 2014) for both science

\footnotetext{
${ }^{7}$ http://www.itu.int/en/ITU-T/climatechange/task-force-sc/Pages/default.aspx ${ }^{8}$ https://eos.org/meeting-reports/submarine-cable-systems-for-future-societalneeds
}

and industry (Wynn et al., 2014). Though cost-effective for long-term and large-scale monitoring programs, comparing autonomous data with traditional approaches remains a key challenge (Bean et al., 2017).

Like Argo floats, "submarine gliders" are slow-moving, AUVs capable of long deployments in the water column (months in duration). They can cross ocean basins (Glenn et al., 2011) profiling the water column in a "saw-tooth" pattern for a wide range of parameters (Suberg et al., 2014) that continue to expand as manufacturers develop and miniaturize new sensors. Gliders relay data in near-real-time via satellite communication. As with floats, these characteristics favor collection of water column data at long temporal and spatial scales, but their slow speed confounds spatial and temporal variability. Wave gliders have recently become available as an alternative autonomously moving platform that can be used in the open ocean. Wave motion is used for moving the vehicles and also provides the energy necessary for measurements, operation control, and communication. Staying on the ocean surface they cannot host sensors for deep ocean observation but may serve as communication hubs exchanging data acoustically with deep-sea installations in the area (e.g., moorings and landers) and connecting them to satellite data transmission. This allows for near-real-time data accessibility from remote locations and for sending commands to deep-sea platforms for adaptive observations.

Propeller-driven AUVs include systems differing in levels of autonomy, navigation, endurance and payload, for high precision systems for seafloor mapping purposes (multibeam echosounder, side-scan sonar, sub-bottom profilers) as well as seafloor imaging of geological and biological features and water column data collection. Lack of endurance and need for service constrain AUVs, pointing to needs for underwater docking stations for power and communications, likely supported by cable systems.

Collaborative research networks maximize effectiveness of observing systems. For example, ONC's large ocean observatory network delivers a wide variety of inter-related science services and data products including geo-hazard, oceanographic data, ecosystems and policy support (Heesemann et al., 2014). In Europe, the European Multidisciplinary Seafloor and water column Observatory (EMSO) is working to coordinate ocean data service (Favali and Beranzoli, 2009). In many ways, this synthesis aims to provide a vision for the global network, including deeper observation needs that will contribute to GOOS in the coming decades.

\section{Sensors and Emerging Technologies}

Instrument deployments in the deep ocean face challenges of accuracy, longevity, pressure resistance, power, communications and timing, miniaturization, drift correction, and deployment costs. Relative to ships, cost savings in orders of magnitude can be achieved by mounting sensors on cabled, autonomous, and robotic submersibles.

Seismic and acoustic sensor technologies matured decades ago, and research vessels now routinely deploy digital ocean bottom seismometers and hydrophones $(\mathrm{OBS} / \mathrm{H})$ both in a campaign mode and connected to real-time cabled observatories. Advanced seafloor emplacement methods include both buried 
and borehole systems to use these sensors to resolve the physical structure of the seafloor, lithosphere, and 3D tomography of the planet, as well as the propagation of acoustic and seismo-acoustic signals within the seafloor and in the water column. In addition to their scientific prowess, and in concert with pressure sensors, real-time seismic systems have a crucial societal role for tsunami warnings. Intriguingly emerging sensing technology shows the potential use of optical fibers (perhaps within telecommunication cables) as acousto/seismic and temperature sensors (Lindsey et al., 2017; Marra et al., 2018).

Sensors that measure physical variables in the deep-ocean such as temperature, salinity, and velocity on ships, moorings, and cabled observatories are relatively mature. Ongoing testing of miniaturized versions that reduce power requirements and drift offer promising application in deep floats and gliders and animal-borne tags. Instrumentation of marine animals with a variety of sensors that not only report on animal movement in four dimensions (horizontal, vertical and time) but on the environment animals are moving within, give insights into how physical and chemical ocean properties shape animal communities and behaviors (Hussey et al., 2015). "Animal oceanographers" have collected vast amounts of CTD data in remote areas often inaccessible to other sensor platforms and are enhancing regional ocean models (e.g., polar regions; Treasure et al., 2017; Silvano et al., 2018). Several groups are globally aiming for standardized quality control, metadata, and data sharing of these products (Roquet et al., 2017). Additional sensors and improvements of animal-borne tags are continuously developed, such as active and passive acoustics or imaging (Thomson and Heithaus, 2014; Fregosi et al., 2016), and miniaturization as well as tag attachment (Shaikh et al., 2019). Already these efforts are becoming valuable for conservation policy and management decisions (Hays et al., 2019) and will prove particularly useful in deep-sea environments.

On a smaller scale, scientists need better and ubiquitous sampling of mixing and turbulence as well as easier and more widespread measurement of heat flux between the ocean and the sea floor. Satellite measurements of sea surface height are mature, while gravity/bottom pressure are less so. Both are essential for global coverage and currently lack high temporal and spatial resolution. A new method for routine in situ calibration (better than $1 \mathrm{~mm} /$ year; Wilcock et al., 2018) promises transformative improvement in measurement of OBP that will greatly facilitate the separation of mass and steric/heat content effects on sea level (Ponte, 2012). Recent work demonstrates the importance of OBP measurements in resolving meridional overturning circulation transport, and the possibility of optical clocks that sense changes in gravity (Hughes et al., 2018). As mentioned in Section "Ocean Bottom Pressure," OBP is in process to become an EOV.

Long-range acoustic "GPS" carried out by an underwaterarray of acoustic transducers can provide accurate, long-term, high temporal resolution float tracking (velocity EOV), longrange $\mathrm{AUV} /$ glider navigation (including under ice), and acoustic tomography (temperature EOV) if the platforms are equipped with acoustic receivers. The same acoustic receivers can carry out wind and rain measurements and monitor marine mammals and "soundscapes" (ocean sound EOV). Cabled (ATOC) and moored scenarios have used this mature technology for decades, with no significant impact on marine mammals. The high signal to noise ratio, no calibration, quadratic growth in data with number of instruments, and sampling at the speed of sound collectively enable high accuracy and high temporal resolution of basin-scale heat content.

In contrast to routine ship- and cable-based deployment, observations of inorganic carbon via alkalinity, $\mathrm{pCO}_{2}$, and $\mathrm{pH}$ on autonomous platforms are currently in the concept or pilot phase. The analytical methods for inorganic carbon are well developed along with certified reference materials, (for DIC and TA) to meet long-term accuracy requirements (Dickson et al., 2007; Wang et al., 2007). Better-calibrated measurements of carbonate variables on autonomous platforms are in development, which will be useful to monitor shortterm variability and seasonality. However, they will likely not be accurate enough to monitor decadal variation, so the accuracy of inorganic nutrient measurements requires improvement in order to quantify changes in the deep ocean. Sensors mounted either on a CTD package or on autonomous vehicles can measure oxygen precisely. One key advance has been the ability to reference oxygen sensors to air, reconfiguring profiling floats and gliders to a standard whenever the sensor is at the surface (Bushinsky et al., 2016). Profiling optical tools (e.g., chl-a fluorescence, optical backscatter, holography, and light-field imaging) can determine particle type-and size-distributions in time or space (e.g., Briggs et al., 2011), allowing quantitative inferences on particulate organic Remineralization Length Scale (RLS; Buesseler and Boyd, 2009), or the types and sizes of particles associated with variation in RLS.

Numerous emerging sensors and methodologies support observations of deep-ocean particle and remineralization processes. Increasingly reliable particle traps that quantify vertical particle flux can also add imaging systems to assess particle sizes and in situ settling velocities or be deployed with neutrally buoyant drifting platforms. Biological oxygen demand or remineralization rate observation techniques are quickly maturing for use across platforms; these are needed to assess the fate of organic matter at the seafloor (seafloor respiration is a suggested EOV). Oxygen consumption measurements no longer require on-board bottle and core incubations but can be assessed in situ by chamber incubations or by micro-profiler recordings of porewater oxygen distributions (e.g., Glud, 2008). Additionally, eddy covariance measurements, an emerging, non-destructive method, has been used successfully in a range of environments including the deep sea (e.g., Berg et al., 2009). All in situ oxygen consumption measurements benefit from the implementation of optical measurements with oxygen optodes (Klimant et al., 1995) that show low drift and stirring sensitivity and are now commercially available in many different sizes and configurations. Trophic structure of food webs requires assessing standing stock or biomass distribution across taxa and faunal size classes. Some taxa and productivity can be assessed through the monitoring of bio-optical instrumentation, bioluminescence or by sound collected via passive or active hydro-acoustic measurements (ocean sound is in the process of becoming an EOV). Stereoscopic imaging, holography, and light-field cameras 
show promise for quantifying fragile marine snow particles and important ecological quantities such as gelatinous zooplankton.

The study of natural, stable carbon, nitrogen, and sulfur isotope signatures (including compound-specific analyses), isotopic enrichment experiments, lipid biomarkers, gut content analyses, and the accumulation of pollutants or tracers found in harvested species or those captured in traps can document trophic interactions and food-web structure. Adaptation and tolerance to ecosystem change are commonly assessed through in situ, shipboard or laboratory experiments, however, logistical challenges limit this approach.

Challenges associated with observation and sampling limit diversity baseline and impact studies. Diversity indicators, such as rare versus abundant species, can help in estimating relative abundances of organisms, resilience to change, and recovery of impacted communities. Further research could identify indicator species that reflect the status and health of different ecosystems and provide early warning of impending change. Automated plankton samplers that collect material for later analyses are being developed and used, e.g., with towed and moored instruments and shipboard underway sampling systems (e.g., Metfies et al., 2016; McQuillan and Robidart, 2017).

\section{Genomics (Multi-Omics)}

High-throughput technologies such as DNA sequencing and mass-spectrometry are revolutionizing ecology and environmental management studies. A very promising approach is the analysis of eDNA that biota release into the environment and that allows for observations of biodiversity without the need to sample the organisms themselves. However, successful application depends on baseline knowledge of species identity, and in the case of eDNA, requires information on local versus exogenous sources and longevity of the DNA signal in the environment. Combinations of metabarcoding, metagenomics, metatranscriptomics, metaproteomics, metabolomics, or epigenomics allow the holistic description of any biomolecular environment, as shown for marine plankton (Lima-Mendez et al., 2015), coastal benthos (Beale et al., 2017), single cells (Lan et al., 2017) or host-symbiont models (Liu et al., 2012; Clark et al., 2017). Current applications of omics-related approaches to deep-sea environments focus mainly on diversity surveys of prokaryotes (e.g., Nunoura et al., 2018), microbial eukaryotes (Pawlowski et al., 2011; Lejzerowicz et al., 2014) and metazoan communities (Sinniger et al., 2016). Multi-omics have also been used to monitor resilience to pollution (e.g., Deepwater Horizon oil spill; Mason et al., 2012; Kimes et al., 2013; Smith et al., 2015), but a lack of reference data impedes broader applications to deep-sea organismal and community functional diversity and ecological interactions. Because deep-sea sediments harbor abundant extracellular DNA (Dell'Anno and Danovaro, 2005), one out of two sequenced DNA molecules might belong to long-dead organisms (Corinaldesi et al., 2018). Given that extracellular or inactive cell population DNA might saturate high-throughput sequencing data, basic omics approaches such as metabarcoding and metagenomics may provide only fragmentary information about active populations. Moreover, several hours to transport biological material from abyssal depths to the surface will certainly affect organisms and bias interpretation. Specifically tailored equipment able to retrieve undisturbed metatranscriptomic samples has quantified in situ metabolism of hydrothermal vent species (Sanders et al., 2013). A Deep-water Environmental Sensor Processor (D-ESP) was successfully deployed for in situ qPCR detection of methanotrophic bacterial species (Ussler et al., 2013), and a recent study improved extraction of nucleic acids from deep-sea settings (Muto et al., 2017). Other innovative instruments including microfluidic systems (Macaulay et al., 2017) could enable multi-omics analyses of deep-sea marine microbe cells (Robidart et al., 2012). The deep ocean could benefit from a large-scale metabarcoding, metagenomic, and transcriptomic census, as has been conducted for marine plankton (Keeling et al., 2014; Carradec et al., 2018). However, researchers must couple accumulation of omics data with other observation and cultivation data (Vilanova and Porcar, 2016) in order to reconstruct ecological systems and better understand deep-sea biology.

\section{Imaging Techniques}

The utility of optical imaging continues to grow (e.g., Durden et al., 2016; Morris et al., 2016; Ramondenc et al., 2016; Thornton et al., 2016). Commercially available systems can now image objects from tens of $\mu \mathrm{m}$ to $\mathrm{cm}$ and larger, e.g., with holographic or structured light systems (Davies et al., 2015). However, technologies for in situ plankton imaging, e.g., Lightframe Onsight Key species Investigation (LOKI, Schulz et al., 2010), flow cytometry, and automated species recognition technology require further work to enhance biodiversity assessment. Indeed, the mosaicing of video and image data now occurs continuously from $\mathrm{m}$ to $\mathrm{km}$ scales at landscape and policy-relevant scales. Many platforms support imaging tools with great promise in being able to mount imaging systems to long range and long endurance AUVs that can navigate repeat vertical sections and seafloor surveys of hundreds of $\mathrm{km}$ and hectares.

Without a seafloor background to scale against, sizing objects in the water column remains challenging. Georeferenced images, structured light, stereoscopic imaging, holography, light-field, and flow cytometry cameras show great utility for quantifying habitats, geologic resources, fragile marine snow particles and important ecological quantities from gelatinous zooplankton to fish (e.g., Wynn et al., 2014; Aguzzi et al., 2015; Ramondenc et al., 2016; Peukert et al., 2018). On the seafloor, imaging can now readily quantify individuals approximately $1 \mathrm{~cm}$ in size, patches of individuals, how they relate to habitat features, and how they relate to landscape features (e.g., Morris et al., 2016; Thornton et al., 2016). Camera systems readily adapt to deep-sea deployment with appropriate window and housing depth ratings. Processing techniques can also render images into 3D data with known photogrammetric error (Kwasnitschka et al., 2016; Thornton et al., 2016). Supporting navigation and camera position and geometry data including structured light, acoustic imaging, or taking advantage of light field (i.e., plenoptic) or stereo-image data processing collectively enable this approach. The improvements from imaging type and photogrammetric approaches allows investigators to extract 
particle biology and ecosystem EOV data from images in a way that begins to approach the accuracy and precision of physics and biogeochemistry EOVs. Imaging technology includes the advantage of imaging many orders of magnitude more objects than can be sampled otherwise and with little or no disturbance, such as to fragile marine snow particles. However, image data typically require context information such as a regional image guide or catalog of species, or calibrations of size, weight, and/or biogeochemical composition. As with omics, optical and acoustic imaging data severely tax data systems.

\section{Super-Deep Hydrographic Measurements}

Shipboard hydrographic measurements conducted at hadal depths for climate studies require the highest possible quality measurements because of the low signal-to-noise ratio. In the past, water sampling in ocean trenches used bottles equipped with reversing thermometers, or CTD observations obtained without water samples to correct the CTD data. Today, fullocean-depth $(11,000 \mathrm{~m})$ reference quality measurements are possible with modern conductivity-temperature-depth/oxygen $\left(\mathrm{CTD} / \mathrm{O}_{2}\right)$ sensors and water sampling equipment through the use of synthetic (polyarylate) fiber coaxial cable (Kawagucci et al., 2018). Acquiring data of the highest possible quality requires in situ calibration of $\mathrm{CTD} / \mathrm{O}_{2}$ sensors. A deep-ocean standard thermometer realizes SI traceable measurements with an uncertainty of $0.7 \mathrm{mK}$ after correction for pressure (Uchida et al., 2015). Practical salinity and dissolved oxygen data require water samples to calibrate sensors in situ. In the Mariana Trench, for example, a salinity profile obtained with in situ calibration is reasonably homogeneous (unpublished data, D. Yanagimoto personal communication), whereas without calibration salinity artifactually increases in the bottom layer. Previous comparisons report a similar artifact (Taira et al., 2005; van Haren et al., 2017).

Rotation and related motion of the CTD package on its cable also affect CTD data quality (Uchida et al., 2015). Used together, an underwater slip-ring swivel, a stabilizing fin, and a traction winch to compensate for the ship's motion enable efficient and safe acquisition of high-quality CTD data (Uchida et al., 2018), although pressure hysteresis of the CTD sensors (temperature, conductivity, and oxygen) must be considered. However, even the highest quality salinity measurements are not adequate for climate studies in ocean trenches. For example, long-term salinity changes in the North Pacific deep ocean due to temperature changes of $\sim 0.0001$ per decade are expected from the temperature-salinity relationship, whereas CTD salinity measurements resolve 0.0004 (0.002 for a laboratory salinometer). Ambiguity of the certified salinity value $( \pm 0.001)$ of standard seawater used to calibrate laboratory salinometers adds another problem (Kawano et al., 2006). An optical interferometric salinometer currently in development uses highprecision refractive index measurements to resolve absolute salinity to better than 0.0002 . However, even the state-of-theart optical interferometric salinometer must be calibrated against standard seawater, which itself requires certification of absolute salinity so that it can be used as reference material for absolute salinity measurements (Uchida et al., 2011).

\section{DATA DISCOVERY, STANDARDIZATION, INTEROPERABILITY, AND SYNTHESIS}

Addressing the ambitious deep-sea science and management challenges described above will require an unprecedented level of data accessibility and integration. The difficult and expensive nature of deep observation means that data will remain sparse, and sharing even more critical.

\section{Current Status and Challenges}

Results from the Inventory of Deep Ocean Observing (see Section "Status of Deep-Ocean Observing") indicate that in many cases the data being collected by deep-ocean observatories are being preserved and made freely accessible online to the larger community. Where exceptions exist, they are largely in smaller programs that lack long-term funding and informatics expertise, in one-time sampling projects, or of less mature EOVs where methods are still evolving.

Despite widespread deep-ocean data availability, challenges remain. Though efforts toward standardization continue, users are often working with heterogeneous systems, varied data formats and access methods, and varied or insufficient metadata. From large observatories to individual labs, there are multiple cyberinfrastructure approaches in operation and in development which work to support data acquisition, storage, processing, and visualization in a single, distributed system. These range from simple data servers containing .csv files, to ERDDAP-based systems ${ }^{9}$ with a stable, versioned file structure such as the ones used by the NOAA IOOS ${ }^{10}$, to compute-on-demand systems like the one used by the OOI ${ }^{11}$.

Further, anyone familiar with attempting to locate or convert data records that exist only in a large collection of mysterious floppy disks or tape reels is well aware of the problem of changing data storage and data delivery technology. The era of "big data" has only accelerated this issue, as more different types of data are collected, and large-volume data types such as video are increasing, that require long-term storage in a stable and accessible format. Future efforts should go into processing of data on cloud servers, using open-source software packages to enable interactive and collaborative data discovery, exploration, and manipulation (e.g., Pangeo ${ }^{12}$ for big data geosciences research ${ }^{13}$ ), but best practices are yet to be widely developed and shared for using cloud resources. Finally, discovery of accessible resources is a substantial challenge. Deep data are served by a complex patchwork of project-specific websites, institutional collections, national and international data centers, thematic data repositories, and journal data appendices. Searching for data from a particular EOV measurement or region requires searches in many systems, not all of which are known to inexpert users. The same or similar data are often served

\footnotetext{
${ }^{9}$ https://coastwatch.pfeg.noaa.gov/erddap/index.html

${ }^{10}$ https://ioos.noaa.gov/

${ }^{11} \mathrm{http}: / /$ oceanobservatories.org/

${ }^{12}$ http://pangeo.io/

${ }^{13} \mathrm{http}: / /$ pangeo-data.org/
} 
from multiple source repositories, with unclear provenance to disambiguate the versions.

\section{Future Steps}

To achieve a future where deep observations are fully shared and able to support broad science and societal needs requires several components: wide agreement on the need to share data, standards to achieve consistency and comparability across data sources, better registries and cross-repository search tools to improve discoverability, and capacity building for both observatories capturing data and those using the data.

\section{Open Data Policies}

The critical foundation in building an ecosystem of accessible and usable deep-sea data is agreement among scientists, funding agencies, publishers, governments, and NGOs that deep ocean data should be openly and freely shared. The FAIR guiding principles (Wilkinson et al., 2016) provide a set of widely endorsed practices to ensure that data, tools, and other cyberinfrastructure are Findable, Accessible, Interoperable and Reusable. It does not require specific technologies, as technology will evolve over time, but rather identifies specific characteristics to meet, such as implementing persistent identifiers for all data, having both human-readable and machine-actionable metadata, and having well-described protocols for both humans and machines to access the data.

While FAIR is gaining support globally ${ }^{14}$, and has been endorsed by both the GOOS and DOOS communities, other similar and well-crafted position and policy statements exist. What is important is not which statement is endorsed, but that the observing community widely adopts a philosophy of data stewardship that ensures data are secure, widely available, and documented for usability. As stated by the American Geophysical Union (2015) "Earth and space sciences data are a world heritage."

\section{Standards}

In order for data systems to work together today, and continue to work in the future, there must be community acceptance of standardized rules for complete, consistent metadata (e.g., Climate and Forecast (CF), International Standards Organization (ISO), or Federal Geographic Data Committee (FGDC) standards) and the use of self-describing data formats (e.g., NetCDF) to allow synthesis of different types of data into a single archive. Archiving in national databases (e.g., $\mathrm{AODN}^{15}$ ) allows for both long-term storage and accessibility, but there is a pressing need for standardized metrics, implementation of common nomenclature within and across fields, improved provenance tracking, and the application of real-time quality control. Some fields and sub-fields have settled on one or two standards (e.g., IRIS, GenBank, WoRMS, OBIS, etc.), but they are not all interoperable, and the nomenclature varies widely. Concerted coordination, and support for the communications platforms needed to reach consensus, are necessary.

\footnotetext{
${ }^{14} \mathrm{http}$ //www.copdess.org/enabling-fair-data-project/enabling-fair-projectoverview/

${ }^{15}$ http://imos.org.au/facilities/aodn/
}

\section{Registries and Coordinated Discovery}

To reduce the challenges of finding deep-ocean data, particularly to non-experts, a concerted effort is needed by the deep observatory community to converge on a small number of widely used registries for data discovery, and to support standards and APIs to allow searches in a central location to query across multiple repositories. Efforts such as GEOSS Portal ${ }^{16}$ and EMODnet ${ }^{17}$ show the promise of this approach.

To bring all ocean data toward FAIR standards will require substantial capacity development involving all stakeholders. Capacity building training programs related to ocean observing already exist and could offer opportunities to build deep oceandedicated-training under these umbrellas. (see Section "Capacity Building" below).

\section{MOVING FORWARD}

\section{Value Propositions}

Oceans provide goods and services that are imperative to human survival and well-being. The ocean's "Blue Economy" is one of the richest and fastest-growing economies, projected to reach over USD 3 trillion by 2030, doubling its current value (OECD, 2016). However, climate change and potentially destructive and unsustainable exploitation of ocean resources put the world's Blue Economy at risk. To ensure that the oceans and Blue Economy are managed efficiently, sustainably, and equitably, it is critical to develop ocean observing programs to improve understanding of the oceans and how they are changing. Key elements of future observing efforts will be community engagement, capacity building and data management.

Ocean observing offers benefits to all elements of the Blue Economy. For example, ocean observations using ROV data have been used to understand the effects of prevailing environmental conditions (current velocity, biofouling) on oil and gas extraction activities, ultimately leading to better asset (infrastructure) management and concomitant cost-savings (Macreadie et al., 2018). Ocean observation, openly and easily accessible (see Section "Data Discovery, Standardization, Interoperability, and Synthesis") can enhance environmental and social responsibility and improve EIA effectiveness and efficiency (Vardaro et al., 2013; Eide and Westad, 2018), which may lead directly to increased regulator and societal confidence and add to the credibility of blue industries (Box 3).

\section{Community Engagement}

Developing a strategy for deep-ocean observation requires attracting more students, early career scientists, and the general public in related science and technology fields. This can be achieved by engaging them with deep-sea research challenges, raising awareness of deep-sea exploration and discoveries, and emphasizing the need to fill gaps in ocean/climate interaction processes, seafloor geological processes, and deep-ecosystem functions and dynamics. Citizen science has proven valuable

\footnotetext{
${ }^{16}$ http://www.geoportal.org/

${ }^{17}$ http://www.emodnet.eu/
} 
for annotations of deep sea-imagery. Live broadcasting of scientific missions, known as telepresence, (e.g., ROV dives) or imagery and sound recordings from cabled observatories (e.g., Neptune Canada ${ }^{18}$ ) have provided unprecedented public access and engagement. There is a need to identify new engagement opportunities in data management, technology innovation, and transfer of best practices, emphasizing broad disciplinary scope and interdisciplinary science. Production of education materials (books, factsheets, tutorials, e-learning, and museum installations) can help disseminate scientific advances to scholars and students. Development of outreach events and ocean literacy material can attract the attention of school children and local communities and emphasize the importance of the deep-ocean contribution to the prosperity and wellbeing of humanity.

\section{Capacity Building}

Existing capacity building training programs related to ocean observing can offer opportunities to contribute or build a dedicated deep-ocean training program under these umbrellas and can contribute to data coordination. UNESCO/IOC IODE and WMO Learn Education and Training Programme ${ }^{19}$ (ETRP) continue to make efforts that facilitate access to a wide range of training materials. The OceanTeacher Global Academy $^{20}$ initiative allows training courses to take place

\footnotetext{
${ }^{18}$ http://www.oceannetworks.ca/sights-sounds/live-video

${ }^{19}$ http://learn.wmo.int

${ }^{20} \mathrm{http}$ ://www.oceanteacher.org
}

simultaneously in multiple locations through the use of video conferencing technology.

The Joint Technical Commission for Oceanography and Marine Meteorology (JCOMM) from UNESCO and IOC has Capacity Development plans to empower developing States [Least Developed Countries (LDCs) and Small Island Developing States (SIDS)] by providing expert training on the applications of ocean observation data for understanding and predicting regional weather, ocean, and climate. The Partnership for Observation of the Global Oceans (POGO) acts as a forum for leaders of major oceanographic institutions to promote global oceanography, particularly for the implementation of international and integrated GOOSs, and provides training and technology transfer to emerging economies to build awareness of future challenges ${ }^{21}$. Additional training opportunities are offered by the GEO, Integrated Marine Biosphere Research (IMBeR), International Ocean Colour Coordinating Group, and North Pacific Marine Science Organization. Also "summer schools" or training workshops are organized by deep-ocean scientific networks such as INDEEP, DOSI, IODP, and InterRidge.

In addition to dedicated courses, there is a need to more widely disseminate availability of berth spaces at sea and training internships on field research, instrumentation development, and data analysis of relevance to deep-sea observation. Funding support for early career scientists and qualified technical personnel from developing countries can be requested from the POGO-SCOR Visiting Fellowships program ${ }^{22}$, and the ISA

\footnotetext{
${ }^{21} \mathrm{http} / /$ www.ocean- partners.org/training-education

${ }^{22}$ http://ocean-partners.org/pogo-scor-fellowship
}

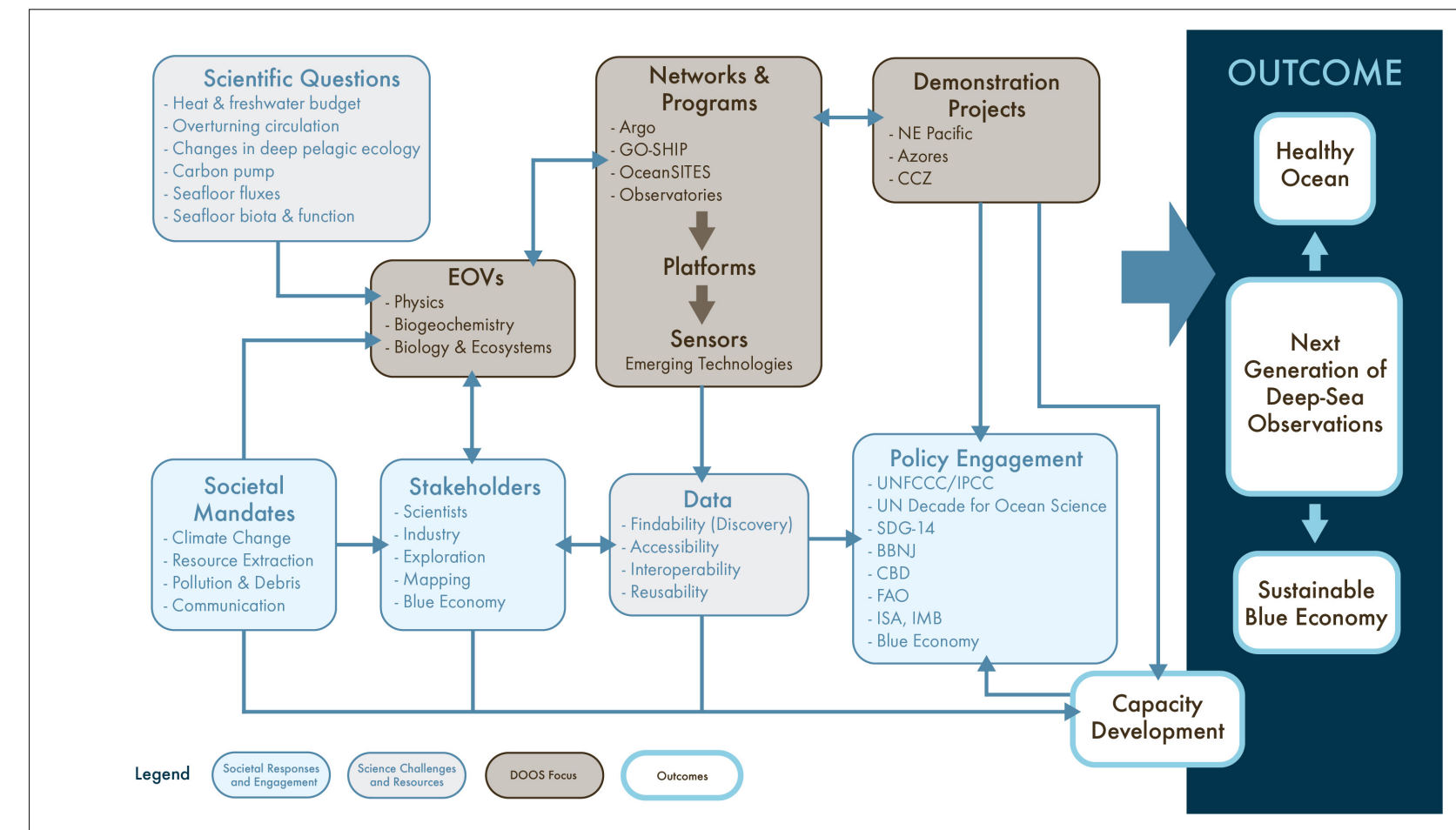

FIGURE 5 | The key components of a deep-ocean observing strategy designed to promote healthy oceans and a sustainable blue economy. 
Endowment Fund for the InterRidge Student and Postdoctoral Fellowship Program for collaborative marine scientific research. Substantial interdisciplinary efforts to develop new capacity to monitor deep-sea environments and biodiversity are required, including the sharing of skills and best practices for the use of existing instrumentation (e.g., robotics, sensors) and for the development of new equipment.

\section{Summary and Recommendations}

A DOOS is conceptualized in Figure $\mathbf{5}$ and is put forward in the following recommendations.

1. Agree upon a set of EOVs that will capture current baseline conditions and future changes in the deep ocean, its ecosystems, and the services they provide. Work with GOOS Expert Panels and the scientific community to standardize, mature and operationalize these EOVs, and advance the availability, reliability, and longevity of autonomous systems (sensors and platforms) that can make these measurements. Emphasize approaches that may be scaled up to provide nearglobal coverage.

2. Develop a means to identify new deep-ocean data needed to address key scientific and societal needs. Develop new communication tools to inform the science community and convey deep-ocean observing needs and advances across disciplines, regions, sectors and jurisdictions. One thoughtful suggestion is to consider conducting a large-scale, decadal metabarcoding, metagenomic, and transcriptomic census in the deep ocean, as has been conducted for marine plankton (Keeling et al., 2014; Carradec et al., 2018).

3. Expand the deep-ocean observing capabilities and capacity (a) by engaging corporate citizens (e.g., the energy, fisheries, seabed mining, cable and shipping industries), the ocean exploration community, biodiversity interests and the public; (b) through enhanced vessel servicing activities; and (c) by reusing and repurposing existing data products. Develop approaches to incentivize engagement by a broader range of stakeholders to achieve this.

4. Enhance data FAIR for scientists and non-experts by converging on a small number of widely used registries for data discovery, and support standards and APIs to allow searches in a central location to query across multiple repositories.

5. Work to integrate deep-ocean observing across disciplines, share skills and best practices for the use of existing instrumentation (e.g., robotics, sensors) and for the development of new equipment (e.g., through demonstration projects).

6. Create collaborations across the deep components of existing regional observing networks such as those in the MBON, OOI, ONC, EMSO 2020, AtlantOS, SOOS, and FRAM and integrate these with global programs (e.g., ARGO, deep ARGO, BGC Argo, OceanSITES, GO-SHIP).

7. Build deep-ocean observing capacity by expanding existing training programs to build "deep-ocean" dedicated training under these umbrellas, while simultaneously integrating capacity building seamlessly into existing and future observing programs.

8. Facilitate use of deep-observing data by a broad range of stakeholders, particularly in the economic and international policy sectors, to achieve a healthy ocean and sustainable blue economy.

9. Engage with the modeling community to (a) better understand and respond to requirements for verification, validation, and calibration of models used for prediction; and (b) improve inverse modeling approaches for optimally extracting and combining information contained in theoretical foundations, where available (e.g., equations of motions), and sparsely sampled observations.

\section{AUTHOR CONTRIBUTIONS}

LL, BB, AG, PH, BH, FJ, AM, HR, PS, and KS helped to conceive the manuscript, coordinated author contributions, wrote the text, edited and contributed to the figures and tables. DB, SB-P, CB, MB, DJB, MC-S, AC, ME, AF, KG, DJ, KK, DK, NLB, AL, FL, PM, DM, FM, TM, AN, JP, CS, SS, HU, MV, RV, and RW contributed the manuscript ideas and text.

\section{FUNDING}

Preparation of this manuscript was supported by NNX16AJ87A (NASA) Consortium for Ocean Leadership, Sub-Award No. SA16-33. AC was supported by FCT-Investigador contract (IF/00029/2014/CP1230/CT0002). LL was supported by a NASA subaward from the Consortium for Ocean Leadership. AG and $\mathrm{HR}$ were supported by Horizon 2020, EU Project "EMSO Link" grant ID 731036. AG, $\mathrm{BB}$, DJ, and HR contributions were supported by the UK Natural Environment Research Council Climate Linked Atlantic Section Science project (NE/R015953/1). JP was funded by the Swiss Network for International Studies, and the Swiss National Science Foundation (grant 31003A_179125). TM was supported by Program Investigador FCT (IF/01194/2013), IFCT Exploratory Project (IF/01194/2013/CP1199/CT0002), H2020 Atlas project (GA 678760), and the H2020 MERCES project (GA 689518). This is PMEL contribution number 4965.

\section{ACKNOWLEDGMENTS}

We thank the many people who contributed to preparation of the DOOS Consultative Draft, the 2016 DOOS Scoping Workshop and Report, and the DOOS Science Implementation Guide. All of their efforts and energy contributed to the ideas in this manuscript. We also thank NASA for its support of Deep Ocean Observing as critical to the planet, Guillermo Mendoza and Leslie Smith for assistance with manuscript preparation, formatting and submission, and two reviewers and the editor for their insightful comments that improved the manuscript. 


\section{REFERENCES}

Aguzzi, J., Doy, C., Tecchio, S., De Leo, F., Azzurro, F., Costa, C., et al. (2015). Coastal observatories for monitoring of fish behaviour and their responses to environmental changes. Rev. Fish Biol. Fish 25, 463-483. doi: 10.1007/s11160015-9387-9

Aleynik, D., Inall, M. E., Dale, A., and Vink, A. (2017). Impact of remotely generated eddies on plume dispersion at abyssal mining sites in the Pacific. Sci. Rep. 7:16959. doi: 10.1038/s41598-017-16912-2

American Geophysical Union (2015). Earth and Space Science Data Should Be Credited, Preserved, Open, and Accessible as an Integral Responsibility of Scientists, Data Stewards, and Sponsoring Institutions. Available at http//sciencepolicy.agu.org/files/2013/07/AGU-Data-Position-StatementFinal-2015.pdf (accessed 13 July 2018).

Amon, D. J., Ziegler, A. F., Dahlgren, T. G., Glover, A. G., Goineau, A., Gooday, A. J., et al. (2016). Insights into the abundance and diversity of abyssal megafauna in a polymetallic-nodule región in the Eastern clarion-clipperton zone. Nat. Sci. Rep. 6:30492. doi: 10.1038/srep30492

Amorim, P., Perán, A. D., Pham, C. K., Juliano, M., Cardigos, F., Tempera, F., et al. (2017). Overview of the ocean climatology and its variability in the azores region of the North Atlantic including environmental characteristics at the seabed. Front. Mar. Sci. 4, 1-16. doi: 10.3389/fmars.2017.00056

Anastasopoulou, A., Mytilineou, C., Smith, C. J., and Papadopoulou, K. N. (2013). Plastic debris ingested by deep-water fish of the Ionian Sea (Eastern Mediterranean). Deep Sea Res. I Oceanogr. Res. Pap. 74, 1-13. doi: 10.1016/j. dsr.2012.12.008

Ballora, M., and Evans, J. (2017). "Spaghetti of Storms - an installation of tropical storm data sonifications," in Proceedings of the 24th International Conference of Auditory Display (ICAD 2017), (Pennsylvania: The Pennsylvania State University)

Ballu, V., Ammann, J., Pot, O., de Viron, O., Sasagawa, G. S., Reverdin, G., et al. (2008). A seafloor experiment to monitor vertical deformation at the Lucky Strike volcano. Mid-Atlantic Ridge. J Geod. 83:147. doi: 10.1007/s001

Barnes, C. R., Best, M. M. R., Johnson, F. R., Pautet, L., and Pirenne, B. (2013). Challenges, benefits, and opportunities in installing and operating cabled ocean observatories: perspectives from NEPTUNE Canada. IEEE J. Ocean. Eng. 38, 144-157. doi: 10.1109/JOE.2012.2212751

Barth, J. A., Menge, B. A., Lubchenco, J., Chan, F., Bane, J. M., Kirincich, A. R., et al. (2007). Delayed upwelling alters nearshore coastal ocean ecosystems in the northern California current. Proc. Natl. Acad. Sci 104, 3719-3724. doi: 10.1073/pnas.0700462104

Beale, D. J., Crosswell, J., Karpe, A. V., Ahmed, W., Williams, M., Morrison, P. D., et al. (2017). A multi-omics based ecological analysis of coastal marine sediments from Gladstone, in Australia's Central Queensland, and Heron Island, a nearby fringing platform reef. Sci. Total Environ. 609, 842-853. doi: 10.1016/j.scitotenv.2017.07.184

Bean, T. P. N., Greenwood, R., Beckett, L., Biermann, J. P., and Bignell, J. L. (2017). A review of the tools used for marine monitoring in the uk: combining historic and contemporary methods with modeling and socioeconomics to fulfill legislative needs and scientific ambitions. Front. Mar. Sci. 4, doi: 10.3389/ fmars.2017.00263

Beazley, L. I., Kenchington, E. L., Murillo, F. J., and Sacau, M. (2013). Deep-sea sponge grounds enhance diversity and abundance of epibenthic megafauna in the Northwest Atlantic. ICES J. Mar. Sci. 70, 1471-1490. doi: 10.1093/icesjms/ fst 124

Bell, K. L. C., Brennan, M. L., Flanders, J., Raineault, N. A., and Wagner, K. (2016). New frontiers in ocean exploration: the E/V Nautilus and NOAA ship okeanos explorer 2015 field season. Oceanography 29(Suppl. 1), 84.

Belley, R., Snelgrove, P. V. R., Archambault, P., and Juniper, S. K. (2016). Environmental Drivers of Benthic Flux Variation and Ecosystem Functioning in Salish Sea and Northeast Pacific Sediments. PLoS One 11:e0151110. doi: 10.1371/journal.pone.0151110

Bellward, A., Bourassa, M., Dowell, M., Briggs, S., Dolman, H., Holmlund, K., et al. (2016). GCOS 2016 Implementation Plan, A. Geneva: World Meteorological Organization.

Berg, P., Glud, R. N., Hume, A., Ståhl, H., Oguri, K., Meyer, V., et al. (2009). Eddy correlation measurements of oxygen uptake in deep ocean sediments. Limnol. Oceanogr. Methods 7, 576-584. doi: 10.4319/lom.2009.7.576
Bergmann, M., Wirzberger, V., Krumpen, T., Lorenz, C., Primpke, S., Tekman, M. B., et al. (2017). High quantities of microplastic in Arctic deep-sea sediments from the HAUSGARTEN Observatory. Envir. Sci. Technol. 51, 11000-11010. doi: 10.1021 /acs.est.7b03331

Bett, B. J. (2001). UK Atlantic Margin Environmental Survey: introduction and overview of bathyal benthic ecology. Cont. Shelf Res. 21, 917-956. doi: 10.1016/ S0278-4343(00)00119-9

Bett, B. J., Malzone, M. G., Narayanaswamy, B. E., and Wigham, B. D. (2001). Temporal variability in phytodetritus and megabenthic activity at the seabed in the deep Northeast Atlantic. Prog. Oceanogr. 50, 349-368. doi: 10.1016/S00796611(01)00066-60

Blasiak, R., Jouffray, J. B., Wabnitz, C. C. C., Sundstrom, E., and Österblom, H. (2018). Corporate control and global governance of marine genetic resources. Sci. Adv. 4:eaar5237. doi: 10.1126/sciadv.aar5237

Block, B. A., Jonsen, I. D., Jorgensen, S. J., Winship, A. J., Shaffer, S. A., Bograd, S. J., et al. (2011). Tracking apex marine predator movements in a dynamic ocean. Nature 475, 86-90. doi: 10.1038/nature 10082

Bond, T., Langlois, T. J., Partridge, J. C., Birt, M. J., Malseed, B. E., Smith, L., et al. (2018). Diel shifts and habitat associations of fish assemblages on a subsea pipeline. Fish. Res. 206, 220-234. doi: 10.1016/j.fishres.2018.05.011

Booth, D. J., Poloczanska, E., Donelson, J. M., García Molinos, J., and Burrows, M. (2018b). "Biodiversity and Climate Change in the Oceans", in "Chapter 4 Climate Change Impacts on Fisheries and Aquaculture: A Global Analysis, Volume I, eds F. Bruce Phillips, and M. Pérez-Ramírez (New Jersey, NJ: John Wiley \& Sons Ltd).

Booth, D. J., Feary, D., Kobayashi, D., Luiz, O., and Nakamura, Y. (2018a). Tropical Marine Fishes and Fisheries and Climate Change. Ch. 26. in Climate Change Impacts on Fisheries and Aquaculture: A Global Analysis, Volume I. eds F. Bruce Phillips, and M. Pérez-Ramírez (New Jersey, NJ: John Wiley \& Sons Ltd).

Bourrel, M., Thiele, T., and Currie, D. (2016). The common heritage of mankind as a means to assess and advance equity in deep sea mining. Mar. Policy. 95, 311-316. doi: 10.1016/j.marpol.2016.07.017

Brandt, A., Gutt, J., Hildebrandt, M., Pawlowski, J., Schwendner, J., Soltwedel, T., et al. (2016). Cutting the umbilical: new technological perspectives in benthic deep-sea research. J. Mar. Sci. Eng. 4:36. doi: 10.3390/jmse4020036

Briggs, N., Perry, M. J., Cetiniæ, I., Lee, C., D’Asaro, E., Gray, A. M., et al. (2011). High-resolution observations of aggregate flux during a sub-polar North Atlantic spring bloom. Deep Sea Res. Part I 58, 1031-1039. doi: 10.1016/ j.dsr.2011.07.007

Brown, J. H., Gillooly, J. F., Allen, A. P., Savage, V. M., and West, G. B. (2004). Toward a metabolic theory of ecology. Ecology 85, 1771-1789. doi: 10.1890/039000

Brumovsk $\iota$, M., Beèanová, J., Kohoutek, J., Thomas, H., Petersen, W., Sørensen, K., et al. (2016). Exploring the occurrence and distribution of contaminants of emerging concern through unmanned sampling from ships of opportunity in the North Sea. J. Mar. Systems 162, 47-56. doi: 10.1016/j.jmarsys.2016. 03.004

Bueno-Pardo, J., Ramalho, S. P., Gracía-Alegre, A., Morgado, M., Vieira, R. P., Cunha, M. R., et al. (2017). Deep-sea crustacean trawling fisheries in Portugal: quantification of effort and assessment of landings per unit effort using a Vessel Monitoring System (VMS). Sci. Rep. 7:40795. doi: 10.1038/srep 40795

Buesseler, K. O., and Boyd, P. W. (2009). Shedding light on processes that control particle export and flux attenuation in the twilight zone of the open ocean. Limnol. Oceanogr. 54, 1210-1232. doi: 10.4319/lo.2009.54.4.1210

Bushinsky, S. M., Emerson, S. R., Riser, S. C., and Swift, D. D. (2016). Accurate oxygen measurements on modified Argo floats using in situ air calibrations. Limnol. Oceanogr. 14, 491-505. doi: 10.1002/lom3.10107:2016

Carradec, Q., Pelletier, E., Da Silva, C., Alberti, A., Seeleuthner, Y., Blanc-Mathieu, R., et al. (2018). A global ocean atlas of eukaryotic genes. Nat. Commun. 9:373. doi: 10.1038/s41467-017-02342-2341

Cavanaugh, C. M., McKiness, Z. P., Newton, I. L. G., and Stewart, F. (2006). "Marine Chemosynthetic Symbioses," in The Prokaryotes, eds M. Dworkin, S. Falkow, E. Rosenberg, K. H. Schleifer, and E. Stackebrandt (New York, NY: Springer)

Chambers, D. P., and Willis, J. K. (2010). A global evaluation of ocean bottom pressure from GRACE. OMCT, and steric-corrected altimetry. J. Atmos. Oceanic Technol. 27, 1395-1402. doi: 10.1175/2010JTECHO738.1 
Chiba, S., Saito, H., Fletcher, R., Yogi, T., Kayo, M., Miyagi, S., et al. (2018). Human footprint in the abyss: 30 year records of deep-sea plastic debris. Mar. Policy 96, 204-212. doi: 10.1016/j.marpol.2018.03.022

Clark, M. S., Sommer, U., Sihra, J. K., Thorne, M. A. S., Morley, S. A., King, M., et al. (2017). Biodiversity in marine invertebrate responses to acute warming revealed by a comparative multi-omics approach. Glob. Chang. Biol. 23, 318-330. doi: $10.1111 /$ gcb. 13357

Colaço, A., Blandin, A. J., Cannat, M., Carval, T., Chavagnac, T. V., Connelly, D., et al. (2011). MoMAR-D: a technological challenge to monitor the dynamics of the Lucky Strike vent ecosystem. ICES J. Mar. Sci. 68, 416-424. doi: 10.1093/ icesjms/fsq075

Constable, S., and Srnka, L. J. (2007). An introduction to marine controlledsource electromagnetic methods for hydrocarbon exploration. Geophysics 72, WA3-WA12. doi: 10.1190/1.2432483

Copley, J. (2014). Just how little do we know about the ocean floor? The Conversation. http://theconversation.com/just-how-little-do-we-know-aboutthe-ocean-floor-32751 accessed October 10, 2014.

Cordes, E. E., Jones, D. O. B., Schlacher, J. T., Amon, D., Bernardino, A., Brooke, S., et al. (2016). Environmental impacts of the deep-water oil and gas industry: a review to guide management strategies. Front. Env. Sci. 4:58. doi: 10.3389/fenvs. 2016.00058

Corinaldesi, C., Tangherlini, M., Manea, E., and Dell'Anno, A. (2018). Extracellular DNA as a genetic recorder of microbial diversity in benthic deep-sea ecosystems. Sci. Rep. 8:1839. doi: 10.1038/s41598-018-20302-7

Corredor, J. E. (2018). Coastal Ocean Observing. Berlin: Springer, 159.

Courtene-Jones, W., Quinn, B., Gary, S. F., Mogg, A. O. M., and Narayanaswamy, B. E. (2017). Microplastic pollution identified in deep-sea water and ingested by benthic invertebrates in the Rockall Trough. North Atlantic Ocean. Environ. Pollut. 231(Pt 1), 271-280. doi: 10.1016/j.envpol.2017.08.026

Cristini, L., Lampitt, R. S., Cardin, V., Delory, E., Haugan, P., O’Neill, N., et al. (2016). Cost and value of multidisciplinary fixed-point ocean observatories. Mar. Policy 71, 138-146. doi: 10.1016/j.marpol.2016.05.029

Crowder, L., and Norse, E. (2008). Essential ecological insights for marine ecosystem-based management and marine spatial planning. Mar. Policy 32, 772-778. doi: 10.1016/j.marpol.2008.03.012

Cuyvers, L., Berry, W., Gjerde, K., Thiele, T., and Wilhem, C. (2018). Deep Seabed Mining: A Rising Environmental Challenge. Gland: IUCN and Gallifrey Foundation, 74 .

Danovaro, R., Aguzzi, J., Fanelli, E., Billett, D., Gjerde, K., Jamieson, A., et al. (2017). An ecosystem-based deep-ocean strategy. Science 355, 452-454. doi: 10.1126/science.aah7178

Danovaro, R., Carugati, L., Berzano, M., Cahill, A. E., Carvalho, S., Chenuil, A., et al. (2016). Implementing and innovating marine monitoring approaches for assessing marine environmental status. Front. Mar. Sci. 3:213. doi: 10.3389/ fmars.2016.00213

Danovaro, R., Dell'Anno, A., Pusceddu, A., Gambi, C., Heiner, I. M., and Møbjerg Kristensen, R. (2010). The first metazoa living in permanently anoxic conditions. BMC Biol. 8:30. doi: 10.1186/1741-7007-8-30

Danovaro, R., Snelgrove, P. V., and Tyler, P. (2014). Challenging the paradigms of deep sea ecology. Trends Ecol. Evol. 29:465. doi: 10.1016/j.tree.2014.06.002

Davies, E. J., Buscombe, D., Graham, G. W., and Nimmo-Smith, W. A. M. (2015). Evaluating unsupervised methods to size and classify suspended particles using digital in-line holography. J. Atmos. Ocean Technol. 32, 1241-1256. doi: 10. 1175/JTECH-D-14-00157.1

Davies, J. H. (2013). Global map of solid Earth surface heat flow. Geochem. Geophys. Geosyst. 14, 4608-4622. doi: 10.1002/ggge.20271

de Lavergne, C., Madec, G., Capet, X., Maze, G., and Roquet, F. (2016a). Getting to the bottom of the ocean. Nat. Geosci. 9, 857-858. doi: 10.1038/ngeo2850

de Lavergne, C., Madec, G., Le Sommer, J., Nurser, G. A. J., and Naveira Garabato, A. C. (2016b). On the consumption of Antarctic bottom water in the abyssal ocean. J. Phys. Oceanogr. 46, 635-661. doi: 10.1175/JPO-D-14-0201.1

de Lavergne, C., Madec, G., Roquet, F., Holmes, R. M., and McDougall, T. J. (2017). Abyssal ocean overturning shaped by seafloor distribution. Nature 551, 181-186. doi: 10.1038/nature24472

De Leo, F. C., Gauthier, M., Juniper, S. K., Nephin, J., and Mihály, S. (2017). Bottom trawling and oxygen minimum zone influences on continental slope benthic community structure off Vancouver Island (NE Pacific). Deep Sea Res. Part. II 137, 404-419. doi: 10.1016/j.dsr2.2016.11.014
De Pooter, D., Appeltans, W., Bailly, N., Bristol, S., Deneudt, K., Eliezer, M., et al. (2017). Toward a new data standard for combined marine biological and environmental datasets - expanding OBIS beyond species occurrences. Biodivers. Data J. 5:e10989. doi: 10.3897/BDJ.5.e10989

Deamer, D., and Damer, B. (2017). Can Life Begin on Enceladus? A Perspective from Hydrothermal Chemistry. Astrobiology 17, 834-839. doi: 10.1089/ast. 2016.1610

Dell'Anno, A., and Danovaro, R. (2005). Extracellular DNA plays a key role in deep-sea ecosystem functioning. Science 309:2179. doi: 10.1126/science. 1117475

Dickson, R. R., Rudels, B., Dye, S., Karcher, M., Meincke, J., and Yashayaev, I. (2007). Current estimates of freshwater flux through Arctic and subarctic seas. Prog. Oceanogr. 73, 210-230. doi: 10.1016/j.pocean.2006.12.003

Doya, C., Chatzievangelou, D., Bahamon, N., Purser, A., Leo, F. C. D., Juniper, S. K., et al. (2017). Seasonal monitoring of deep-sea megabenthos in Barkley Canyon cold seep by internet operated vehicle (IOV). PLoS One 12:e0176917. doi: 10.1371/journal.pone.0176917

Duda, T. F., Morozov, A. K., Howe, B. M., Brown, M. G., Speer, K., Lazarevich, P., et al. (2006). Evaluation of a long-range joint acoustic navigation/thermometry system in Proceedings of the MTS/IEEE Oceans 2006 Conference, Massachusetts. $1-6$.

Duffy, E. J., and Stachowicz, J. J. (2006). Why biodiversity is important to oceanography: potential roles of genetic, species, and trophic diversity in pelagic ecosystem processes. Mar. Ecol. Progr. Ser. 311, 179-189. doi: 10.3354/ meps 311179

Durden, J. M., Lallier, L. E., Murphy, K., Jaeckel, A., Gjerde, K., and Jones, D. O. B. (2018). Environmental Impact Assessment process for deep-sea mining in 'the Area'. Mar. Policy 87, 194-202. doi: 10.1016/j.marpol.2017.10.013

Durden, J. M., Schoening, T., Althaus, F., Friedmann, A., Garcia, R., Glover, A., et al. (2016). Perspectives in visual imaging for marine biology and ecology: from acquisition to understanding. Oceanogr. Mar. Biol. Ann. Rev. 54, 1-72. doi: $10.1201 / 9781315368597-2$

Eide, I., and Westad, A. (2018). Automated multivariate analysis of multisensor data submitted online: real-time environmental monitoring. PLoS One 13:e0189443. doi: 10.1371/journal.pone.0189443

Ellis, J. I., Clark, M. R., Rouse, H. L., and Lamarche, G. (2017). Environmental management frameworks for offshore mining: the New Zealand approach. Mar. Policy 84, 178-192. doi: 10.1016/j.marpol.2017.07.004

European Marine Board. (2013). "Sustainable use of deep sea resources," in Navigating the Future IV. Position Paper 20 of the European Marine Board, ed. N. McDonough (Belgium: Ostend).

Favali, P., and Beranzoli, L. (2009). EMSO: European multidisciplinary seafloor observatory. Nucl. Instrum. Methods Phys. Res. A 602, 21-27. doi: 10.1016/j. nima.2008.12.214

Favali, P., Beranzoli, L., and De Santis, A. (2015). Seafloor Observatories: A new vision of the Earth from the Abyss. Switzerland: Springer-Praxis Publishing

Feely, R., Doney, S., and Cooley, S. (2009). Ocean acidification: present conditions and future changes in a high-CO2 world. Oceanography 22, 36-47. doi: 10.5670/ oceanog.2009.95

Feely, R. A., Sabine, C. L., Hernandez-Ayon, J. M., Ianson, D., and Hales, B. (2008). Evidence for upwelling of corrosive "acidified" water onto the continental shelf. Science 320, 1490-1492. doi: 10.1126/science.1155676

Fine, R. A. (2011). Observations of CFCs and SF6 as Ocean Tracers. Annu. Rev. Mar. Sci. 3, 173-119. doi: 10.1146/annurev.marine.010908.163933

Fregosi, S., Klinck, H., Horning, M., Costa, D. P., Mann, D., Sexton, K., et al. (2016). An animal-borne active acoustic tag for minimally invasive behavioral response studies on marine mammals. Animal Biotelem. 4, 1-15. doi: 10.1186/s40317016-0101-z

Friedrich, J., Janssen, F., Aleynik, D., Bange, H. W., Boltacheva, N., Çagatay, M. N., et al. (2014). Investigating hypoxia in aquatic environments: diverse approaches to addressing a complex phenomenon. Biogeosciences 11, 1215-1259. doi: 10 . 5194/bg-11-1215-2014

Gage, J. D., and Tyler, P. A. (1991). Deep-Sea Biology: a Natural History of Organisms at the Deep-Sea Floor. Cambridge: Cambridge University Press, 504.

Gallo, N. D., Cameron, J., Hardy, K., Fryer, P., Bartlett, D. H., and Levin, L. A. (2015). Submersible-and lander-observed community patterns in the Mariana and New Britain trenches: influence of productivity and depth on epibenthic 
and scavenging communities. Deep Sea Res. 99, 119-133. doi: 10.1016/j.dsr. 2014.12.012

Gamo, T., and Shitashima, K. (2018). Chemical characteristics of hadal waters in the Izu-Ogasawara Trench of the western Pacific Ocean. Proc. Jpn. Acad., Ser. B 94, 45-55. doi: 10.2183/pjab.94.004

Gass, S. E., and Roberts, J. M. (2006). The occurrence of the cold-water coral Lophelia pertusa (Scleractinia) on oil and gas platforms in the North Sea: colony growth, recruitment and environmental controls on distribution. Mar. Pollut. Bull. 52, 549-559. doi: 10.1016/j.marpolbul.2005.10.002

Gates, A. R., Benfield, M. C., Booth, D. J., Fowler, A. M., Skropeta, D., and Jones, D. O. B. (2017). Deep-sea observations at hydrocarbon drilling locations: Contributions from the SERPENT Project after 120 field visits. Deep Sea Res. Part II: Top. Stud. Oceanogr. 137, 463-479. doi: 10.1016/j.dsr2.2016. 07.011

Gilichinsky, D. (2002). "Permafrost model of extraterrestrial habitat" in Astrobiology, eds G. Horneck and C. Baumstark-Khan, (Berlin: SpringerVerlag), 125-142. doi: 10.1007/978-3-642-59381-9_9

Glenn, S., Schofield, O., Kohut, J. J., McDonnell, J., Ludescher, R., Seidel, D., et al. (2011). The trans-Atlantic Slocum glider expeditions: a catalyst for undergraduate participation in ocean science and technology. Mar. Technol. Soc. Journal 45, 52-67. doi: 10.4031/MTSJ.45.1.12

Glud, R. N. (2008). Oxygen dynamics of marine sediments. Mar. Biol. Res. 4, 243-289. doi: 10.1080/17451000801888726

Godø, O. R., Johnsen, S., and Torkelsen, T. (2014). The LoVe ocean observatory is in operation. Mar. Technol. Soc. J. 48, 24-30. doi: 10.4031/MTSJ.48.2.2

Gooday, A. J., Holzmann, M., Goineau, A., Pearce, R. B., Voltski, I., Weber, A., et al. (2017). Five new species and two new genera of xenophyophores (Foraminifera: Rhizaria) from part of the abyssal equatorial Pacific licensed for polymetallic nodule exploration. Zool. J. Linnean Soc. 183, 723-748. doi: 10.1093/zoolinnean/zlx093

Gould, W. J. (2005). From Swallow floats to Argo-The development of neutrally buoyant floats. Deep Sea Res. Part I 52, 529-543. doi: 10.1016/j.dsr2.2004.12.005

Grassle, J. F., and Stocks, K. (1999). A Global Ocean Biogeographic Information System (OBIS) for the Census of Marine Life. Oceanography 12, 12-14. doi: 10.5670/oceanog.1999.03

Griffies, S. M., Yin, J., Durack, P. J., Goddard, P., Bates, S. C., Behrens, E., et al. (2014). An assessment of global and regional sea level for years 1993-2007 in a suite of interannual CORE-II simulations. Ocean Model. 78, 35-89. doi: 10.1016/j.ocemod.2014.03.004

Harden-Davies, H. (2017). Deep-sea genetic resources: new frontiers for science and stewardship in areas beyond national jurisdiction. Deep Sea Res. Part II 137, 504-513. doi: 10.1016/j.dsr2.2016.05.005

Harrington, R., Anton, C., Dawson, T. P., de Bello, F., Feld, C. K., Haslett, J. R., et al. (2010). Ecosystem services and biodiversity conservation: concepts and a glossary. Biodivers. Conserv. 19, 2773-2790. doi: 10.1007/s10531-010-9834-9

Hartman, S. E., Hartman, M. C., Hydes, D. J., Jiang, Z. P., Smythe-Wright, D., and Gonzalez-Pola, C. (2014). Seasonal and inter-annual variability in nutrient supply in relation to mixing in the Bay of Biscay. Deep Sea Res. Part II 106, 68-75. doi: 10.1016/j.dsr2.2013.09.032

Hartman, S. E., Lampitt, R. S., Larkin, K. E., Pagnani, M., Campbell, J., Gkritzalis, T., et al. (2012). The Porcupine Abyssal Plain fixed-point sustained observatory (PAP-SO): variations and trends from the Northeast Atlantic fixed-point time series. ICES J. Mar. Sci. 69, 776-783. doi: 10.1093/icesjms/fss077

Hays, G. C., Bailey, H., Bograd, S. J., Bowen, W. D., Campagna, C., Carmichael, R. H., et al. (2019). Translating Marine Animal Tracking Data into Conservation Policy and Management. Trends Ecol. Evol. 34, 459-473. doi: 10.1016/j.tree.2019.01.009

Hedgpeth, J. W. (1957). Classification of marine environments. Geol. Soc. Am. Mem. 67, 17-28. doi: 10.1130/MEM67V1

Heesemann, M., Insua, T. L., Scherwath, M., Juniper, K. S., and Moran, K. (2014). Ocean networks Canada from geohazards research laboratories to smart ocean systems. Oceanography 27, 151-153. doi: 10.5670/oceanog.2014.50

Helm, K., Bindoff, N., and Church, J. (2011). Observed decreases in oxygen content of the global ocean. Geophys. Res. Lett. 38, L23602. doi: 10.1029/2011GL049513

Herring, P. (2002). The biology of the deep ocean. Oxford: Oxford University Press.

Higgs, N. D., Gates, A. R., and Jones, D. O. B. (2014). Fish food in the deep sea: revisiting the role of large food-falls. PLoS One 9:e96016. doi: 10.1371/journal. pone.0096016
Hoegh-Guldberg, O. (2015). Reviving the Ocean Economy: The Case for Action2015. Gland: WWF International.

Honjo, S., Eglinton, T. I., Taylor, C. D., Ulmer, K. M., Sievert, S. M., Bracher, A., et al. (2014). Understanding the role of the biological pump in the global carbon cycle: an imperative for ocean science. Oceanography 27, 10-16. doi: 10.5670/oceanog.2014.78

Horton, T., Gofas, S., Kroh, A., Poore, G. C. B., Read, G., Rosenberg, G., et al. (2017). Improving nomenclatural consistency: a decade of experience in the World Register of Marine Species. Eur. J. Taxon. 389, doi: 10.5852/ejt. 2017.389

Hoving, H. J. T., Zeidberg, L. D., Benfield, M. C., Bush, S. L., Robison, B. H., and Vecchione, M. (2013). First in situ observations of the deep-sea squid Grimalditeuthis bonplandi reveal unique use of tentacles. Proc. R. Soc. B Biol. Sci. 280:20131463. doi: 10.1098/rspb.2013.1463

Howe, B. M., Chao, Y., Arabshahi, P., Roy, S., McGinnis, T., and Gray, A. (2010). A smart sensor web for ocean observation: fixed and mobile platforms, integrated acoustics, satellites and predictive modeling. IEEE J. Sel. Top. Appl. Earth Obs. Remote Sens 3, 507-521. doi: 10.1109/JSTARS.2010.2052022 2010

Howe, B. M., and Workshop Participants (2015). From Space to the Deep Seafloor: Using SMART Submarine Cable Systems in the Ocean Observing System, Report of NASA Workshops, 9-10 October 2014, Pasadena, CA, and 26-28 May 2015, Honolulu, HI. SOEST Contribution 9549. Available at: www.soest.hawaii.edu/NASA_SMART_Cables/NASA_SMART_Cables_Work shop_Report_2015.pdf

Hughes, C. W., Williams, J., Blaker, A., Coward, A., and Stepanov, V. (2018). A window on the deep ocean: the special value of ocean bottom pressure for monitoring the large-scale, deep-ocean circulation. Prog. Oceanogr. 161, 19-46. doi: 10.1016/j.pocean.2018.01.011

Humborstad, O. B., Lokkeborg, S., Hareide, N. R., and Furevik, D. M. (2003). Catches of Greenland halibut (Reinhardtius hippoglossoides) in deep-water ghost-?shing gillnets on the Norwegian continental slope. Fish. Res. 64, 163-170. doi: 10.1016/S0165-7836(03)00215-217

Hussey, N. E., Kessel, S. T., Aarestrup, K., Cooke, S. J., Cowley, P. D., Fisk, A. T., et al. (2015). Aquatic animal telemetry: a panoramic window into the underwater world. Science 348, doi: 10.1126/science.1255642

Huvenne, V. A. I., Bett, B. J., Masson, D. G., Bas, T. P. L., and Wheeler, A. J. (2016). Effectiveness of a deep-sea cold-water coral Marine Protected Area, following eight years of fisheries closure. Biol. Conserv. 200, 60-69. doi: 10.1016/j.biocon. 2016.05.030

IOC (2018). Revised Roadmap for the UN Decade of Ocean Science for Sustainable Development. Paris: UNESCO

ISA (2012). Decision of the Council relating to an environmental management plan for the Clarion-Clipperton Zone, ISBA/18/C/22. Jamaica: International Seabed Authority.

Jamieson, A. J., Kilgallen, N. M., Rowden, A. A., Fujii, T., Horton, T., Lorz, A. N., et al. (2011). Bait-attending fauna of the Kermadec Trench. SW Pacific Ocean: evidence for an ecotone across the abyssal-hadal transition zone. Deep Sea Res. Part I 58, 49-62. doi: 10.1016/j.dsr.2010.11.003

Jamieson, A. J., Linley, T. D., and Craig, J. (2017). Baited camera survey of deep-sea demersal fishes of the West African oil provinces off Angola: 12002500m depth. East Atlantic Ocean. Mar. Env. Res. 129, 347-364. doi: 10.1016/j. marenvres.2017.05.009

Janssen, F., Treude, T., and Witte, U. (2000). Scavenger assemblages under differing trophic conditions: a case study in the deep Arabian Sea. Deep Sea Res. Part II 47, 2999-3026. doi: 10.1016/S0967-0645(00)00056-4

Johnson, G. C., Lyman, J. M., and Loeb, N. G. (2016). Improving estimates of Earth's energy imbalance. Nat. Clim. Change 6, 639-640. doi: 10.1038/nclimate3043

Jones, D. O., Kaiser, S., Sweetman, A. K., Smith, C. R., Menot, L., Vink, A., et al. (2017). Biological responses to disturbance from simulated deep-sea polymetallic nodule mining. PLoS One 12:e0171750. doi: 10.1371/journal.pone. 0171750

Jones, D. O. B., Gates, A. R., and Lausen, B. (2012). Recovery of deepwater megafaunal assemblages from hydrocarbon drilling disturbance in the Faroe-Shetland Channel. Mar. Ecol. Prog. Ser. 461, 71-82. doi: 10.3354/meps 09827

Jones, D. O. B., Walls, A., Clare, M., Fiske, M. S., Weiland, R. J., O'brien, R., et al. (2014). Asphalt mounds and associated biota on the Angolan margin. Deep Sea Res. Part I 94, 124-136. doi: 10.1016/j.dsr.2014.08.010 
Kajikawa, H., and Kobata, T. (2014). Reproducibility of calibration results by 0-A-0 pressurization procedures for hydraulic pressure transducers. Measure. Sci. and Technol. 25,

Kawagucci, S., Makabe, A., Kodama, T., Matsui, Y., Yoshikawa, C., Ono, E., et al. (2018). Hadal water biogeochemistry over the Izu-Ogasawara Trench observed with a full-depth CTD-CMS. Ocean, Sci. 14, 575-588. doi: 10.5194/os-14-5752018

Kawano, T., Aoyama, M., Joyce, T., Uchida, H., Takatsuki, Y., and Fukasawa, M. (2006). The latest batch-to-batch difference table of standard seawater and its application to the WOCE onetime sections. J. Oceanogr. 62, 777-792. doi: 10.1007/s10872-006-0097-8

Keeling, P. J., Burki, F., Wilcox, H. M., Allam, B., Allen, E. E., Amaral-Zettler, L. A., et al. (2014). The Marine Microbial Eukaryote Transcriptome Sequencing Project (MMETSP): illuminating the functional diversity of eukaryotic life in the oceans through transcriptome sequencing. PLoS Biol. 12:e1001889. doi: 10.1371/journal.pbio.1001889

Keeling, R. F., Körtzinger, A., and Gruber, N. (2010). Ocean deoxygenation in a warming world. Ann. Rev. Mar. Sci. 2, 199-299. doi: 10.1146/annurev.marine. 010908.163855

Keller, A. A., Ciannelli, L., Wakefield, W. W., Simon, V., Barth, J. A., and Pierce, S. D. (2015). Occurrence of demersal fishes in relation to near-bottom oxygen levels within the California Current large marine ecosystem. Fish. Oceanogr. 24, 162-176. doi: 10.1111/fog. 12100

Kelley, D. S., Delaney, J. R., and Cabled Array Team. (2016). NSF's Cabled Array: A wired tectonic plate and overlying ocean. Monterey, CA: IEEE.

Kimes, N. E., Callaghan, A. V., Aktas, D. F., Smith, W. L., Sunner, J., Golding, B. T., et al. (2013). Metagenomic analysis and metabolite profiling of deep-sea sediments from the Gulf of Mexico following the Deepwater Horizon oil spill. Front. Microbiol. 4:50. doi: 10.3389/fmicb.2013.00050

Klimant, I., Meyer, V., and Kuhl, M. (1995). Fiberoptic oxygen microsensors, a new tool in aquatic biology. Limnol. Oceanogr. 40, 1159-1165. doi: 10.4319/lo.1995. 40.6.1159

Klymak, J. M., Pinkel, R., and Rainville, L. (2008). Direct breaking of the internal tide near topography: kaena ridge, Hawaii. J. Phy. Oceanogr. 38, 380-399. doi: 10.1175/2007JPO3728.1

Konnecker, G. (2002). "Sponge Fields," in Offshore Directory. Review of a selection of habitats, communities and species of the North-East Atlantic, ed. cpsfnm cpefnmScpsfnm. Gubbaycpefnm (WWF-UK: North-East Atlantic Programme).

Kress, N., Homung, H., and Herut, B. (1998). Concentrations of Hg, Cd, Cu, Zn, $\mathrm{Fe}$ and $\mathrm{Mn}$ in deep sea benthic fauna from the Southeastern Mediterranean Sea: a comparison study between fauna collected at a pristine area and at two waste disposal sites. Mar. Pollut. Bull 36, 911-921. doi: 10.1016/S0025-326X(98) 00069-1

Kwasnitschka, T., Köser, K., Sticklus, J., Rothenbeck, M., Weiß, T., Wenzlaff, E., et al. (2016). Deepsurveycam-a deep ocean optical mapping system. Sensors 16:164. doi: 10.3390/s16020164

Lan, F., Demaree, B., Ahmed, N., and Abate, A. R. (2017). Single-cell genome sequencing at ultra-high-throughput with microfluidic droplet barcoding. Nat. Biotechnol. 35, 640-646. doi: 10.1038/nbt.3880

Lejzerowicz, F., Esling, P., and Pawlowski, J. (2014). Patchiness of deep-sea benthic Foraminifera across the Southern Ocean: insights from high-throughput DNA sequencing. Deep-Sea Res. Part II 108, 17-27. doi: 10.1016/j.dsr2.2014. 07.018

Levin, L. A. (2018). Manifestation, drivers, and emergence of open ocean deoxygenation. Annu. Rev. Mar. Sci. 10, 229-260. doi: 10.1146/annurevmarine-121916-163359

Levin, L. A., and Le Bris, N. (2015). The deep ocean under climate change. Science 350, 766-768. doi: 10.1126/science.aad0126

Levin, L. A., Mengerink, K., Gjerde, K. M., Rowden, A. A., Van Dover, C. L., Clark, M. R., et al. (2016). Defining "serious harm" to the marine environment in the context of deep-seabed mining. Mar. Policy 74, 245-259. doi: 10.1016/j.marpol. 2016.09.032

Levin, L. A., and Sibuet, M. (2012). Understanding continental margin biodiversity: a new imperative. Ann. Rev. Mar. Sci. 4, 79-112. doi: 10.1146/annurev-marine120709-142714

Levitus, S., Antonov, J. I., Boyer, T. P., Baranova, O. K., Garcia, H. E., and Locarnini, R. A. (2012). World ocean heat content and thermosteric sea level change (0-2000 m), 1955-2010. Geophys. Res. Lett. 39:L10603. doi: 10.1029/ 2012GL051106

Lim, S. C., Wiklund, H., Glover, A. G., Dahlgren, T. G., and Tan, K. S. (2017). A new genus and species of abyssal sponge commonly encrusting polymetallic nodules in the Clarion-Clipperton Zone. East Pacific Ocean. Syst. Biodivers. 15, 507-519. doi: 10.1080/14772000.2017.1358218

Lima-Mendez, G., Faust, K., Henry, N., Decelle, J., Colin, S., Carcillo, F., et al. (2015). Determinants of community structure in the global plankton interactome. Science 348:1262073. doi: 10.1126/science.1262073

Lindh, M. V., Maillot, B. M., Shulse, C. N., Gooday, A. J., Amon, D. J., Smith, C. R., et al. (2017). From the surface to the deep-sea: bacterial distributions across polymetallic nodule fields in the clarion-clipperton zone of the Pacific Ocean. Front. Microbiol. 8:1696. doi: 10.3389/fmicb.2017.01696

Lindsey, N. J., Martin, E. R., Dreger, D. S., Freifeld, B., Cole, S., James, S. R., et al. (2017). Fiber-optic network observations of earthquake wave?elds. Geophy. Res. Lett., 44 11:799. doi: 10.1002/2017GL075722

Lindstrom, E. J., Gunn, A., Fischer, A., and McCurdy, L. K. (2012). A Framework for Ocean Observing. By the Task Team for an Integrated Framework for Sustained Ocean Observing, Paris: UNESCO

Liu, M., Fan, L., Zhong, L., Kjelleberg, S., and Thomas, T. (2012). Metaproteogenomic analysis of a community of sponge symbionts. ISME J. 6, 1515-1525. doi: 10.1038/ismej.2012.1

Lodge, M., Johnson, D., Le Gurun, G., Wengler, M., Weaver, P., and Gunn, V. (2014). Seabed mining: international Seabed Authority environmental management plan for the Clarion-Clipperton Zone. A partnership approach. Mar. Policy 49, 66-72. doi: 10.1016/j.marpol.2014.04.006

Lohmann, K., Jungclaus, J. H., Matei, D., Mignot, J., Menary, M., Langehaug, H. R., et al. (2014). The role of subpolar deep-water formation and Nordic Seas overflows in simulated multidecadal variability of the Atlantic meridional overturning circulation. Ocean. Sci. 10, 227-241. doi: 10.5194/os-10-227-2014

Lozier, M. S., Li, F., Bacon, S., Bahr, F., Bower, A. S., Cunningham, S. A., et al. (2019). A sea change in our view of overturning in the subpolar North Atlantic. Science 363, 516-521. doi: 10.1126/science.aau6592

Macaulay, I. C., Ponting, C. P., and Voet, T. (2017). Single-Cell multiomics: multiple measurements from single cells. Trends Genet. 33, 155-168. doi: 10. 1016/j.tig.2016.12.003

MacKinnon, J. A., Zhao, Z., Whalen, C. B., Waterhouse, A. F., Trossman, D. S., Sun, O. M., et al. (2017). Climate Process Team on Internal Wave-Driven Ocean Mixing. Bull. Am. Meteorol. Soc. 98, 2429-2454. doi: 10.1175/BAMS-D-160030.1

Macreadie, P. I., McLean, D. L., Thomson, P. G., Partridge, J. C., Jones, D. O., Gates, A. R., et al. (2018). Eyes in the sea: unlocking the mysteries of the ocean using industrial, remotely operated vehicles (ROVs). Sci. Total Environ. 634, 1077-1091. doi: 10.1016/j.scitotenv.2018.04.049

Marra, G., Clivati, C., Luckett, R., Tampellini, A., Kronjäger, J., Wright, L., et al. (2018). Ultrastable laser interferometry for earthquake detection with terrestrial and submarine cables. Science 361, 486-490. doi: 10.1126/science.aat4458

Mashayek, A., Ferrari, R., Vettoretti, G., and Peltier, W. R. (2013). The role of the geothermal heat flux in driving the abyssal ocean circulation. Geophys. Res. Lett. 40, 3144-3149. doi: 10.1002/grl.50640

Mason, O. U., Hazen, T. C., Borglin, S., Chain, P. S. G., Dubinsky, E. A., Fortney, J. L., et al. (2012). Metagenome, metatranscriptome and single-cell sequencing reveal microbial response to Deepwater Horizon oil spill. ISME J. 6, 1715-1727. doi: 10.1038 /ismej.2012.59

Mayer, L., Jakobsson, M., Allen, G., Dorschel, B., Falconer, R., Ferrini, V., et al. (2018). The Nippon Foundation-GEBCO Seabed 2030 Project: the quest to see the world's oceans completely mapped by 2030. Geosciences 8:63. doi: 10 . 3390/geosciences 8020063

McLean, D. L., Partridge, J. C., Bond, T., Birt, M. J., Bornt, K. R., and Langlois, T. J. (2017). Using industry ROV videos to assess fish associations with subsea pipelines. Cont. Shelf Res. 141, 76-97. doi: 10.1016/j.csr.2017.05.006

McQuillan, J. S., and Robidart, J. C. (2017). Molecular-biological sensing in aquatic environments: recent developments and emerging capabilities. Curr. Opin. Biotechnol. 45, 43-50. doi: 10.1016/j.copbio.2016.11.022

Melet, A., Legg, S., and Hallberg, R. (2016). Climatic impacts of parameterized local and remote tidal mixing. J. Clim. 29, 3473-3500. doi: 10.1175/JCLI-D-150153.1

Mellersh, H. E. L. (1968). FitzRoy of the Beagle. London: Rupert Hart-Davis. 
Mengerink, K. J., Van Dover, C. L., Ardron, J., Baker, M. C., Escobar-Briones, E., Gjerde, K., et al. (2014). A call for deep-ocean stewardship. Science 344, 696-698. doi: 10.1126/science. 1251458

Metfies, K., Schroeder, F., Hessel, J., Wollschlager, J., Micheller, S., Wolf, C., et al. (2016). High-resolution monitoring of marine protists based on an observation strategy integrating automated on-board filtration and molecular analyses. Ocean Sci. 12, 1237-1247. doi: 10.5194/os-12-1237-2016

Mikhalevsky, P. N., Sagen, H., Worcester, P. F., Baggeroer, A. B., Orcutt, J., Moore, S. E., et al. (2015). Multipurpose acoustic networks in the integrated arctic ocean observing system. Arctic 68, 1-17. doi: 10.14430/arctic4449

Miller, K. A., Thompson, K. F., Johnston, P., and Santillo, D. (2018). An Overview of Seabed Mining Including the Current State of Development. Environmental Impacts, and Knowledge Gaps. Front. Mar. Sci. 4:418. doi: 10.3389/fmars.2017. 00418

Miloslavich, P., Bax, N. J., Simmons, S. E., Klein, E., Appeltans, W., AburtoOropeza, O., et al. (2018). Essential ocean variables for global sustained observations of biodiversity and ecosystem changes. Global Change Biol. 24, 2416-2433. doi: 10.1111/gcb.14108

Montagna, P. A., Baguley, J. G., Cooksey, C., Hartwell, I., Hyde, L. J., Hyland, J. L., et al. (2013). Deep-sea benthic footprint of the Deepwater Horizon blowout. PLoS One 8:e70540. doi: 10.1371/journal.pone.0070540

Moorhouse, P. (2015). A Modern History of the Manned Submersible. Mar. Technol. Soc. J. 49, 65-78. doi: 10.4031/MTSJ.49.6.9

Moran, M. A., Kujawinski, E. B., Stubbins, A., Fatland, R., Aluwihare, L. I., Buchan, A., et al. (2016). Deciphering ocean carbon in a changing world. Proc. Natl. Acad. Sci. U.S.A. 113, 3143-3151. doi: 10.1073/pnas.1514645113

Morato, T., Lemey, E., Menezes, G., Pham, C. K., Brito, J., Soszynski, A., et al. (2016). Food-web and ecosystem structure of the open-ocean and deep-sea environments of the Azores. NE Atlantic. Front. Mar. Sci. 3:245. doi: 10.3389/ fmars.2016.00245

Morris, K. J., Bett, B. J., Durden, J. M., Benoist, N. M. A., Huvenne, V. A. I., and Jones, D. O. B. (2016). Landscape-scale spatial heterogeneity in phytodetrital cover and megafauna biomass in the abyss links to modest topographic variation. Nat. Scient. Rep. 6:34080. doi: 10.1038/srep34080

Morris, K. J., Bett, B. J., Durden, J. M., Huvenne, V. A. I., Milligan, R., Jones, D. O. B., et al. (2014). A new method for ecological surveying of the abyss using autonomous underwater vehicle photography. Limnol. Oceanogr. Methods 12, 795-809. doi: 10.4319/lom.2014.12.795

Muller-Karger, F. E., Kavanaugh, M. T., Montes, E., Balch, W. M., Breitbart, M., Chavez, F. P., et al. (2014). A framework for a marine biodiversity observing network within changing continental shelf seascapes. Oceanography 27, 18-23. doi: 10.5670/oceanog.2014.56

Muller-Karger, F. E., Miloslavich, P., Bax, N. J., Simmons, S., Costello, M. J., Sousa Pinto, I., et al. (2018). Advancing Marine Biological Observations and Data Requirements of the Complementary Essential Ocean Variables (EOVs) and Essential Biodiversity Variables (EBVs) Frameworks. Front. Mar. Sci.

Muller-Karger, F. E., Varela, R., Thunell, R., Luerssen, R., Hu, C., and Walsh, J. J. (2005). The importance of continental margins in the global carbon cycle. Geophy. Res. Lett. 32, L01602. doi: 10.1029/2004GL021346

Muto, H., Takaki, Y., Hirai, M., Mino, S., Sawayama, S., Takai, K., et al. (2017). A Simple and Efficient RNA Extraction Method from Deep-Sea Hydrothermal Vent Chimney Structures. Microbes Environ. 32, 330-335. doi: 10.1264/jsme2. ME17048

National Research Council (1990). The Role of Monitoring in Environmental Management, Managing Troubled Waters: The Role of Marine Environmental Monitoring. Washington D. C: National Academy Press.

Naveira Garabato, A. C. (2012). A perspective on the future of physical oceanography. Phil. Trans. R.108 Soc. A. 370, 5480-5511. doi: 10.1098/rsta.2012. 0400

Netto, S. A., Fonseca, G., and Gallucci, F. (2010). Effects of drill cuttings discharge on meiofauna communities of a shelf break site in the southeast Atlantic. Environ Monit. Asses. 167, 49-63. doi: 10.1007/s10661-010-1515-3

Nguyen, A., Ocaña, V., Garg, V., Heimbach, P., Toole, J., Krishfield, R., et al. (2017). On the Benefit of Current and Future ALPS Data for Improving Arctic Coupled Ocean-Sea Ice State Estimation. Oceanography 30, 69-73. doi: 10.5670/oceanog. 2017.223

Nishi, E., and Rouse, G. W. (2014). First whale fall chaetopterid; a gigantic new species of Phyllochaetopterus (Chaetopteridae: Annelida) from the deep sea off
California. Proc. Biol. Soc. Wash. 126, 287-298. doi: 10.2988/0006-324X-126.4 287

Normark, W. R., Morton, J. L., and Ross, S. L. (1987). Submersible observations along the Southern Juan de Fuca Ridge: 1984 Alvin Programs. J. Geophys. Res 92, 11283-11290. doi: 10.1029/JB092iB11p11283

Nunoura, T., Nishizawa, M., Hirai, M., Shimamura, S., Harnvoravongchai, P., Koide, O., et al. (2018). Microbial Diversity in Sediments from the Bottom of the Challenger Deep, the Mariana Trench. Microbes Environ. 33, 186-194. doi: 10.1264/jsme2.ME17194

Nunoura, T., Takaki, Y., Hirai, M., Shimamura, S., Makabe, A., Koide, O., et al. (2015). Hadal biosphere: insight into the microbial ecosystem in the deepest ocean on Earth. Proc. Natl. Acad. Sci. U.S.A. 112, E1230-E1236. doi: 10.1073/ pnas.1421816112

OECD (2016). The Ocean Economy in 2030. Paris: OECD Publishing.

Osterloff, J., Nilssen, I., and Nattkemper, T. W. (2016). "Computational coral feature monitoring for the fixed underwater observatory LoVe" in Proceedings of IEEE OCEANS. Monterey CA: IEEE Oceans

Pawlowski, J., Christen, R., Lecroq, B., Bachar, D., Shahbazkia, H. R., AmaralZettler, L., et al. (2011). Eukaryotic richness in the abyss: insights from pyrotag sequencing. PLoS One 6:e18169. doi: 10.1371/journal.pone.0018169

Petersen, W. (2014). FerryBox systems: state-of-the-art in Europe and future development. J. Mar. Syst. 140, 4-12. doi: 10.1016/j.jmarsys.2014.07.003

Peukert, A., Schoening, T., Alevizos, E., Köser, K., Kwasnitschka, T., and Greinert, J. (2018). Understanding Mn-nodule distribution and evaluation of related deep-sea mining impacts using AUV-based hydroacoustic and optical data. Biogeosciences 15, 2525-2549. doi: 10.5194/bg-15-2525-2018

Piecuch, C. G., Heimbach, P., Ponte, R. M., and Forget, G. (2015). Sensitivity of contemporary sea level trends in a global ocean state estimate to effects of geothermal fluxes. Ocean Model. 96, 214-220. doi: 10.1016/j.ocemod.2015.10. 008

Ponte, R. M. (2012). An assessment of deep steric height variability over the global ocean. Geophys. Res. Lett. 39, L04601. doi: 10.1029/2011GL050681

Posamentier, H. W., and Kolla, V. (2003). Seismic geomorphology and stratigraphy of depositional elements in deep-water settings. J. Sediment. Res. 73, 367-388. doi: $10.1306 / 111302730367$

Purser, A. (2015). A Time Series Study of Lophelia pertusa and Reef Megafauna Responses to Drill Cuttings Exposure on the Norwegian Margin. PLoS One 10:e0134076. doi: 10.1371/journal.pone.0134076

Purser, A., Thomsen, L., Barnes, C., Best, M., Chapman, R., Hofbauer, M., et al. (2013). Temporal and spatial benthic data collection via an internet operated deep sea crawler. Methods Oceanogr. 5, 1-18. doi: 10.1016/j.mio.2013.07.001

Ramirez-Llodra, E., De Mol, B., Company, J. B., Coll, M., and Sarda, F. (2013). Effects of natural and anthropogenic processes in the distribution of marine litter in the deep Mediterranean Sea. Prog. Oceanogr. 118, 273-287. doi: 10. 1016/j.pocean.2013.07.027

Ramirez-Llodra, E., Tyler, P. A., Baker, M. C., Bergstad, O. A., Clark, M. R., Escobar, E., et al. (2011). Man and the last great wilderness: human impact on the deep sea. PLoS One 6:e22588. doi: 10.1371/journal.pone.0022588

Ramondenc, S., Goutx, M., Lombard, F., Santinelli, C., Stemmann, L., Gorsky, G., et al. (2016). An initial carbon export assessment in the Mediterranean Sea based on drifting sediment traps and the Underwater Vision Profiler data sets. Deep-Sea Res. part I 117, 107-119. doi: 10.1016/j.dsr.2016. 08.015

Ray, R. D. (2013). Precise comparisons of bottom-pressure and altimetric ocean tides. J. Geophys. Res. Oceans 118, 4570-4584. doi: 10.1002/jgrc.20336

Rex, M. A., and Etter, R. J. (2010). Deep-sea biodiversity: Pattern and scale. Cambridge: Harvard University Press.

Rice, D. D., and Claypool, G. E. (1981). Generation, accumulation and resource potential of biogenic gas. Am. Assoc. Pet. Geol. Bull. 65, 5-25.

Robert, K., Jones, D. O. B., Roberts, M. J., and Huvenne, V. A. J. (2016). Improving predictive mapping of deep-water habitats: considering multiple model outputs and ensemble techniques. Deep Sea Res. I 113, 80-89. doi: 10.1016/j.dsr.2016. 04.008

Roberts, C. M. (2002). Deep impact: the rising toll of fishing in the deep sea. Trends Ecol. Evol. 17, 242-245. doi: 10.1016/S0169-5347(02)02492-8

Roberts, J. M., Wheeler, A. J., and Freiwald, A. (2006). Reefs of the deep: the biology and geology of cold-water coral ecosystems. Science 312, 543-547. doi: $10.1126 /$ science. 1119861 
Robidart, J. C., Shilova, I. N., and Zehr, J. P. (2012). “Omics”-Enabled Microbial Sensors on Ocean Platforms. In Molecular Biological Technologies for Ocean Sensing. Totowa, NJ: Humana Press, 1-32.

Roe, H. S. J., and Shale, D. M. (1979). A new multiple rectangular midwater trawl (RMT $1+8 \mathrm{M}$ ) and some modifications to the Institute of Oceanographic Sciences' RMT 1+8. Mar. Biol. 50, 283-288. doi: 10.1007/BF0039 4210

Roquet, F., Boehme, L., Fedak, M. A., Block, B., Charrassin, J.-B., Costa, D., et al. (2017). ocean observations using tagged animals. Oceanography 30, 139. doi: 10.5670/oceanog.2017.235

Rudnick, D. L., Davis, R. E., Eriksen, C. C., Fratantoni, D. M., and Perry, M. J. (2004). Underwater Gliders for Ocean Research. Mar. Technol. Soc. 38, 73-84. doi: $10.4031 / 002533204787522703$

Ruhl, H. A., Andre, M., Beranzoli, L., Cagatay, M. N., Colaco, A., Cannat, M., et al. (2011). Societal need for improved understanding of climate change, anthropogenic impacts, and geo-hazard warning drive development of ocean observatories in European Seas. Prog. Oceanogr. 91, 1-33. doi: 10.1016/j.pocean. 2011.05.001

Sanders, J. G., Beinart, R. A., Stewart, F. J., Delong, E. F., and Girguis, P. R. (2013). Metatranscriptomics reveal differences in in situ energy and nitrogen metabolism among hydrothermal vent snail symbionts. ISME J. 7, 1556-1567. doi: 10.1038/ismej.2013.45

Sarmiento, J. L., Hughes, T. M. C., Stougger, R. J., and Syukuro, M. (1998). Simulated response of the ocean carbon cycle to anthropogenic climate warming. Nature 393, 245-249. doi: 10.1038/30455

Sasagawa, G., and Zumberge, M. A. (2013). A self-calibrating pressure recorder for detecting seafloor height change. IEEE J. Ocean Eng. 38, 447-454. doi: 10.1109/JOE.2012.2233312

Schlining, K., von Thun, S., Kuhnz, L., Schlining, B., Lundsten, L., Stout, N. J., et al. (2013). Debris in the deep: using a 22 -year video annotation database to survey marine litter in Monterey Canyon, central California. USA. Deep-Sea Res. Part I-Oceanogr. Res. Papers 79, 96-105. doi: 10.1016/j.dsr.2013.05.006

Schofield, O., Ducklow, H. W., Martinson, D. G., Meredith, M. P., Moline, M. A., and Fraser, W. R. (2010). How Do Polar Marine Ecosystems Respond to Rapid Climate Change? Science 328, 1520-1523. doi: 10.1126/science.1185779

Schulte, M., Blake, D., Hoehler, T., and McCollom, T. (2006). Serpentinization and Its Implications for Life on the Early Earth and Mars. Astrobiology 6, 364-376. doi: 10.1089/ast.2006.6.364

Schulz, J., Barz, K., Ayon, P., Lüdtke, A., Zielinski, O., Mengedoht, D., et al. (2010). Imaging of plankton specimens with the lightframe on-sight keyspecies investigation (LOKI) system. J. Eur. Opt. Soc. 5:10017. doi: 10.2971/jeos.2010. $10017 \mathrm{~s}$

Shaikh, S. F., Mazo-Mantilla, H. F., Qaiser, N., Khan, S. M., Nassar, J. M., Geraldi, N. R., et al. (2019). Noninvasive featherlight wearable compliant "marine skin": standalone multisensory system for deep-sea environmental monitoring. Small 15:1804385. doi: $10.1002 /$ smll.201804385

Silvano, A., Rintoul, S. R., Peña-Molino, B., Hobbs, W. R., van Wijk, E., Aoki, S., et al. (2018). Freshening by glacial meltwater enhances melting of ice shelves and reduces formation of Antarctic Bottom Water. Sci. Adv. 4, eaa9467. doi: 10.1126/sciadv.aap9467

Sinniger, F., Pawlowski, J., Harii, S., Gooday, A. J., Yamamoto, H., Chevaldonné, P., et al. (2016). Worldwide Analysis of Sedimentary DNA Reveals Major Gaps in Taxonomic Knowledge of Deep-Sea Benthos. Front. Mar. Sci. 3:92. doi: $10.3389 /$ fmars.2016.00092

Smith, K. L., Sherman, A. D., Huffard, C. L., McGill, P. R., Henthorn, R., Von Thun, S., et al. (2014). Large salp bloom export from the upper ocean and benthic community response in the abyssal northeast Pacific: day to week resolution. Limnol. Oceanogr. 59, 745-757. doi: 10.4319/lo.2014.59.3.0745

Smith, M. B., Rocha, A. M., Smillie, C. S., Olesen, S. W., Paradis, C., Wu, L., et al. (2015). Natural bacterial communities serve as quantitative geochemical biosensors. MBio 6, e326-e315. doi: 10.1128/mBio.00326-15

Smith, K. L., Ruhl, H. A., Bett, B. J., Lampitt, D. S. M., and Kaufmann, R. S. Jr. (2009). Climate, carbon cycling, and deep-ocean ecosystems. Proc. Natl. Acad. Sci. USA 106, 19211-19218. doi: 10.1073/pnas.0908322106

Smith, K. L., Sherman, A. D., McGill, P. R., Henthorn, R. G., Ferreira, J., and Huffard, C. L. Jr. (2017). Evolution of monitoring an abyssal time- series station in the northeast Pacific over 28 years. Oceanography 30, 72-81. doi: 10.5670/ oceanog. 2017.425
Snelgrove, P. V. R., Thrush, S. F., Wall, D. H., and Norkko, A. (2014). Real world biodiversity-ecosystem functioning: a seafloor perspective. Trends Ecol. Evol. 29, 398-405. doi: 10.1016/j.tree.2014.05.002

Snow, K., Hogg, A. M., Downes, S. M., Sloyan, B. M., Bates, M. L., and Griffies, S. M. (2015). Sensitivity of abyssal water masses to overflow parameterisations. Ocean Modell. 89C, 84-103. doi: 10.1016/j.ocemod.2015.03.004

Snow, K., Hogg, A. M., Sloyan, B. M., and Downes, S. M. (2016). Sensitivity of Antarctic Bottom Water to Changes in Surface Buoyancy Fluxes. Climate J. 29, 313-330. doi: 10.1175/JCLI-D-15-0467.1

Stephens, G. L., Li, J., Wild, M., Clayson, C. A., Loeb, N., Kato, S., et al. (2012). An update on Earth's energy balance in light of the latest global observations. Nat. Geosci. 5, 691-696. doi: 10.1038/ngeo1580

Stramma, L., Johnson, G. C., Sprintall, J., and Mohrholz, V. (2008). Expanding oxygen-minimum zones in the tropical oceans. Science 320, 655-658. doi: 10. 1126/science.1153847

Suberg, L., Wynn, R. B., Van Der Kooij, J., Fernand, L., Fielding, S., Guihen, D., et al. (2014). Assessing the potential of autonomous submarine gliders for ecosystem monitoring across multiple trophic levels (plankton to cetaceans) and pollutants in shallow shelf seas. Methods Oceanogr. 10, 70-89. doi: 10.1016/ j.mio.2014.06.002

Sweetman, A. K., Thurber, A. R., Smith, C. R., Levin, L. A., Mora, C., Wei, C. L., et al. (2017). Major impacts of climate change on deep-sea benthic ecosystems. Elementa

Taira, K., Yanagimoto, D., and Kitagawa, S. (2005). Deep CTD casts in the Challenger Deep. Mariana Trench. J. Oceanogr. 61, 447-454. doi: 10.1007/ s10872-005-0053-z

Talley, L. D., Feely, R. A., Sloyan, B. M., Wanninkhof, R., Baringer, M. O., Bullister, J. L., et al. (2016). Changes in ocean heat, carbon content, and ventilation: a review of the first decade of GO-SHIP global repeat hydrography. Ann. Rev. Mar. Sci. 8, 185-215. doi: 10.1146/annurev-marine-052915100829

Taylor, J. R., DeVogelaere, A. P., Burton, E. J., Frey, O., Lundsten, L., Kuhnz, L. A., et al. (2014). Deep-sea faunal communities associated with a lost intermodal shipping container in the Monterey Bay National Marine Sanctuary. CA. Mar. Pollut. Bull. 83, 92-106. doi: 10.1016/j.marpolbul.2014.04.014

Taylor, M. L., Gwinnett, C., Robinson, L. F., and Woodall, L. C. (2016). Plastic microfibre ingestion by deep-sea organisms. Sci. Rep. 6:33997. doi: 10.1038/ srep33997

Thomson, J. A., and Heithaus, M. R. (2014). Animal-borne video reveals seasonal activity patterns of green sea turtles and the importance of accounting for capture stress in short-term biologging. J. Exp. Mar Biol. Ecol. 450, 15-20. doi: 10.1016/j.jembe.2013.10.020

Thornton, B., Bodenmann, A., Pizarro, O., Williams, S. B., Friedman, A., Nakajima, R., et al. (2016). Biometric assessment of deep-sea vent megabenthic communities using multi-resolution 3D image reconstructions. Deep Sea Res Part I 116, 200-219. doi: 10.1016/j.dsr.2016.08.009

Thurber, A. R., Sweetman, A. K., Narayanaswamy, B. E., Jones, D. O. B., Ingels, J., and Hansman, L. R. (2014). Ecosystem function and services provided by the deep sea. Biogeosciences 11, 3941-3963. doi: 10.5194/bg-11-3941-2014

Treasure, A., Roquet, F., Ansorge, J. I, Bester, M., and Boehme, L. (2017). Marine mammals exploring the oceans pole to pole: a review of the MEOP consortium. Oceanography 30, 132-138. doi: 10.5670/oceanog.2017.234

Tyler, P. A. (ed.) (2003). Ecosystems of the Deep Ocean. Amsterdam: Elsevier Science.

Uchida, H., Kawano, T., Aoyama, M., and Murata, A. (2011). Absolute salinity measurements of standard seawaters for conductivity and nutrients. La Mer 49, 237-244.

Uchida, H., Maeda, Y., and Kawamata, S. (2018). Compact underwater slip ring swivel. Minimizing effect of CTD package rotation on data quality. Sea Technol. $59,30-32$.

Uchida, H., Nakano, T., Tamba, J., Widiatmo, J. V., Yamazawa, K., Ozawa, S., et al. (2015). Deep ocean temperature measurement with an uncertainty of $0.7 \mathrm{mK}$. J. Atmos. Oceanic Technol. 32, 2199-2210. doi: 10.1175/JTECH-D-15-0013.1

UNCLOS (1982). United National Convention on the Law of the Sea. Part IX. Montego Bay: UNCLOS.

Underwood, A. J. (1992). Beyond BACI - the Detection of Environmental Impacts on Populations in the Real, but Variable. World. J. Exp. Mar. Biol. Ecol. 161, 145-178. doi: 10.1016/0022-0981(92)90094-q 
Ussler, W., Preston, C., Tavormina, P., Pargett, D., Jensen, S., Roman, B., et al. III. (2013). Autonomous application of quantitative PCR in the deep sea: in situ Surveys of Aerobic Methanotrophs using the deep-sea environmental sample processor. Environ. Sci. Technol. 47, 9339-9346. doi: 10.1021/es4023199

Van Cauwenberghe, L., Vanreusel, A., Maes, J., and Janssen, C. R. (2013). Microplastic pollution in deep sea sediments. Environ. Pollut. 182, 495-499. doi: 10.1016/j.envpol.2013.08.013

van der Wielen, P. W. J. J., Bolhuis, H., Borin, S., Daffonchio, D., Corselli, C., Giuliano, L., et al. (2005). The Enigma of Prokaryotic Life in Deep Hypersaline Anoxic Basins. Science 307, 121-123. doi: 10.1126/science.1103569

van Haren, H., Berndt, C., and Klaucke, I. (2017). Ocean mixing in deep-sea trenches: new insights from the Challenger Deep. Mariana Trench. Deep-Sea Res. Part I 129, 1-9. doi: 10.1016/j.dsr.2017.09.003

Vanreusel, A., Hilario, A., Ribeiro, P. A., Menot, L., and Arbizu, P. M. (2016). Threatened by mining, polymetallic nodules are required to preserve abyssal epifauna. Sci. Rep. 6:26808. doi: 10.1038/srep26808

Vardaro, M. F., Bagley, P. M., Bailey, D. M., Bett, B. J., Jones, D. O., Milligan, R. J., et al. (2013). A southeast atlantic deep-ocean observatory: first experiences and results. Limnol. Oceanogr. Methods 11, 304-315. doi: 10.4319/lom.2013.11.304

Vilanova, C., and Porcar, M. (2016). Are multi-omics enough? Nat. Microbiol. 1:16101. doi: $10.1038 /$ nmicrobiol.2016.101

Visbeck, M. (2018). Ocean science research is key for a sustainable future. Nat. Commun. 9:690. doi: 10.1038/s41467-018-03158-3

Wang, X., and Müller, W. (2009). Marine biominerals: perspectives and challenges for polymetallic nodules and crusts. Trends Biotechnol. 27, 375-383. doi: 10 . 1016/j.tibtech.2009.03.004

Wang, Z. A., Liu, X., Byrne, R. H., Wanninkhof, R., Bernsteina, R. E., Kaltenbachera, E. A., et al. (2007). Simultaneous spectrophotometric flowthrough measurements of $\mathrm{pH}$, carbon dioxide fugacity, and total inorganic carbon in seawater. Anal. Chim. Acta 596, 23-36. doi: 10.1016/j.aca.2007. 05.048

Watson, R. A., and Morato, T. (2013). Fishing down the deep: accounting for within-species changes in depth of fishing. Fish. Res. 140, 63-65. doi: 10.1016/j. fishres.2012.12.004

Welsford, D. C., Ewing, G. P., Constable, A., Hibberd, T., and Kilpatrick, R. (2014). Demersal fishing interactions with marine benthos in the Australian EEZ of the Southern Ocean: An Assessment of the vulnerability of benthic habitats to impact by demersal gears. Australia: Australian Antarctic Division and the Fisheries Research and Development Corporation.

White, H. K., Hsing, P.-Y., Cho, W., Shank, T. M., Cordes, E. E., Quattrini, A. M., et al. (2012). Deepwater Horizon spill impacts deepwater corals. Proc. Natl. Acad. Sci. U.S.A 109, 20303-20308. doi: 10.1073/pnas.1118029109

Wilcock, W. S. D., Manalang, D. A., Harrington, M., et al. (2018). New Approaches to In Situ Calibration for Seafloor Geodetic Measurements. 2018 OCEANS -
MTS/IEEE Kobe Techno-Oceans (OTO). Piscataway, NJ. : IEEE Operations Center, doi: 10.1109/OCEANSKOBE.2018.8559178

Wilkinson, M. D., Dumontier, M., Aalbersberg, I. J. J., Appleton, G., Axton, M., Baak, A., et al. (2016). The FAIR guiding principles for scientific data management and stewardship. Sci. Data 3:160018. doi: 10.1038/sdata.2016.18

Williams, J., Hughes, C. W., and Tamisiea, M. E. (2015). Detecting trends in bottom pressure measured using a tall mooring and altimetry. J. Geophys. Res. Oceans 120, 5216-5232. doi: 10.1002/2015JC010955

Woodall, L., Andradi-brown, D., Brierley, A., Clark, M., Connelly, D., Hall, R., et al. (2018). A multidisciplinary approach for generating globally consistent data on mesophotic, deep-pelagic, and bathyal biological communities. Oceanography 31, doi: 10.5670/oceanog.2018.301

Wright, G., Rochette, J., Gjerde, K. M., and Levin, L. A. (2018). Protect the neglected half of our blue planet. Nature 554, 163-165. doi: 10.1038/d41586018-01594-1

Wunsch, C. (2016). Global ocean integrals and means, with trend implications. Ann. Rev. Mar. Sci. 8, 1-33. doi: 10.1146/annurev-marine-122414-034040

Wunsch, C., and Ferrari, R. (2004). Vertical mixing, energy, and the general circulation of the oceans. Ann. Rev. Fluid Mech. 36, 281-314. doi: 10.1146/ annurev.fluid.36.050802.122121

Wynn, R. B., Huvenne, V. A. I., Le Bas, T. P., Murton, B. J., Connelly, D. P., Bett, B. J., et al. (2014). Autonomous underwater vehicles (AUVs): their past, present and future contributions to the advancement of marine geoscience. Mar. Geol. 352, 451-468. doi: 10.1016/j.margeo.2014.03.012

Xu, G., Jackson, D., Bemis, K. G., and Ivakin, A. (2017). Long-term, quantitative observations of seafloor hydrothermal venting using an imaging sonar. J. Acoust. Soc. Am. 142, 2504-2504. doi: 10.1121/1.5014145

You, Y. (2010). Harnessing telecoms cables for science. Nature 466, 690-691. doi: $10.1038 / 466690$ a

Conflict of Interest Statement: The authors declare that the research was conducted in the absence of any commercial or financial relationships that could be construed as a potential conflict of interest.

Copyright (c) 2019 Levin, Bett, Gates, Heimbach, Howe, Janssen, McCurdy, Ruhl, Snelgrove, Stocks, Bailey, Baumann-Pickering, Beaverson, Benfield, Booth, CarreiroSilva, Colaço, Eblé, Fowler, Gjerde, Jones, Katsumata, Kelley, Le Bris, Leonardi, Lejzerowicz, Macreadie, McLean, Meitz, Morato, Netburn, Pawlowski, Smith, Sun, Uchida, Vardaro, Venkatesan and Weller. This is an open-access article distributed under the terms of the Creative Commons Attribution License (CC BY). The use, distribution or reproduction in other forums is permitted, provided the original author(s) and the copyright owner(s) are credited and that the original publication in this journal is cited, in accordance with accepted academic practice. No use, distribution or reproduction is permitted which does not comply with these terms. 